\title{
MATERIALS DESIGN FROM FIRST PRINCIPLES stability and magnetism of nanolaminates
}

\author{
Martin Dahlqvist
}

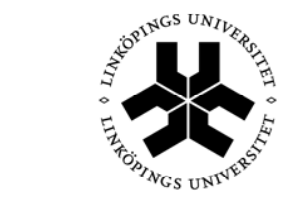

\section{Linköping University}

\author{
Materials Design \\ Thin Film Physics Division \\ Department of Physics, Chemistry, and Biology (IFM) \\ Linköping University \\ SE-581 83 Linköping, Sweden
}

Linköping 2014 
The front cover image is a close up of $M$ (red and blue spheres) and $X$ (grey sphere) in $M_{2} A X$. In the background its nanolaminated structure consisting of ordered, clustered, and disordered atoms or magnetic moments is illustrated.

The spine image shows charge redistribution for an interstitial oxygen atom in $\mathrm{Cr}_{2} \mathrm{AlC}$ where blue indicate gain of electrons and red loss of electrons.

The back cover image shows charge redistribution when oxygen substitutes for carbon in $\mathrm{Ti}_{2} \mathrm{AlC}$ where blue indicate gain of electrons and red loss of electrons.

My daughter described it as "a planet, with water, and trees, and blue leaves".

(c) Martin Dahlqvist, unless otherwise stated.

ISBN: 978-91-7519-411-0

ISSN: 0345-7524

Printed by LiU-Tryck, Linköping, Sweden, 2014 
To my JETs $\bullet$ 



\section{ABSTRACT}

In this thesis, first-principles calculations within density functional theory are presented, with a principal goal to investigate the phase stability of so called $M_{n+1} A X_{n}$ (MAX) phases. MAX phases are a group of nanolaminated materials comprised of a transition metal $(M)$, a group 12-16 element $(A)$, and carbon or nitrogen $(X)$. They combine ceramic and metallic characteristics, and phase stability studies are motivated by a search for new phases with novel properties, such as magnetism, and for the results to be used as guidance in attempted materials synthesis in the lab.

To investigate phase stability of a hypothetical material, a theoretical approach has been developed, where the essential part is to identify the set of most competing phases relative to the material of interest. This approach advance beyond more traditional evaluation of stability, where the energy of formation of the material is generally calculated relative to its single elements, or to a set of ad hoc chosen competing phases. For phase stability predictions to be reliable, validation of previous experimental work is a requirement prior to investigations of new, still hypothetical, materials. It is found that the predictions from the developed theoretical approach are consistent with experimental observations for a large set of MAX phases. The predictive power is thereafter demonstrated for the new phases $\mathrm{Nb}_{2} \mathrm{GeC}$ and $\mathrm{Mn}_{2} \mathrm{GaC}$, which subsequently have been synthesized as thin films. It should be noted that Mn is used for the first time as sole $M$-element in a MAX phase. Hence, the theory is successfully used to find new candidates, and to guide experimentalists in their work on novel promising materials. Phase stability is also evaluated for MAX phase alloys. Incorporation of oxygen in different $M_{2} \mathrm{AlC}$ phases are studied, and the results show that oxygen prefer different sites depending on $M$-element, through the number of available non-bonding $M d$ electrons. The theory also predicts that oxygen substituting for carbon in $\mathrm{Ti}_{2} \mathrm{AlC}$ stabilizes the material, which explains the experimentally observed 12.5 at $\%$ oxygen $(\chi=0.5)$ in $\mathrm{Ti}_{2} \mathrm{Al}\left(\mathrm{C}_{1-x} \mathrm{O}_{x}\right)$.

Magnetism is a recently attained property of MAX phase materials, and a direct result of this Thesis work. We have demonstrated the importance of choice of magnetic spin configuration and electron correlations approximations for theoretical evaluation of the magnetic ground state of $\mathrm{Cr}_{2} \mathrm{AC}$ ( $\mathrm{A}=\mathrm{Al}, \mathrm{Ga}, \mathrm{Ge}$ ). Furthermore, alloying $\mathrm{Cr}_{2} \mathrm{AlC}$ with $\mathrm{Mn}$ to obtain the first magnetic MAX phase have been theoretically predicted and experimentally verified. Using $\mathrm{Mn}_{2} \mathrm{GaC}$ as model system, Heisenberg Monte Carlo simulations have been used to explore also noncollinear magnetism, suggesting a large set of possible spin configurations (spin waves and spin spirals) to be further investigated in future theoretical and experimental work. 



\section{POPULÄRVETENSKAPLIG SAMMANFATTNING}

\section{Materialdesign med en dator som verktyg}

I en dator på avdelningen för Tunnfilmsfysik uppstår nya material som sedan kan skapas i vårt laboratorium. Olika atomslag staplas i individuella lager till en tårta, ${ }^{1}$ eller ett så kallat nanolaminat, som bildar det omtalade materialet $M A X$-fas. $M$ står för en övergångsmetall (t.ex. titan), $A$ för en metall/halvmetall (t.ex. aluminium) och $X$ för kol och/eller kväve. Vad som gör materialet intressant och lovande är kombinationen av både metalliska och keramiska egenskaper. Med tillsats av mangan (Mn) kan materialet nu även bli magnetiskt vilket öppnar helt nya möjliga tillämpningsområden.

"We are living in a material world" ${ }^{2}$ är en textrad som passar väl in när det kommer till tillämpning av material i vår vardag. Exempel är elektroniken i din mobiltelefon, lagringsmedium, reptåligt glas, antireflexbehandlade glasögon, och förkromade vattenkranar. I takt med att utvecklingen går framåt behövs nya material, och som materialforskare vill jag förstå, förbättra och förnya $M A X$-faserna. Till min hjälp använder jag mig av beräkningar som utgår från de mest grundläggande egenskaperna hos de ingående atomerna. Mina resultat kan sammanfattas i två olika områden - stabilitet och magnetism.

Stabilitet är ett mått för att kunna förutsäga om ett nytt hypotetiskt material kan bildas. För att ta fram stabiliteten har jag utvecklat en teoretisk metod som testats på ett flertal kända MAXfaser, och de teorestiskt stabila och de experimentellt kända faserna sammanfaller. Med metoden har jag därefter kunnat förutsäga två nya $\mathrm{MAX}$-faser, $\mathrm{Nb}_{2} \mathrm{GeC}$ och $\mathrm{Mn}_{2} \mathrm{GaC}$, vilka sedan tillverkats experimentellt. Genom att delvis byta ut ett atomslag i ett material kan man förändra dess egenskaper. Min metod har därför använts för att undersöka hur syre påverkar MAX-fasers stabilitet, samt om mangan (Mn) kan användas för att skapa de första magnetiska MAX-faserna. I ett första steg har jag studerat en välkänd MAX-fas, $\mathrm{Cr}_{2} \mathrm{AlC}$, och undersökt i vilken mån det är möjligt att byta ut $\mathrm{Cr}$-atomer mot $\mathrm{Mn}$ för att få ett magnetiskt material. Mina teoretiska resultat visade att det borde vara möjligt, och materialet tillverkades därefter framgångsrikt. På samma sätt utvecklades sedan det nya magnetiska materialet $\mathrm{Mn}_{2} \mathrm{GaC}$, som är den första MAX-fasen med enbart mangan (Mn) som atomslag $M$.

Nya magnetiska material är viktiga för t.ex. hårddiskar, datalagring och dataöverföring. Med Mn blir MAX-faser magnetiska, och jag har i denna avhandling visat hur en mängd olika magnetiska egenskaper (i teorin) skulle kunna genereras. Detta arbete är bara början på ett nytt forskningsområde, och på en familj av nya material. Framtiden kommer att visa på deras fulla potential, och möjliga tillämpningsområden.

\footnotetext{
${ }^{1}$ Materialet är även likt en tårta där val av botten och fyllning tilltalar olika människor likväl kan olika kombinationer av atomslag i de individuella lagren passa för olika typer av tillämpningar.

${ }^{2}$ Madonnas andra singel från 1984 års album Like a Virgin.
} 



\title{
PREFACE
}

This Thesis is the result of my doctoral studies in the Materials Design group within the Thin Film Physics Division at Linköping University. I have primarily been working on predictions of stability and magnetism of MAX phases from a theoretical perspective. The main tool at hand is first-principles calculations using VASP. The research was financially supported by Linköping University, the Swedish Research Council, Knut and Alice Wallenberg Foundation, and the European Research Council. All calculations were carried out using supercomputer resources provided by the Swedish National Infrastructure for Computing (SNIC) at the NSC, HPC2N, and PDC centers.

First and foremost, I am very grateful for my supervisor, Johanna Rosen, for accepting me as a graduate student, for giving me the opportunity to work freely ("Jag råkade..."), and for all guidance in making lengthy texts less long. Björn should be thanked for sharing his vast knowledge and ideas, Igor, I'm grateful for your invaluable expertise and opinions in theoretical issues, and all co-authors for making excellence come true. All present and former colleagues of Materials Design, Thin Film Physics, Nanostructured Materials, and other groups are recognized for appreciated discussions, lunches, and especially kaffe.

Gaston, you put me into this by your inspiring scientific knowledge. Enjoy reading!

Family and friends, near and far, I'm deeply grateful for your invaluable support.

My inspiring, wonderful, and lovely kids Ester and Tore, who make life a joy.

Finally, I want to thank Jenny for your immeasurable support, for standing by my side when things were tough, and your warm heart. This is for you.

\author{
"There's beauty in the silver, singin' river \\ There's beauty in the sunrise in the sky \\ But none of these and nothin' else can touch the beauty \\ That I remember in my true loves eyes" \\ Tomorrow is a long time, Bob Dylan \\ "Det finns skönhet i flodens silversånger \\ Det finns skönhet i gryningssolens sken \\ Men då ser jag i min älskades ögon \\ En skönhet större än allting som jag vet" \\ Men bara om min älskade väntar, Ulf Dageby \\ Även om Dageby står för översättningen av Dylans verk \\ föredrar jag Thåströms framförande.
}

Martin Dahlqvist

Linköping, February 2014 



\section{INCLUDED PAPERS}

\section{PAPER I}

Phase stability of $\mathrm{Ti}_{2} \mathrm{AlC}$ upon oxygen incorporation: A first-principles investigation

M. Dahlqvist, B. Alling, I. A. Abrikosov, and J. Rosen

Physical Review B 81, 024111 (2010)

PAPER II

Oxygen incorporation and defect formation in $\mathrm{Ti}_{2} \mathrm{AlC}, \mathrm{V}_{2} \mathrm{AlC}$, and $\mathrm{Cr}_{2} \mathrm{AlC}$ from first-principles calculations

M. Dahlqvist and J. Rosen

In manuscript

PAPER III

Stability trends of MAX phases from first principles

M. Dahlqvist, B. Alling, and J. Rosen

Physical Review B 81, 220102(R) (2010)

PAPER IV

Discovery of the Ternary Nanolaminated Compound $\mathrm{Nb}_{2} \mathrm{GeC}$ by a Systematic Theoretical-Experimental Approach

P. Eklund, M. Dahlqvist, O. Tengstrand, L. Hultman, J. Lu, N. Nedfors, U. Jansson, and J. Rosen

Physical Review Letters 109, 035502 (2012)

\section{PAPER V}

Correlation between magnetic state and bulk modulus of $\mathrm{Cr}_{2} \mathrm{AlC}$

M. Dahlqvist, B. Alling, and J. Rosen

Journal of Applied Physics 113, 216103 (2013)

\section{PAPER VI}

Magnetic ground state of $\mathrm{Cr}_{2} \mathrm{AlC}, \mathrm{Cr}_{2} \mathrm{GaC}$, and $\mathrm{Cr}_{2} \mathrm{GeC}$ from first-principles interplay of spin configurations and strong electrons correlation

M. Dahlqvist, B. Alling, and J. Rosen

Submitted for publication 


\section{PAPER VII}

Magnetic nanoscale laminates with tunable exchange coupling from first principles

M. Dahlqvist, B. Alling, I. A. Abrikosov, and J. Rosen

Physical Review B 84, 220403(R) (2011)

\section{PAPER VIII}

\section{A Nanolaminated Magnetic Phase: $\mathbf{M n}_{2} \mathbf{G a C}$}

A. S. Ingason, A. Petruhins, M. Dahlqvist, F. Magnus, A. Mockute, B. Alling, L. Hultman, I. A. Abrikosov, P. O. A. Persson, and J. Rosen

Materials Research Letters 2, 89 (2014)

\section{PAPER IX}

\section{Complex magnetism in nanolaminated $\mathrm{Mn}_{2} \mathrm{GaC}$}

M. Dahlqvist, B. Alling, A. S. Ingason, F. Magnus, A. Thore, A. Petruhins, A. Mockute, R. Meshkian, M. Sahlberg, P. O. Å. Persson, B. Hjörvarsoon, I. A. Abrikosov, and J. Rosen In manuscript

\section{Comment on my contribution to the papers}

In Papers I - III, V - VII, and IX, I carried out the calculations, took a major part in the analysis of the results, and were responsible for writing the papers.

In Paper IV, I carried out the calculations, took part in the analysis of the results, and shared responsibility with P. Eklund in writing the paper.

In Paper VIII, I carried out the calculations, took part in the analysis of the results, and contributed to writing the paper.

Unfortunately, or luckily, I did not take part in synthesis of $\mathrm{Nb}_{2} \mathrm{GeC}$ and $\mathrm{Mn}_{2} \mathrm{GaC}$ in Paper IV and VIII, although it would have been fun and interesting doing so. 


\section{RELATED PAPERS}

Magnetic self-organized atomic laminate from first principles and thin film synthesis A. S. Ingason, A. Mockute, M. Dahlqvist, F. Magnus, S. Olafsson, U. B. Arnalds, B. Alling, I. A. Abrikosov, B. Hjörvarsson, P. O. Å. Persson, and J. Rosen Physical Review Letters 110, 1995502 (2013)

Synthesis and ab initio calculations of nanolaminated $(\mathrm{Cr}, \mathrm{Mn})_{2} \mathrm{AlC}$ compounds A. Mockute, M. Dahlqvist, J. Emmerlich, L. Hultman, J. M. Schneider, P. O. Å. Persson, and J. Rosen

Physical Review B 87, 094113 (2013)

Phase stability of $\mathrm{Cr}_{\mathrm{n}+1} \mathrm{GaC}_{\mathrm{n}} \mathrm{MAX}$-phases from first principles and $\mathrm{Cr}_{2} \mathrm{GaC}$ thin film synthesis using magnetron sputtering from elemental targets

Petruhins, A. S. Ingason, M. Dahlqvist, A. Mockute, M. Junaid, J. Birch, J. Lu, L. Hultman, P. O. Å. Persson, and J. Rosen

Physica Status Solidi Rapid Research Letters 7 , 971 (2013)

Oxygen incorporation in $\mathrm{Ti}_{2} \mathrm{AlC}$ : Tuning of anisotropic conductivity J. Rosen, M. Dahlqvist, S. Simak, D. R. McKenzie, and M. M. M. Bilek Applied Physics Letters 97, 073103 (2010)

Oxygen Incorporation in $\mathrm{Ti}_{2} \mathrm{AlC}$ Thin Films Studied by EELS and $\mathrm{Ab}$ initio Calculations

A. Mockute, M. Dahlqvist, L. Hultman, P. O. Å. Persson, and J. Rosen

Journal of Materials Science 48, 3686 (2013)

Temperature dependent phase stability of $\mathrm{Ti}_{n+1} \mathrm{AlC}_{n}$ MAX phases from first-principles calculations

A. Thore, M. Dahlqvist, B. Alling, and J. Rosen

Submitted for publication 



\section{TABLE OF CONTENTS}

1 INTRODUCTION 1

1.1 Materials science 1

1.2 MAX phases 2

1.3 Objectives 4

2 MAX Phases ANd Related Materials 5

$2.1 M_{n+1} A X_{n}(\mathrm{MAX})$ phases $\quad 5$

2.2 MAX Phase alloys $\quad 8$

2.3 Related laminated materials 9

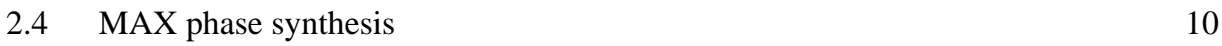

3 TheOretical Methods $\quad 13$

3.1 Density Functional Theory 13

3.2 Special quasi-random structures method 21

3.3 Linear optimization for prediction of phase stability 23

4 MAX Phase Stability 27

4.1 Cohesive energy 29

$\begin{array}{lll}4.2 & \text { Formation energy } & 30\end{array}$

4.3 Validation of theoretical approach 34

4.4 Prediction of new MAX phases 37

4.5 Oxygen incorporation 41

5 Modeling Magnetism in MAX Phases $\quad 45$

$5.1 \quad$ Spin configurations of $M_{2} A X$ phases 48

5.2 Magnetic ground state of $\mathrm{Cr}_{2} A \mathrm{C}(A=\mathrm{Al}, \mathrm{Ga}, \mathrm{Ge}) \quad 58$

$\begin{array}{ll}5.3 \text { Effects from alloying } \mathrm{Cr}_{2} A \mathrm{C} \text { with } \mathrm{Mn} & 60\end{array}$

5.4 Magnetic ground state of $\mathrm{Mn}_{2} \mathrm{GaC} \quad 65$

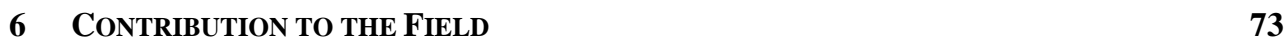

$\begin{array}{lll}7 & \text { BibLIOGRAPHY } & 75\end{array}$ 

"Discovery, dissolved all illusion Mystery, destroyed with conclusion And illusion never restored" Planned obsolescence, 10,000 Maniacs

\section{1}

\section{INTRODUCTION}

\subsection{Materials science}

Materials have always been essential to advance civilization and ensure necessities for our everyday living. Just a glimpse at the names of eras and one realizes what impact different materials had, e.g. the Stone Age, the Bronze Age, and the Iron Age. Each era thus reflects the technological advancements made as a result of the material used. Today, at the basis of all simple as well as sophisticated technologies realized by advanced materials one might say that we are living in the Materials Age.

The large interdisciplinary field of materials science and engineering deals with all classes of materials ${ }^{3}$ with an emphasis to understand the relationship between materials composition, structure, properties, performance, and its relation to synthesis methods. In order to improve known materials or to discover new tailor-made materials with specific properties, investigations ranging from atomic to macroscopic level are needed. Tools at hand can be of both experimental and computational nature.

\footnotetext{
${ }^{3}$ Examples of material classification and where they can be found; metals (electronic circuits, jewelries), ceramics (knifes, membranes), polymers (paints, plastics), biomaterials (body implants, DNA), and composites (wood to concrete).
} 


\subsubsection{Theoretical studies}

Experiments can be expensive and time consuming, and the experimental conditions may be restricted physically by, e.g., temperature and pressure. The benefits of in silico ${ }^{4}$ investigations using computational tools are thus multifold. With access to supercomputers, theoretical studies can be comparatively fast, and the materials investigated can be real but also of hypothetical character, i.e. not yet experimentally synthesized. Moreover, simulations allow focus on different parameters, e.g., structure or magnetic moments, but also properties that may be difficult to resolve experimentally. This is highly valuable for improved understanding of existing and new materials, and in turn vital for application-inspired materials design.

\subsubsection{Magnetic materials}

Magnetic materials have a long history. People have been using compasses for thousands of years [1]. In modern times magnetic materials are used in a large number of applications such as switches, medical equipment, power conversion in motors, and storage media. However, new magnetic materials and applications are being developed.

Interest in layered magnetic materials was boosted by the observation of interlayer exchange coupling in magnetic multilayers and the subsequent discovery of giant/tunnel magnetoresistance (GMR/TMR) [2-4], a phenomena used for data storage and magnetic recording. ${ }^{5}$ A simple magnetic multilayer is made of two alternating layers (of different materials), where at least one of them is ferromagnetic (FM). The period of the multilayer, being the sum of the individual layer thicknesses, is commonly in the nm range. The magnetic coupling in multilayer systems is shown to be strongly dependent on the layer thickness, the interface quality/roughness [5, 6] and the lattice mismatch [7], which in turn can result in magnetic frustration and non collinear coupling $[8,9]$. The applicability of magnetic materials depends on how much control one has over these features.

\subsection{MAX phases}

A group of nanolaminated materials that combines ceramic and metallic characteristics are the $M_{n+1} A X_{n}$ (MAX) phases, $n=1-3$, comprised of transition metal $(M)$ carbide or nitride $(X)$ sheets $\left(M_{n+1} X_{n}\right)$ interleaved by a single layer of a group 12-16 element $(A)[10,11]$. The elements forming these so-called MAX phases are illustrated in Figure 1, and in Figure 2 the characteristic multilayered structure is exemplified for $M_{2} A X(n=1)$. The inherently nanolaminated and highly stable structure, with suggested tunable anisotropic properties [12],

\footnotetext{
4 The term in silico refer to experiments performed on a computer such as calculations and simulations. Examples of related terms are in vivo (experiments on a living organism) and in vitro (experiments in a "test tube", i.e. isolated from its natural surrounding).

${ }^{5}$ In 2007, Albert Fert and Peter Grünberg were awarded the Nobel Prize in Physics for the discovery of a new physical effect known as GMR.
} 
suggest a material with potential for functionalization in magnetic multilayer structures. That is, if magnetism can be added to the already unique combination of properties, an advantage compared to traditional magnetic multilayers would be the possibility to stack compositionally different MAX phases with similar lattice parameters in a single crystal, and hence allow improved control of both the layer thickness and interface quality.

\begin{tabular}{|c|c|c|c|c|c|c|c|c|c|c|c|c|c|c|c|c|c|c|}
\hline $\mathrm{Li}$ & $\mathrm{Be}$ & & & & & & & & & & & 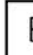 & & $\bar{C}$ & $\mathrm{~N}$ & 0 & $F$ & $\mathrm{Ne}$ \\
\hline $\mathrm{Na}$ & $\mathrm{Mg}$ & & & & & & & & & & & & & Si & $P$ & $S$ & $\mathrm{Cl}$ & AR \\
\hline$K$ & $\mathrm{Ca}$ & Sc & $\mathrm{Ti}$ & V & $\mathrm{Cr}$ & $\mathrm{Mr}$ & $\mathrm{Fe}$ & $\mathrm{Cc}$ & $\mathrm{Ni}$ & $a$ & $\mathrm{Zr}$ & & & $\mathrm{Ge}$ & As & $\mathrm{Se}$ & $\mathrm{Br}$ & $\mathrm{Kr}$ \\
\hline $\mathrm{Rb}$ & $\mathrm{Sr}$ & $Y$ & $\mathrm{Zr}$ & $\mathrm{Nb}$ & Mo & TC & $R u$ & $\mathrm{RH}$ & $\mathrm{Pd}$ & $A_{g}$ & $\mathrm{Cc}$ & & & $5 n$ & $\mathrm{Sb}$ & Te & 1 & $\mathrm{Xe}$ \\
\hline Cs & $\mathrm{Ba}$ & Lu & $\mathrm{Hf}$ & $\mathrm{Ta}$ & W & $\operatorname{Re}$ & Os & Ir & Pt & $A l$ & $\mathrm{H}$ & & & $\mathrm{b}$ & $\mathrm{Bi}$ & Po & At & $\mathrm{Rn}$ \\
\hline $\mathrm{Fr}$ & $\mathrm{Ra}$ & $\mathrm{Lr}$ & Unc & Unp & Unh & Uns & Unc & Un & Uur & Uu & Uu & & & Juq & Uup & Uuh & Uus & Uno \\
\hline
\end{tabular}

Figure 1. Periodic table indicating $M, A$, and $X$ elements forming $M_{n+1} A X_{n}$ phases.

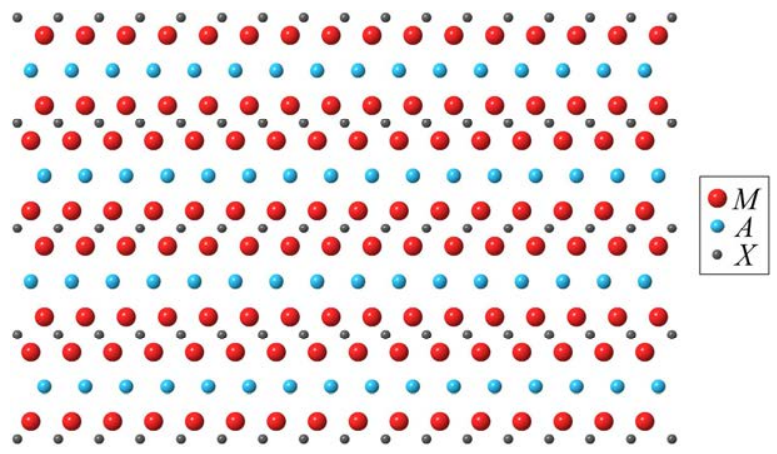

Figure 2. Nanolaminated structure of $M_{2} A X(n=1)$ with sheets of $M_{2} X$ interleaved by an atomic layer of $A$ atoms.

The first example of theoretically suggested magnetic MAX phases were based on iron as $M$ element, $\mathrm{Fe}_{2} \mathrm{AlC}$ and $\mathrm{Fe}_{2} \mathrm{SiC}$ [13], and none has been reported experimentally. In a later study Fe2AlC was demonstrated to be not stable [14]. Another strategy could be to alloy already known MAX phases with a magnetic element ${ }^{6}$.

\footnotetext{
${ }^{6}$ Magnetic elements such as Mn which traditionally does not belong to the definition of a $M$-element.
} 


\subsection{Objectives}

The general objective of this thesis is to use theoretical methods to further increase the understanding of MAX phases, with a particular focus on phase stability, magnetism, and impurity incorporation.

Stability calculations based on here developed approach are used to elucidate if a hypothetical compound is likely to exist or not. The reliability of such predictions is justified when confirming previous experimental findings. Validation of history is thus a requirement before predictions on stability of hypothetical MAX phases are attempted and used as guide for experimentalists working with novel materials.

In this Thesis magnetic MAX phases are envisaged, and explored. Magnetic ground states and magnetic interactions, both short and long range, are investigated theoretically. Promising candidates for materials synthesis are also identified

Oxygen incorporation in MAX phases has been shown experimentally for $\mathrm{Ti}_{2} \mathrm{AlC}$ and $\mathrm{Cr}_{2} \mathrm{AlC}$, in the former by substituting for carbon while believed to be an interstitial in the latter. This work attempts to explain this difference, and to investigate if the driving force for oxygen incorporation in $\mathrm{Ti}_{2} \mathrm{AlC}$ can be generalized to other MAX phases. 
"Gather 'round people

Wherever you roam

And admit that the waters

Around you have grown"

The times they are a-changin, Bob Dylan

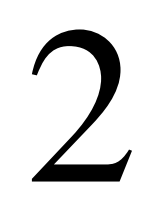

MAX PHASES AND RELATED MATERIALS

$M_{n+1} A X_{n}$ (MAX) phases, $n=1-3$, are comprised of a transition metal $(M)$, an A group element $(A)$ and carbon or nitrogen $(X)[10,11]$. These materials originate from the comprehensive research carried out in the 1960s by the Vienna-based group of Hans Nowotny and coworkers, when more than 100 new carbides and nitrides materials were discovered [15]. Out of these, 39 were so-called "H-phases" of archetypical structure $\mathrm{Cr}_{2} \mathrm{AlC}$, see e.g. Ref. [16-21], and corresponding structural relatives $\mathrm{Ti}_{3} \mathrm{SiC}_{2}$ [22] and $\mathrm{Ti}_{3} \mathrm{GeC}_{2}$ [23]. However, it took about 30 years until Barsoum and El-Raghy [24] showed that $\mathrm{Ti}_{3} \mathrm{SiC}_{2}$ exhibits unique material properties combining the characteristics of metals and ceramics, a finding which intensified the research on this class of materials. Also another structural relative, $\mathrm{Ti}_{4} \mathrm{AlN}_{3}$, was discovered [25] with similar properties.

\section{1 $M_{n+1} A X_{n}(\mathrm{MAX})$ phases}

The "H-phases" are today more known as MAX phases and to this date more than 60 phases have been synthesized in bulk and/or thin film form [11]. In Table 1 and Table 2 experimentally confirmed phases to this date are listed. Only recently, Lu and Mn were added as new $M$-elements due to the discoveries of $\mathrm{Lu}_{2} \mathrm{SnC}$ [26] and $\mathrm{Mn}_{2} \mathrm{GaC}$ [27]. 
Table 1. Experimentally known $M_{n+1} A X_{n}$ phases $(n=1-3)$ where $M$ is a $3 d$-transition metal.

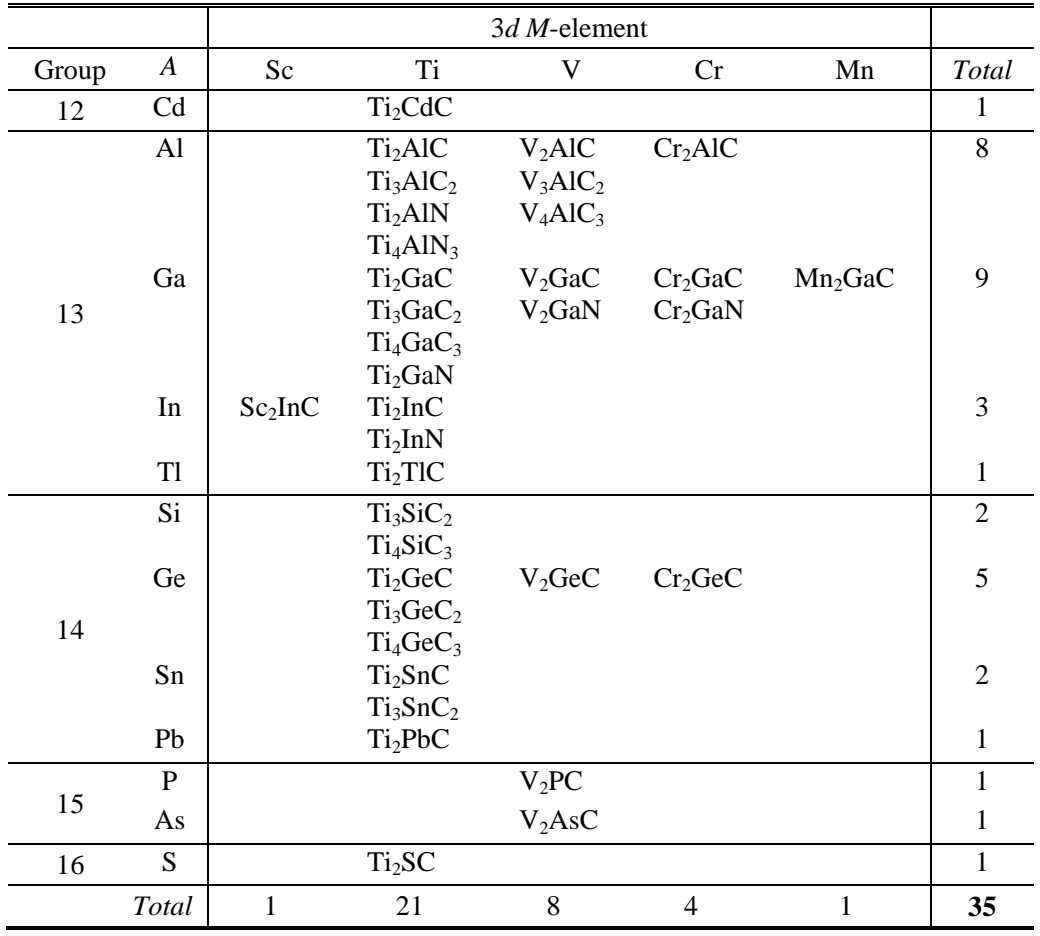

Table 2. Experimentally known $M_{n+1} A X_{n}$ phases $(n=1-3)$ where $M$ is a $4 d$ - or $5 d$-transition metal.

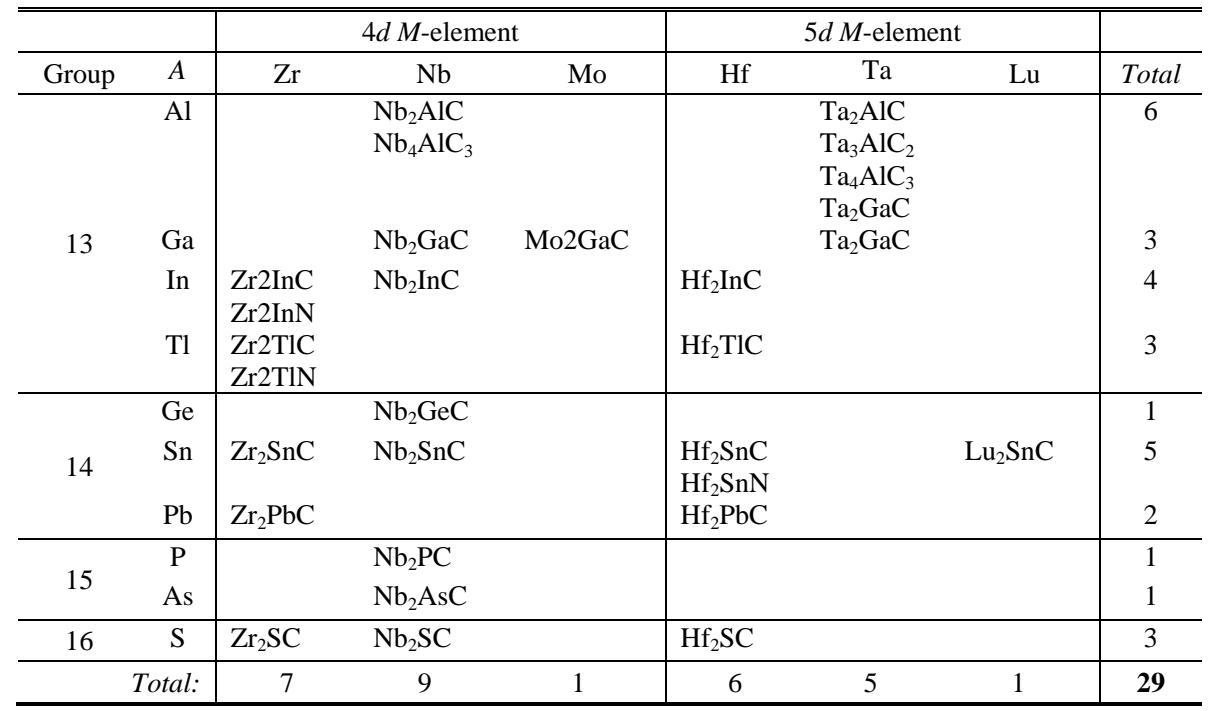


A condensed notation often used, based on their stoichiometry, is $211(n=1), 312(n=2)$, and $413(n=3)$. The crystal structure of $M_{n+1} A X_{n}$ is hexagonal with space group $\mathrm{P}_{3} / \mathrm{mmc}$ $(\# 194)^{78}$. Illustrated in Figure 3 are the unit cells (uc) for $n=1-3$, consisting of two formula units $(\mathrm{fu})$. In total there are $4(n+1)$ atoms per uc or $2(n+1)$ atoms per fu. Corresponding structural parameters are given in Table 3 for the archetypical structures, including the Wyckoff positions for describing the position of the atoms for a given space group. For $n=1$ only three positions (4f, $2 \mathrm{~d}$, and $2 \mathrm{a}$ ) are needed to build the crystal structure. The Bilbao crystallographic server [28-31] includes the Wyckoff positions for all space groups. In combination with the Landolt-Börnstein database [32] it is possible to construct most crystal structures useful for calculation, model fitting or visualization.
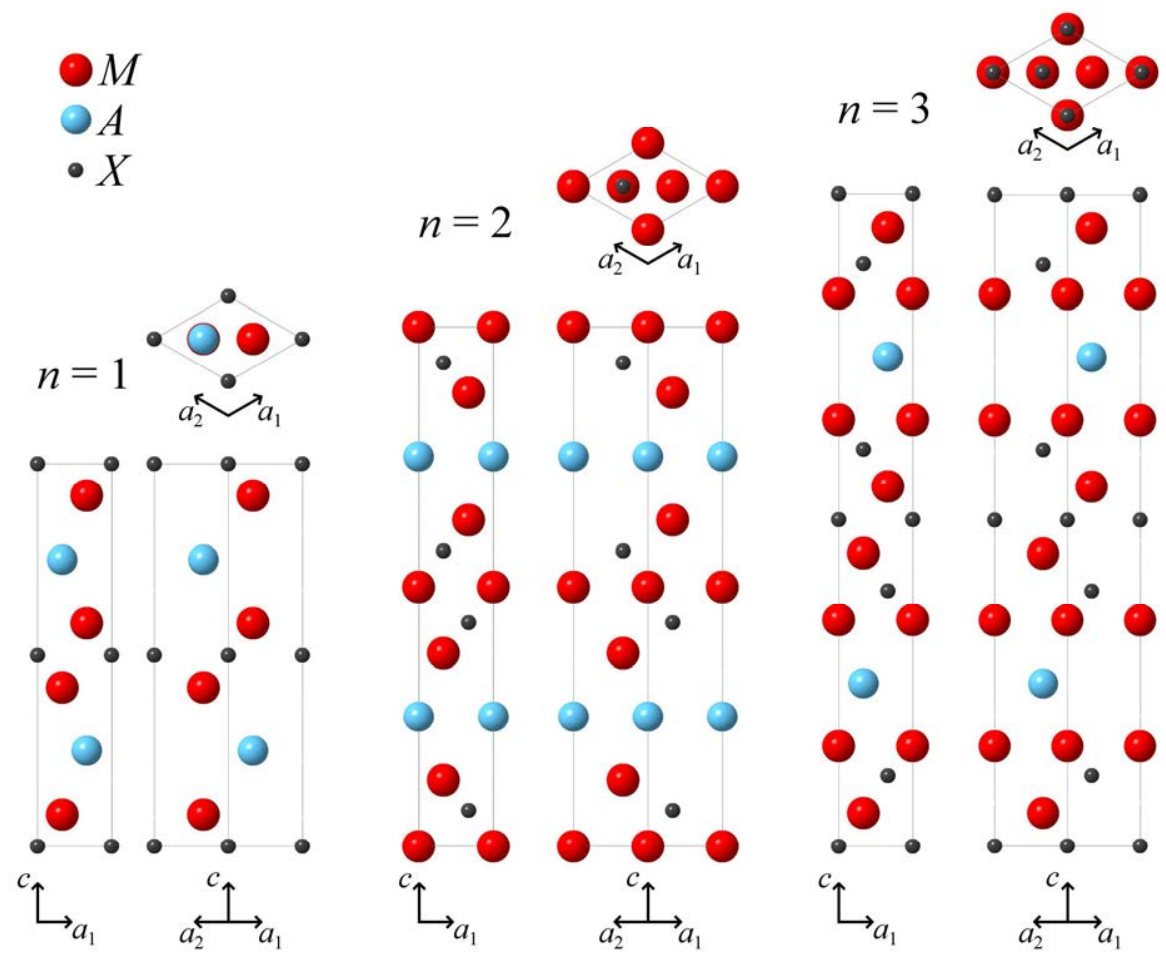

Figure 3. Crystal structure of $M_{n+1} A X_{n}$ phases $(n=1-3)$ with hexagonal symmetry clearly shows $A$-layers interleaved between blocks of $M_{n+1} X_{n}$ layers. Two side views (bottom) and a top view (top) are displayed for each $n$.

\footnotetext{
${ }^{7}$ A primitive unit cell $(\mathrm{P})$ with 3 six-fold rotational or screw axes $\left(6_{3}\right)$, two mirror planes $(m)$, where the first $(/ m)$ is perpendicular to the $c$-axis, and a glide plane along the $c$-axis $(c)$. Can you find them in Figure 3 ! This is the Hermann-Mauguin notation used to represent symmetry elements in point groups and space groups and it is preferred in crystallography.

${ }^{8}$ Another notation is the Schönflies notation $D_{6 h}^{4}$ which is usually used in spectroscopy.
} 
In addition to the archetypical structures in Table 3, different types of polymorphs have been observed for the 312 and 413 phases, respectively. The 312 displays shearing of the $A$-layers (from Wyckoff position $2 \mathrm{~b}$ to $2 \mathrm{~d}$ ) induced by high pressure, and transforms into $\beta-M_{3} A X_{2}$ [3335]. This pressure induced polymorphic transformation has also been suggested theoretically for 211 phases $\mathrm{Ti}_{2} \mathrm{AlC}$ and $\mathrm{Ti}_{2} \mathrm{AlN}[36,37]$. The other kind of polymorphism have been observed for $\mathrm{Ta}_{4} \mathrm{AlC}_{3}$ [38-40] ( $M 2$ changes from Wyckoff position $4 \mathrm{e}$ to $4 \mathrm{f}$ and $X 2$ from $4 \mathrm{f}$ to $4 \mathrm{e})$ and is most likely thermodynamically driven [41].

Table 3. Structural parameters for prototype structures of $M_{n+1} A X_{n}(n=1-3)$ phases.

\begin{tabular}{|c|c|c|c|c|c|c|}
\hline$n$ & Atom & $\begin{array}{l}\text { Wyckoff } \\
\text { position }\end{array}$ & $x$ & $y$ & $z^{\dagger}$ & $\begin{array}{c}\text { Prototype } \\
\text { structure }\end{array}$ \\
\hline \multirow[t]{3}{*}{1} & $M$ & $4 \mathrm{f}$ & $1 / 3$ & $2 / 3$ & 0.084 & $\mathrm{Cr}_{2} \mathrm{AlC}$ \\
\hline & A & $2 d$ & $1 / 3$ & $2 / 3$ & $3 / 4$ & \\
\hline & $X$ & $2 a$ & 0 & 0 & 0 & \\
\hline \multirow[t]{4}{*}{2} & $M 1$ & $2 \mathrm{a}$ & 0 & 0 & 0 & $\mathrm{Ti}_{3} \mathrm{SiC}_{2}$ \\
\hline & $M 2$ & $4 \mathrm{f}$ & $1 / 3$ & $2 / 3$ & 0.1355 & \\
\hline & $A$ & $2 b$ & 0 & 0 & $1 / 4$ & \\
\hline & $X$ & $4 f$ & $1 / 3$ & $2 / 3$ & 0.5722 & \\
\hline \multirow[t]{5}{*}{3} & $M 1$ & $4 \mathrm{f}$ & $1 / 3$ & $1 / 3$ & 0.05453 & $\mathrm{Ti}_{4} \mathrm{AlN}_{3}$ \\
\hline & $M 2$ & $4 \mathrm{e}$ & 0 & 0 & 0.15808 & \\
\hline & $A$ & $2 \mathrm{c}$ & $1 / 3$ & $2 / 3$ & $1 / 4$ & \\
\hline & $X 1$ & $2 a$ & 0 & 0 & 0 & \\
\hline & $X 2$ & $4 \mathrm{f}$ & $1 / 3$ & $1 / 3$ & 0.6032 & \\
\hline
\end{tabular}

\subsection{MAX Phase alloys}

In addition to the more than 60 MAX phases known experimentally, a vast number of isostructural solid solutions on $M$-, $A$ - and $X$-sites can be formed, giving an additional degree of freedom for tuning and/or enhancing materials properties.

Many studies have been focused on solid solution of two or more elements. By alloying $\mathrm{V}$ in $\mathrm{Ti}_{2} \mathrm{AlC}$, a solid solution hardening effect was predicted theoretically $[43,44]$ and later observed [45]. In a recent study [46] the thermal expansion coefficient (TEC) of $\mathrm{Cr}_{2}\left(\mathrm{Al}_{x} \mathrm{Ge}_{1-}\right.$ ${ }_{x}$ ) C was found to be constant in-plane but decrease out-of-plane, along $c$-axis, with increasing Al content. At $x=0.75$ the TEC for in- and out-of plane was equal. Such a study clearly shows how one can tune material properties. For theoretical studies of solid solutions it is important, depending on method used, to construct super cells large enough to mimic a real alloy. In Section 3.2 a brief introduction will be given on this subject. 
The number of $X$ elements is by definition limited by to only $\mathrm{C}$ and $\mathrm{N}$ but due to their similar chemical bonding characteristics, resembling its binaries $M C$ and $M \mathrm{~N}$, they can form a wide range of MAX carbonitride solid solutions [47, 48]. This allows investigation on correlations between chemistry and physical properties. In particular $\mathrm{Ti}_{2} \mathrm{Al}(\mathrm{C}, \mathrm{N})$ solid solutions [47-52] have been extensively studied. For example, $\mathrm{Ti}_{2} \mathrm{Al}\left(\mathrm{C}_{0.5} \mathrm{~N}_{0.5}\right)[50,53]$ has been shown to be harder and stiffer than its end members, $\mathrm{Ti}_{2} \mathrm{AlC}$ and $\mathrm{Ti}_{2} \mathrm{AlN}$.

Oxygen does not belong to the elements in the MAX phase family, as no $M_{n+1} A \mathrm{O}_{n}$ have been synthesized. However, O can form MAX phase oxycarbides [54, 55], but not to the same extent as the carbonitrides due to reduced structural stability [56]. In Paper I of this Thesis the stability of $\mathrm{Ti}_{2} \mathrm{Al}\left(\mathrm{C}_{1-x} \mathrm{O}_{x}\right)$ was studied and predicted to be stable up to $x=0.75$ [57]. In Paper II the stability concept is used for studying different types of oxygen incorporation as well as vacancy formation for $M_{2} \mathrm{AlC}(M=\mathrm{Ti}, \mathrm{V}, \mathrm{Cr}, \mathrm{Zr}, \mathrm{Hf})$. A motivation for studies of oxygen incorporation, despite its suggested ability to tune properties [12], is that dissolution is of importance for the design of self-healing MAX phases [58-60].

MAX phase solid solutions haves been studied in several of the papers included in this Thesis. In addition to Paper I and II mentioned above, Paper VI presents theoretical predictions indicating that alloying $\mathrm{Cr}_{2} \mathrm{AlC}$ with $\mathrm{Mn}$ would form a stable magnetic MAX phase and allow for different magnetic ordering depending on the $\mathrm{Cr} / \mathrm{Mn}$ ratio and the chemical ordering [14]. This was later experimentally realized by Mockute et al. [61]. Also (Cr,Mn) ${ }_{2} \mathrm{GeC}$ [62] and $(\mathrm{Cr}, \mathrm{Mn})_{2} \mathrm{GaC}[63]$ was predicted stable and later synthesized.

\subsection{Related laminated materials}

There are reports of phases with $n \neq 1-3$, such as $\mathrm{Ta}_{6} \mathrm{AlC}_{5}$ and $\mathrm{Ti}_{7} \mathrm{SnC}_{6}$. However these are observed locally as irregular stackings, within $\mathrm{Ta}_{4} \mathrm{AlC}_{3}$ and $\mathrm{Ti}_{2} \mathrm{SnC}$ grains, with stacking sequences of a few unit cells, therefore they do not fulfill the definition of being a phase on their own $[64,65]$. What does exists in sizes larger than a few unit cells are "intergrown structures" of MAX phases. First discovered by Palmquist et al. [66] was $\mathrm{Ti}_{5} \mathrm{Si}_{2} \mathrm{C}_{3}$ and $\mathrm{Ti}_{7} \mathrm{Si}_{2} \mathrm{C}_{5}$, or so called 523 and 725 phases. These can be seen as combinations of alternating half-unit cell stackings of 211 and 312 for 523, and of 312 and 413 for 725 . Later the same phases were revealed also for the Ti-Ge-C [67] and Ti-Al-C [68-71] systems. In the latter system there has been a controversy weather the 523 consist of 20 atoms/uc, space group $\mathrm{P} 6_{3} / m m c$ (194) [70], or 30 atoms/uc, space group $P 3 m 1$ (156) [68, 69] or $R \overline{3} m$ (166) [71]. Lane et al. presented evidence from both experimental and simulated X-ray diffraction (XRD) as well as selected area electron diffraction patterns proving that the double stacking sequence of atoms is wrong; it needs to be repeated three times [68]. As a comparison, the energy difference between $M_{n+1} A X_{n}$ phases and its building blocks, $M X$ and $M A$, using 


$$
\Delta E=\frac{E\left[M_{n+1} A X_{n}\right]-n E[M X]}{2(n+1)}
$$

is shown in Figure 4 for the Ti-Al-C system demonstrating why $\mathrm{Ti}_{5} \mathrm{Al}_{2} \mathrm{C}_{3}$, of space group 156 , does exist.

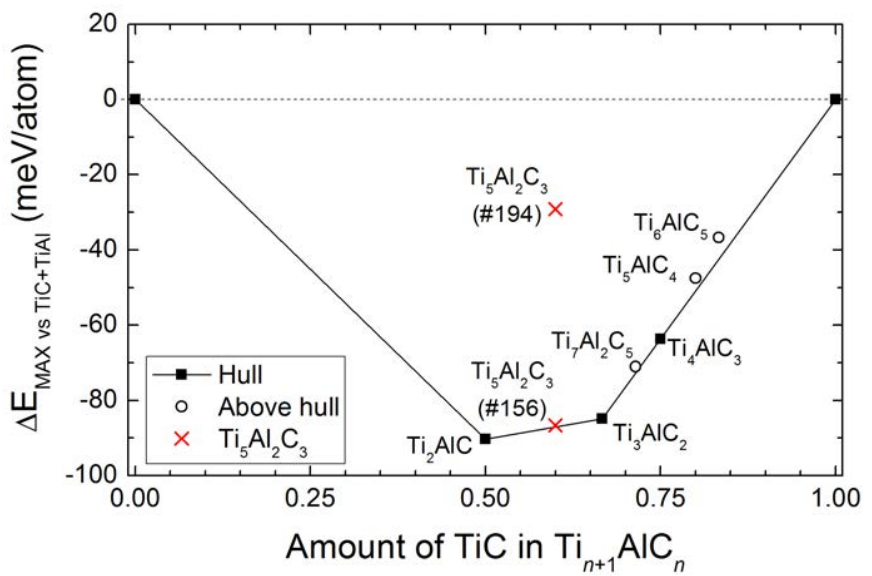

Figure 4. Energy difference of $\mathrm{Ti}_{n+1} \mathrm{AlC}_{n}$ phases relative TiC and TiAl. Note the major energy difference for the 523 structure of space group 156 and 194 (58 meV/atom).

\subsection{MAX phase synthesis}

The majority of the MAX phases synthesized to date are in bulk form. Many bulk methods are based on sintering where powders are mixed and placed in a mold and through atomic diffusion compounds are formed. The process can also involve high temperatures and/or high pressures. Using hot isostatic pressing (HIP) Barsoum and El-Raghy [24] obtained >95 \% phase-pure polycrystalline $\mathrm{Ti}_{3} \mathrm{SiC}_{2}$ along with small amounts of $\mathrm{TiC}$ and $\mathrm{SiC}$. Synthesis of single-crystal MAX phases $\left(\mathrm{Ta}_{3} \mathrm{AlC}_{2}, \mathrm{Ta}_{4} \mathrm{AlC}_{3}, \mathrm{~V}_{2} \mathrm{AlC}, \mathrm{V}_{4} \mathrm{AlC}_{3-x}\right)$ have been proven successful using molten metal technique where powders of $M, \mathrm{Al}$, and $\mathrm{C}$ are put in an excess bath of molten $\mathrm{Al}$ and held at high temperature $\left(\sim 1500^{\circ} \mathrm{C}\right)$ for several days $[72,73]$.

A thin film ${ }^{9}$ is when a (thin) layer of material (coating) is deposited onto another material (substrate) in order to modify or achieve better properties then the coating or substrate alone. Common approaches for thin film synthesis of MAX phases are chemical vapor deposition (CVD) and physical vapor deposition (PVD). With CVD volatile gases react at the substrate forming the coating. The main advantages with CVD are the high deposition rate and possibility to coat complex geometries. However, it requires high substrate temperatures

\footnotetext{
${ }^{9}$ Thin films can be as thin as an atomic layer (ultra thin film range) up to several $\mu \mathrm{m}$.
} 
$\left(1000-1300{ }^{\circ} \mathrm{C}\right)$ and can involve hazardous gases. $\mathrm{Ti}_{3} \mathrm{SiC}_{2}$ was the first CVD made MAX phase [74].

PVD is a physical process where atoms from a solid or liquid material is sputtered or vaporized from a target, to condensate on a substrate and form a film. This has to be carried out under vacuum conditions, which provides a process with very low contamination level. PVD methods are in contrast to CVD line-of-sight methods where only the substrate surface facing the target will be coated. Much work on PVD-based thin film synthesis of MAX phases has been performed by sputtering techniques ${ }^{10}$ where the target surface is being bombarded by energetic ions, e.g. argon ions, that ejects atoms that can travel to the substrate. The target material can be either a compound [66, 75] or elemental $[27,76,77]$. The advantageous of the latter choice is a flexible individual control of the amount of material released, i.e. the elemental flux, from $M, A$, and $X$ targets. The substrate is most often heated to increase the surface mobility of the arriving atoms. Typical substrate temperature are in the range $700-1000{ }^{\circ} \mathrm{C}$ but temperatures as low as $450{ }^{\circ} \mathrm{C}$ have been used successfully to synthesize $\mathrm{V}_{2} \mathrm{GeC}$ [78] and $\mathrm{Cr}_{2} \mathrm{AlC}$ [79]. In Paper IV and VIII, thin films of $\mathrm{Nb}_{2} \mathrm{GeC}$ and $\mathrm{Mn}_{2} \mathrm{GaC}$ were deposited by magnetron sputter epitaxy.

Another PVD technique is cathodic $\operatorname{arc}^{11}$ which operates at much higher currents as compared to sputtering techniques. At the cathode surface (target) a discharged ( $\operatorname{arc})$ of extremely high current density leads to erosion of molten and solid particles through micro explosions. This results in plasma of a high degree of ionization [80] that allows for control of ion energy using electric and magnetic fields, in turn to enhance control of microstructural evolution and thin film properties. The arc can be operated in a continuous direct current (DC) mode or in a pulsed mode. The latter involves much higher current and has been proven successful for MAX phase synthesis [81, 82].

\footnotetext{
${ }^{10}$ Example of techniques used for MAX phases synthesis are magnetron sputtering, reactive magnetron sputtering which involves, e.g., $\mathrm{N}_{2}$ as a reactive gas, and high-power impulse magnetron sputtering (HIPIMS).

${ }^{11}$ An arc is an electrical discharge with current transported through a medium normally being insulating. You may all have seen an arc in the form of lightning.
} 

"The quantum world can be a touch absurd, Describable in numbers but nonsense in words,

Where waves are really particles,

And particles are blurry, What can we infer from all of this"

Heisenberg's uncertainty principle, Jonny Berliner

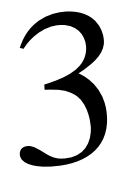

\section{THEORETICAL METHODS}

Within this chapter the tool box used during the progress leading to this thesis is introduced. A brief description is given of the theoretical framework used, density functional theory (DFT), followed by an introduction to how to model and describe configurational order/disorder in a material. Finally the linear optimization method used to investigate phase stability of $M_{n+1} A X_{n}$ phases is presented.

\subsection{Density Functional Theory}

In methods stated to be ab initio, meaning "from the beginning", or from first-principles there are no empirical parameters. Instead they are directly based on quantum mechanics. The complexity encountered when treating a material quantum mechanically is the correlation between many particles. The full many-body Schrödinger equation involves $3 \mathrm{~N}$ degrees of freedom for $N$ electrons, while DFT instead consider the electron density $n(\mathbf{r})$, as the only relevant physical quantity, only depending on 3 degrees of freedom (the position). DFT is a ground state theory which has proven to be very successful in describing structural and electronic properties for a range of materials, from atoms and molecules to simple crystals and complex extended systems. The theory is also computationally simple, which is why it has become a common tool for describing and predicting properties in condensed matter systems.

This idea of treating the particles as a function of electron density was presented in 1927 when Thomas and Fermi $[83,84]$ used a statistical model to approximate the distribution of electrons in an atom. However, it was not until 1964-65 that the theory to be used practically, enabled by Hohenberg, Kohn, and Sham [85, 86]. For more details on electronic structure, a book by Richard M. Martin [87] is highly recommended. 


\subsubsection{Hohenberg-Kohn theorems}

Almost 50 years ago, in 1964, Pierre Hohenberg and Walter Kohn [85] formulated the fundament for DFT with the central idea to replace the many-body problem with an equation for the electron density. The theory consists of two theorems in which Hohenberg and Kohn stated and proved that:

Theorem 1 For any system of interacting particles in an external potential $V_{\text {ext }}(\mathbf{r})$, the potential $V_{\text {ext }}(\mathbf{r})$ is uniquely determined, apart from an additive constant, by knowledge of the ground state particle density $n_{0}(\mathbf{r})$.

Theorem 2 A universal functional for the energy $E[n]$ in terms of the density $n(\mathbf{r})$ can be defined, valid for any external potential $V_{\text {ext }}(\mathbf{r})$. For any particular $V_{\text {ext }}(\mathbf{r})$, the exact ground state energy of the system is the global minimum value of this functional, and the density $n(\mathrm{r})$ that minimizes the functional is the exact ground state density $n_{0}(r)$.

If the exact form of the functional $E[n]$ was known, the exact ground state density $n_{0}(\mathbf{r})$ would be found and hence all ground state properties (no guidance of excited states) of the system could be completely determined. However, the explicit form of such functional is not known and approximations are needed to make use of the theory in practice.

\subsubsection{Kohn-Sham equations}

In 1965, Walter Kohn and Lu Jeu Sham [86] proposed an alternative approach, the KohnSham ansatz, illustrated in Figure 5. The key is to substitute the real interacting system with an auxiliary system of non-interacting particles with the same density as the real system. This is realized by letting the non-interacting particles be subject to an effective potential $V_{e f f}(\mathbf{r})$ instead of an external potential $V_{\text {ext }}(\mathbf{r})$.

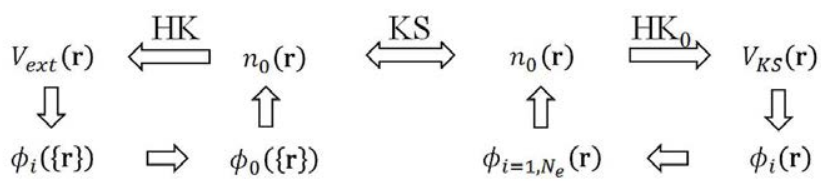

Figure 5. Schematic of the Kohn-Sham ansatz (KS) showing the connection between the many-body (left hand side) and independent-particle (right hand side) system. $\mathrm{HK}$ and $\mathrm{HK}_{0}$ denotes the Hohenberg-Kohn theorem applied to the many-body and non-interacting problem, respectively. After Martin [87].

The non-interacting particles are described by wavefunctions solving the single-particle Schrödinger-like equations, more known as the Kohn-Sham equations

$$
\left(-\frac{1}{2} \nabla^{2}+V_{e f f}(\boldsymbol{r})\right) \phi_{\mathrm{i}}(\mathbf{r})=\varepsilon_{\mathrm{i}} \phi_{\mathrm{i}}(\mathbf{r}),
$$


with the effective potential given by

$$
V_{e f f}(\mathbf{r})=V_{e x t}(\mathbf{r})+\int \frac{n\left(\mathbf{r}^{\prime}\right)}{\left|\mathbf{r}-\mathbf{r}^{\prime}\right|} d \mathbf{r}^{\prime}+\frac{\delta E_{X C}[n(\mathbf{r})]}{\delta n(\mathbf{r})},
$$

in turn expressed by the external potential, the electron-density interaction, and the exchangecorrelation function. The density of $N$ particles is just a sum over the one-particle wave functions.

$$
n(\mathbf{r})=\sum_{i=1}^{N}\left|\phi_{\mathrm{i}}(\mathbf{r})\right|^{2}
$$

and from this the Kohn-Sham total energy functional can be derived as

$$
E_{K S}[n]=T_{S}[n]+\int d \mathbf{r} V_{\text {ext }}(\mathbf{r}) n(\mathbf{r})+E_{\text {Hartree }}[n]+E_{X C}[n]+E_{I I},
$$

where $T_{S}[n]$ is the kinetic energy of the auxiliary system of non-interacting particles, $V_{\text {ext }}(\mathbf{r})$ is the external potential, $E_{\text {Hartree }}[n]$ is the Coluomb energy for electron-electron interactions, and $E_{I I}$ is the energy representing interacting nuclei. Many-body effects are represented by the exchange-correlation energy functional $E_{X C}[n]$ which cannot be calculated exactly, and as such is the only term within the Kohn-Sham approach that needs to be approximated.

\subsubsection{Self-consistent solution}

Based on the energy functional in Eq. (5), the total energy can be minimized to find the ground-state energy and electron density. However, since both $V_{\text {eff }}(\mathbf{r})$ and $\phi_{\mathrm{i}}(\mathbf{r})$ depends on the electron density $n(\mathbf{r})$, an iterative process needs to be used, as illustrated in Figure 6 . The first step is to generate an initial electron density $n_{0}(\mathbf{r})$, e.g. by adding single atom densities. Next, an effective potential $V_{\text {eff }}(\mathbf{r})$ is constructed based on $n_{0}(\mathbf{r})$. The third step involves solving the Kohn-Sham equation (Eq. (2) resulting in a new set of wave functions which can be added together using Eq. (4) to construct a new density $\tilde{n}_{k+1}(\mathbf{r})$. To check the convergence, a comparison of the input density $n_{k}(\mathbf{r})$ with the new density $\tilde{n}_{k+1}(\mathbf{r})$ is made. If the difference is larger than convergence value $\epsilon$, a new density $n_{k+1}(\mathbf{r})$ needs to be generated, utilizing different schemes such as the Anderson method [88] or the Broyden method $[89,90]$. A new $V_{\text {eff }}(\mathbf{r})$ is then constructed and the iterative process continues until the density has converged below $\epsilon$ and self-consistency is reached. 


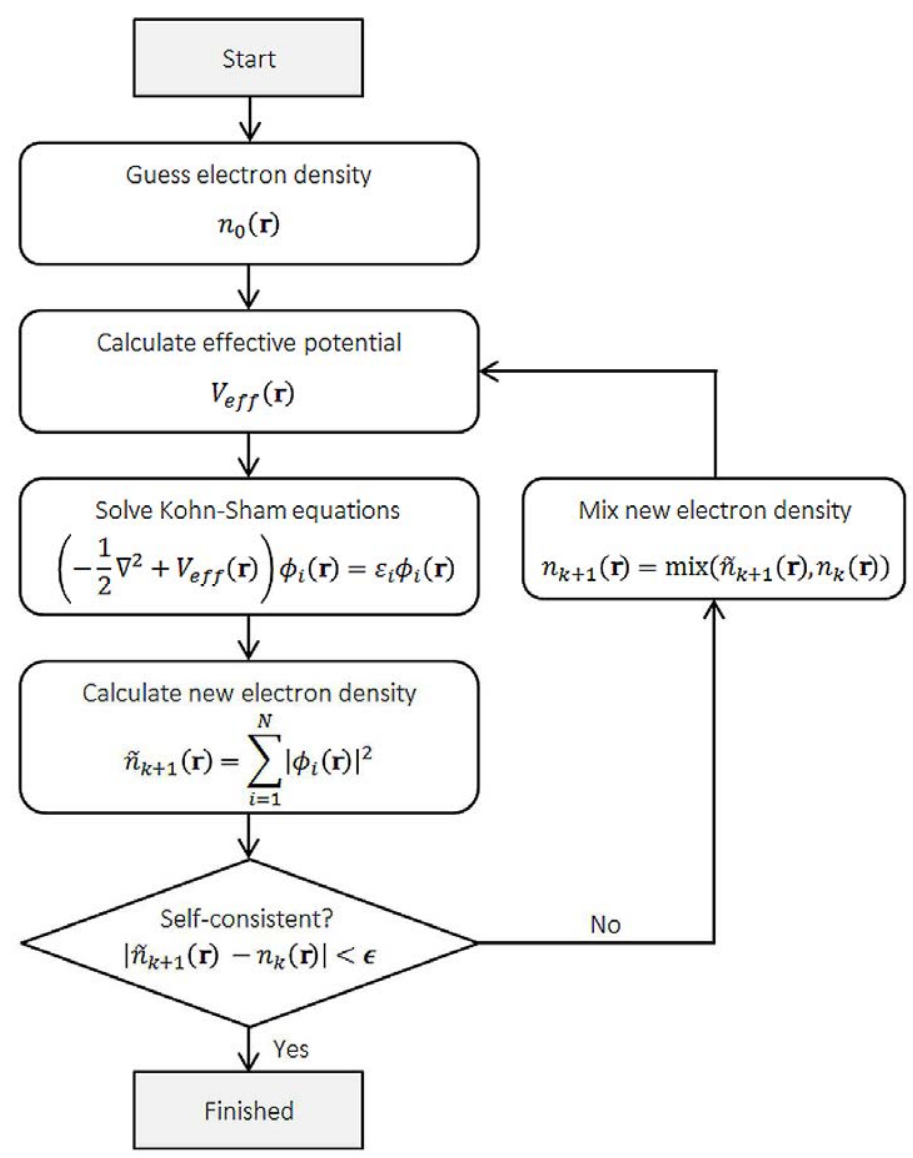

Figure 6. Schematic representation of the basic steps in the Kohn-Sham self-consistent loop. After Martin [87].

\subsubsection{Exchange and correlation approximations}

In Eq. (5) the challenging part is the exchange-correlation energy functional $E_{X C}[n]$ which treats many-body effects. Since it is not known, approximations are needed. The first approximation was suggested in the original paper by Kohn and Sham, and was called the local density approximation (LDA) where solids are approximated as a homogenous electron gas.[86]

$$
E_{X C}^{L D A}[n]=\int d \mathbf{r} \varepsilon_{X C}^{h o m o}([n], \mathbf{r}) n(\mathbf{r})
$$

LDA works best for metals where the regions describing the bonds are far from the nuclei, and thus the electron density varies slowly. A weakness of LDA calculations is the overbinding found for many systems resulting in underestimated lattice parameters. For 
systems with large density gradients, e.g. for $3 d$ transition metals, LDA may not be suitable. An improved approximation allowing more significant non-homogeneous densities is to also implement the effect of density gradients $\nabla n$, like in the generalized gradient approximation (GGA),

$$
E_{X C}^{G G A}[n]=\int d \mathbf{r} \varepsilon_{X C}^{G G A}([n, \nabla n], \mathbf{r}) n(\mathbf{r})
$$

There are many different GGA schemes available, e.g. those proposed by Becke (B88) [91], Perdew and Wang (PW91) [92], and by Perdew, Burke, and Ernzerhof (PBE) [93]. GGA is a better approximation as compared to LDA for many $3 d$ transition metal systems, as the larger density gradients of the semi-core states, compared to valence state electrons, are more accurately described.

The effect of using different exchange-correlation approximations is shown in Figure 7, exemplified by $M_{2} A C$ MAX phase lattice parameters. The overbinding from LDA results in values of $a$ and $c$ to be 1.5 to $5 \%$ below experimental values. Corresponding values from GGA calculations are within $\pm 0.7 \%$ of experimental ones.

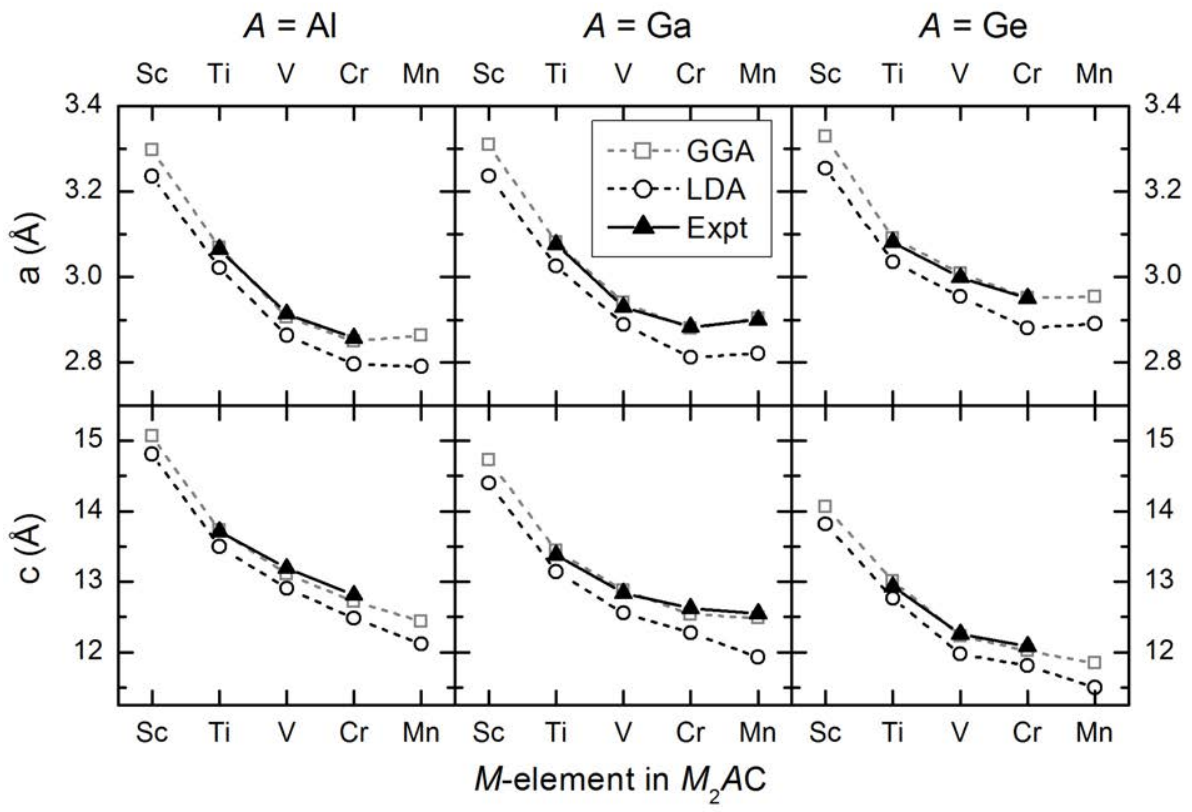

Figure 7. Lattice parameters $a$ and $c$ for $M_{2} A \mathrm{C}(M=\mathrm{Sc}, \mathrm{Ti}, \mathrm{V}, \mathrm{Cr}, \mathrm{Mn}, A=\mathrm{Al}, \mathrm{Ga}, \mathrm{Ge})$ based on calculations using GGA $(\square)$ and LDA (०). For comparison experimental values are included ( $\mathbf{\Delta})$ [10, 17, 27, 94-96].

Even though the lattice parameters from GGA and LDA differ, the central parts of this thesis are associated with phase stability for which the energy of the phases are most important. A 
comparison the of formation enthalpy $\Delta H_{c p}$, described in detail in Chapter 4.2, using both LDA and GGA functionals is illustrated in Figure 8 for $15 M_{2} A C$ phases. Both functionals predict stability $\left(\Delta H_{c p}<0\right)$ for experimentally known phases. They only differ in the results for $\mathrm{Mn}_{2} \mathrm{AlC}$, with the GGA results being consistent with experiment (as $\mathrm{Mn}_{2} \mathrm{AlC}$ has not been reported). Note that the set of most competing phases identified and used for calculating $\Delta H_{c p}$ are identical for both functionals. Further details of this will be given in Chapter 3.2.

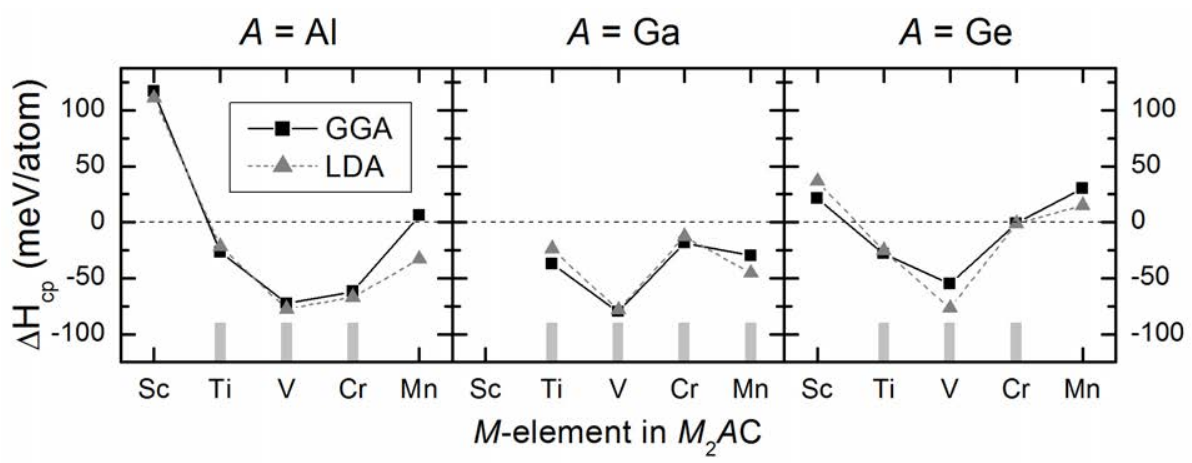

Figure 8. Calculated formation enthalpy $\Delta H_{c p}$ for $M_{2} A \mathrm{C}(M=\mathrm{Sc}, \mathrm{Ti}, \mathrm{V}, \mathrm{Cr}, \mathrm{Mn}, A=\mathrm{Al}, \mathrm{Ga}$, Ge) using GGA ( $)$ and LDA $(\Delta)$. Experimentally verified phases are indicated with a vertical grey bar ( $\mid$ ). Negative $\Delta H_{c p}$ indicates stability of a $M_{2} A C$ phase.

Some materials cannot be represented by GGA or LDA alone, e.g., where there are localized electrons in strongly correlated systems like transition-metal oxides [97, 98]. For strongly correlated materials, the large Coulombic repulsion between localized electrons might not be well represented. One approach is to add a so-called Hubbard $U$ to the density functional, an approach known as $\mathrm{LDA}+\mathrm{U}$ (or GGA+U). In this implementation, localized $d$ electrons, on which the Hubbard term $\mathrm{U}$ will act, are separated from the delocalized $s$ and $p$ electrons. The latter are correctly described by the standard approximations [99].

Whether use of $+\mathrm{U}$ methods is necessary for calculating MAX phase properties is not clear. The discrepancies between experimental and theoretical bulk modulus of $\mathrm{Cr} 2 \mathrm{AlC}$ have been used as motivation for use of $+\mathrm{U}$, giving better agreement $[100,101]$. However, in Paper V we suggest that this inconsistency can be related to considered magnetic spin configurations [102]. Recently $+\mathrm{U}$ have also been used for studying $\mathrm{Cr}_{2} \mathrm{GeC}$ [103-106]. In Paper VI we investigate the effect of $\mathrm{U}$ on magnetic ground state, structure, and bulk modulus for $\mathrm{Cr}_{2} A \mathrm{C}$ ( $A=\mathrm{Al}, \mathrm{Ga}, \mathrm{Ge})$ using the rotationally invariant approach by Dudarev et al. [107].

\subsubsection{Plane waves and pseudopotentials}

When solving the Kohn-Sham equations (Eq. (2)), the unknown single-particle wavefunctions $\phi_{i}(\mathbf{r})$ needs to be represented by a basis set. For crystals, which by definition are periodic, a suitable basis set description is to expand $\phi_{i}(\mathbf{r})$ by plane waves. However, such expansion is problematic since $\phi_{i}(\mathbf{r})$ oscillates rapidly close to the nuclei and more slowly in the 
interstitial regions. A huge number of plane waves with a very high cutoff energy are thus needed which limits the size of systems to be solved. Attempts to solve this are based on the approach that electrons in an atom can be categorized into:

- Core states: Localized electrons that do not take part in bonding.

- Valence states: In general non-localized electrons responsible for bonding.

- Semi-valence states: Localized electrons that do not directly contribute to bonding but may affect valence states.

In many methods, only the valence states are fully included. Depending on what properties one wants to calculate and the accuracy of the calculations, the other two states may be included as well. One example is the frozen-core approximation, where the core states are included only once, in the beginning of the calculation, as if they were in a single isolated atom. An approximation which does treat the electrons in such way is the pseudopotential method which substitutes the electron wave functions and potentials after the initial step by smooth pseudo wave functions and potentials inside a specified radius from the nucleus [87, 108]. An extension of this method is the projector augmented wave (PAW), introduced by Blöchl [109] and further developed by Kresse et al. [110]. It is an all-electron method where the wavefunctions of the core states are kept in the calculation while still applying the frozen core approximation. Thus, they are unaffected by valence states, but still available for total energy evaluations. Throughout the thesis work the PAW approach has been used as implemented within the Vienna ab-initio Simulation Package (VASP) [110, 111].

\subsection{6 $k$-points and energy cutoff}

To obtain accurate results, parameters like $k$-point density and plane wave cutoff energy $E_{\text {cutoff }}$ have to be optimized. When considering the electronic structure of a solid it is not necessary to consider all wave vectors, only those inside the region of reciprocal space known as the first Brillouin zone (BZ) ${ }^{12}$. Due to symmetry, these can be reduced further into the irreducible Brillouin zone (IBZ), thus reducing the computational cost needed. The $k$-points specify points in the $\mathrm{BZ}$ at which plane waves are generated. More $\mathbf{k}$ points mean more plane waves resulting in better description of the basis set. One approach commonly used is the Monkhorst-Pack scheme [112] where the $k$-point density is specified in the direction of the reciprocal lattice vectors. The $k$-point density is inversely proportional to the corresponding unit cell vector. If $\mathbf{a}_{1}=a$ and $\mathbf{a}_{2}=4 a$ are the unit cell vectors then there should be a four times denser $k$-grid along reciprocal vector $\mathbf{b}_{1}$.

The cutoff energy determines the maximum energy for plane waves used in the expansions of the wavefunctions in Eq. (2) and therefore the number of plane waves in the basis set. Illustrated in Figure 9 are the total energies (left panels) and volumes (right panels) as a

\footnotetext{
${ }^{12}$ The first Brillouin zone is the Wigner-Seitz cell of the reciprocal lattice, which is defined by the planes that are the perpendicular bisectors of the vectors from the origin of the reciprocal lattice points.
} 
function of cutoff energy for $\mathrm{Ti}_{2} \mathrm{AlC}$, $\mathrm{TiC}$, and $\mathrm{TiAl}$. Note that for each phase three different $\mathrm{k}$-grid densities are shown. It is obvious the total energy as well as the volume depends on the choice of $E_{\text {cutoff }}$ as well as the $k$-point density. Just as important when performing phase stability calculations are energy difference between phases, shown in Figure 10 (numbers used for calculating $\Delta E$ are displayed in Figure 9). Already at $300 \mathrm{eV}$ with a mid $k$-point density, a convergence in $\Delta E$ is obtained. In this work we have used a $E_{\text {cutoff }}$ of $400 \mathrm{eV}$ with high $k$-point densities.
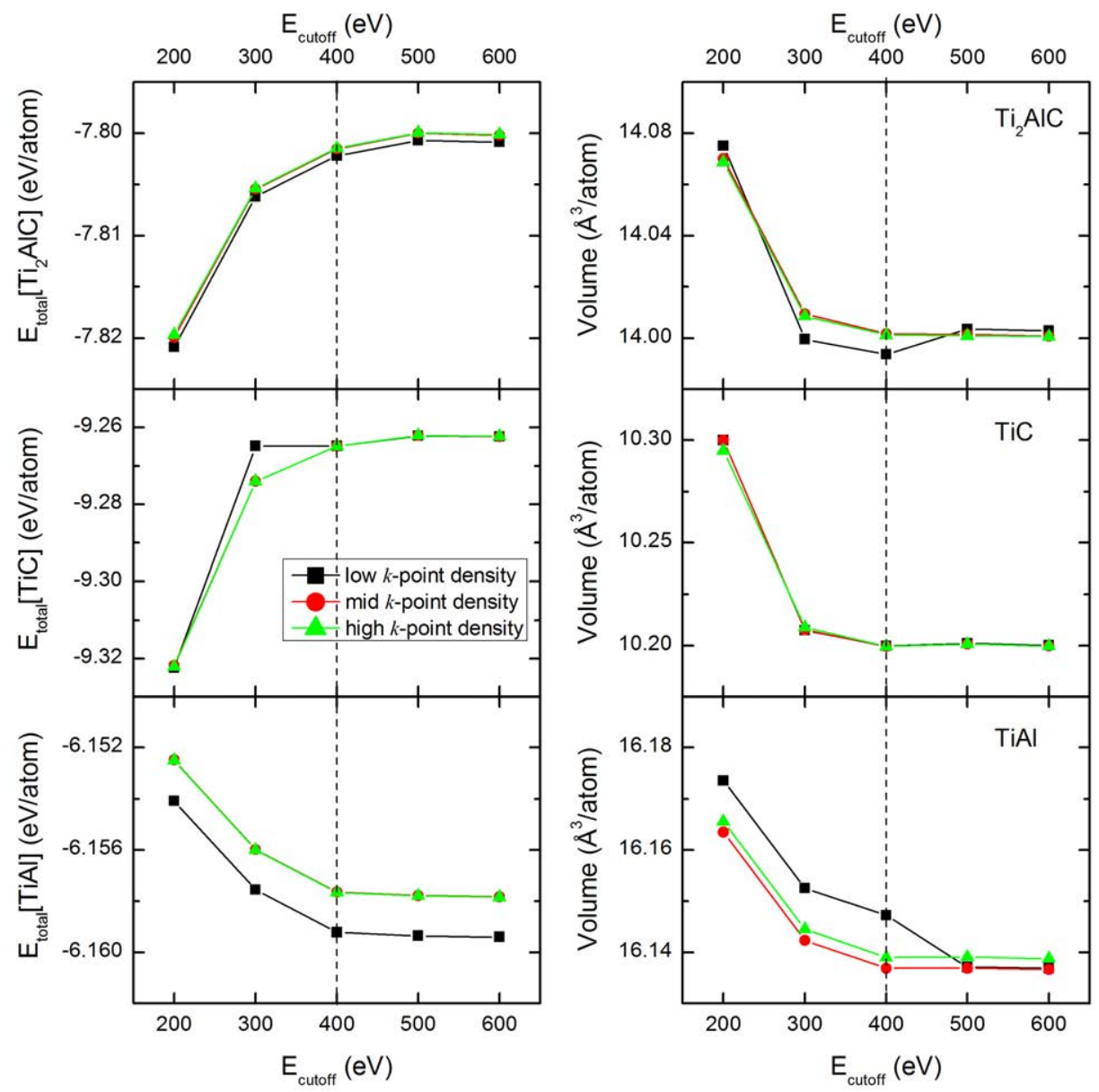

Figure 9. Example of energy (left panels) and volume (right panels) dependence on plane wave energy cutoff $E_{\text {cutoff }}$ and $k$-point density for $\mathrm{Ti}_{2} \mathrm{AlC}, \mathrm{TiC}$, and TiAl. Dashed vertical line indicate $E_{\text {cutoff }}(400 \mathrm{eV})$ used within this thesis work. 


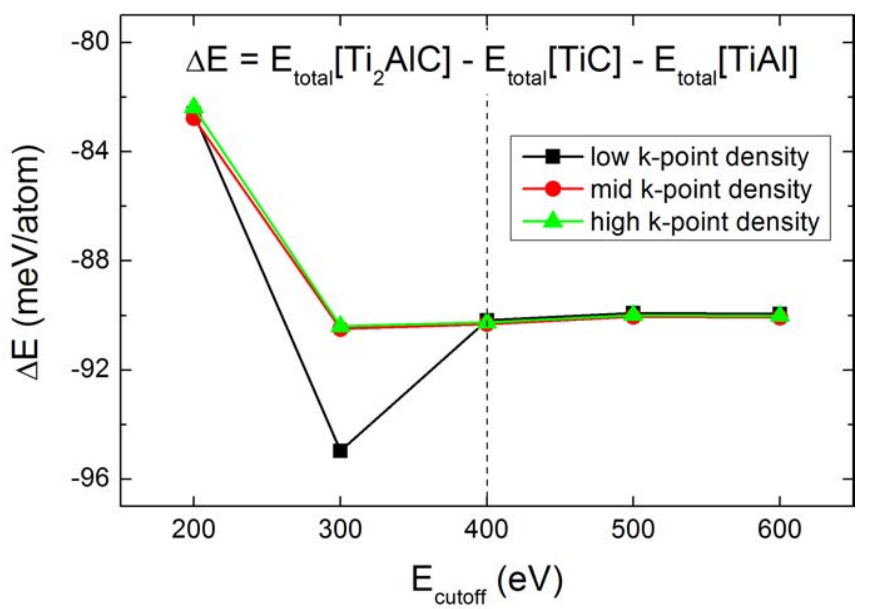

Figure 10. Energy difference of $\mathrm{Ti}_{2} \mathrm{AlC}$ relative $\mathrm{TIC}$ and $\mathrm{TiAl}$ as function of plane wave energy cutoff $E_{\text {cutoff }}$ and different $k$-point densities. Dashed vertical line indicate $E_{\text {cutoff }}$ $(400 \mathrm{eV})$ used within this work.

\subsection{Special quasi-random structures method}

Order and disorder in a material can strongly affect the material properties. Illustrated in Figure 11 is a 2-dimensional picture composed of three different configurational states for a compound with two types of atoms in a crystal lattice. From a highly ordered state (left), with every nearest neighbor of opposite kind, to a disordered state (right) with a stochastic distribution of the two atom types. In between, the atoms are clustered with those of the same type. Whether or not atoms prefer to be in one or the other type of ordering depends, at least in part, on the configurational interaction. At increased temperature the configurational entropy becomes more pronounced and at high enough temperatures the disordered state is the equilibrium configuration.

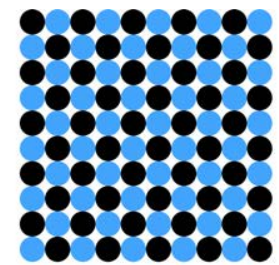

(a)

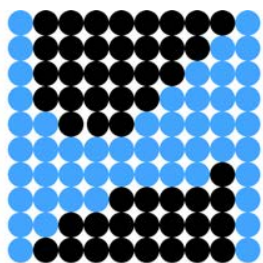

(b)

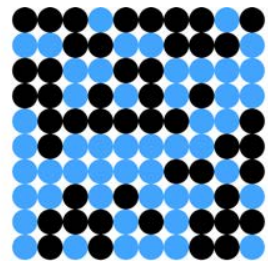

(c)

Figure 11. 2-dimensional illustration of three different atomic configurations of atoms $\mathrm{A}(\bullet)$ and B (•) on a crystal lattice: (a) ordering, (b) clustering, and (c) disordered solid solution. 
Within this work disordered states have been model by the so-called special quasi-random structures (SQS) method, introduced by Zunger et al. [113]. Supercells are then created to mimic the atom distribution in a random alloy. The method can briefly be described as a way of creating as many nearest neighbor A-B bonds, next-nearest neighbor A-B bonds, etc., as found in a completely random alloy. Hence the method attempts to avoid ad hoc constructed supercells, which may lead to non-consistent results ${ }^{13}$.

With increasing size of the supercell, the so called Warren-Cowley SRO parameters of A- and $\mathrm{B}$ atoms within a sublattice can be optimized toward a random distribution of A and B. For an ideal random alloy these parameters are equal to zero [114, 115]. Hence, supercells are created to obtain short-range order (SRO) values as close to zero as possible for an increased number of shells. In Table 4 the $\mathrm{SRO}$ parameters are presented for $\operatorname{Ti}_{2} \mathrm{Al}\left(\mathrm{C}_{1-x} \mathrm{O}_{x}\right)$ supercells containing $32[\mathrm{C}+\mathrm{O}]$ atoms. As the parameters are equal or close to zero for the first ten coordination shells, a random distribution of $\mathrm{C}$ and $\mathrm{O}$ on the carbon sublattice is represented..

Table 4. Short-range order (SRO) parameters for the supercells used to model different compositions of $\mathrm{O}$ on the carbon sublattice in $\mathrm{Ti}_{2} \mathrm{Al}\left(\mathrm{C}_{1-x}, \mathrm{O}_{x}\right)$. The $\mathrm{SRO}$ parameters are given for the coordination shells of carbon, within a supercell containing $32[\mathrm{C}+\mathrm{O}]$ atoms

\begin{tabular}{ccccccccccc}
\hline & \multicolumn{10}{c}{ Shell } \\
\cline { 2 - 11 }$x$ & 1 & 2 & 3 & 4 & 5 & 6 & 7 & 8 & 9 & 10 \\
\hline $0.25,0.75$ & 0.00 & 0.00 & 0.11 & 0.00 & 0.00 & 0.00 & 0.00 & 0.00 & 0.00 & 0.11 \\
0.50 & 0.00 & 0.00 & 0.00 & 0.00 & 0.00 & 0.00 & -0.13 & 0.00 & -0.08 & 0.00 \\
\hline
\end{tabular}

The larger the supercell used, the more correlation functions can be defined in order to mimic a random alloy. Whether a supercell can be seen as random or not in total-energy calculations is given by the nature of the effective interactions, e.g. short- or long range, in the system $[114,115]$. The accuracy of using the SQS method must, as stated above, be weighed against the computational cost, and therefore supercells of different sizes should be constructed to find the limit where systems can be seen as "random". This is illustrated in Figure 12 where the energy $\Delta E$ for different sizes of SQS generated supercells is shown relative to the energy of the largest supercell for two different systems investigated in Paper I and Paper VII. In the left panel oxygen is substituted for carbon in $\mathrm{Ti}_{2} \mathrm{AlC}$, with cell sizes varied from $1 \mathrm{x} 1 \mathrm{x} 1$ (two $[\mathrm{C}+\mathrm{O}]$ atoms $)$ to $4 \times 2 \times 2(32[\mathrm{C}+\mathrm{O}]$ atoms $)$ unit cells. From $16[\mathrm{C}+\mathrm{O}]$ atoms, $\Delta E$ is within 1 meV/atom. In the right panel $\mathrm{Mn}$ is alloyed with $\mathrm{Cr}_{2} \mathrm{AlC}$ forming a $\left(\mathrm{Cr}_{1-x} \mathrm{Mn}_{x}\right)_{2} \mathrm{AlC}$ solid solution. For all $x \Delta E$ is within $1.5 \mathrm{meV} /$ atom for 16 [Cr+Mn] atoms. For both systems the largest supercell, with $32[\mathrm{C}+\mathrm{O}]$ or $[\mathrm{Cr}+\mathrm{Mn}]$ atoms have been used in this thesis work. Note the different behavior for the two systems when the supercell is constructed by a just one or a few unit cells. For [C+O] its unfavorable to be less disordered whereas $\left.\mathrm{Cr}_{1-x} \mathrm{Mn}_{x}\right)_{2} \mathrm{AlC}$ prefer a

\footnotetext{
${ }^{13}$ Might be difficult to distinguish a clustered, or semi-ordered, structure from a solid solution structure.
} 
more ordered configuration arising from more favorable magnetic configuration when $\mathrm{Mn}$ atoms are "clustered" together.

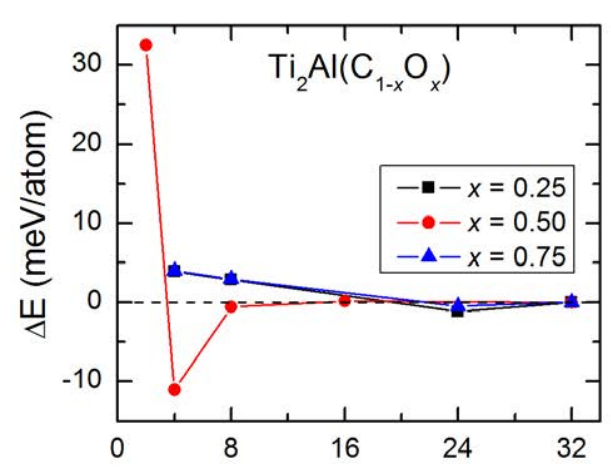

Number of $\mathrm{C}+\mathrm{O}$ atoms in supercell

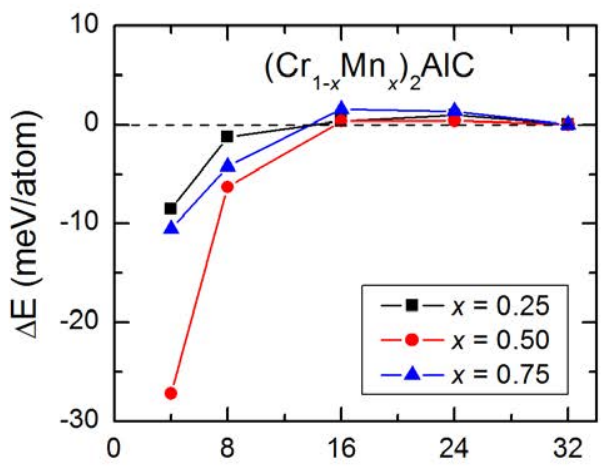

Number of $\mathrm{Cr}+\mathrm{Mn}$ atoms in supercell

Figure 12. Relative energy difference for different supercell sizes created using SQS to mimic a random distribution of $\mathrm{O}$ and $\mathrm{C}$ atoms on $\mathrm{X}$-site in $\mathrm{Ti}_{2} \mathrm{AlC}$ (left panel) or of $\mathrm{Mn}$ and $\mathrm{Cr}$ atoms on $M$-site in $\mathrm{Cr}_{2} \mathrm{AlC}$ (right panel).

Not only has the SQS method been used for configurational disorder but also for modeling magnetic disorder in Paper V, VI, VII, and IX. The paramagnetic (PM) state was approximated by means of the disorder local moment (DLM) model [116, 117]. For $\mathrm{Mn}_{2} \mathrm{GaC}$, the DLM was represented by a random configuration of Mn atoms with up $\mathrm{Mn} \uparrow$ and down $\mathrm{Mn} \downarrow$ spins in a $\left(\mathrm{Mn}_{0.5} \uparrow \mathrm{Mn}_{0.5} \downarrow\right)_{2} \mathrm{GaC}$ alloy. In a similar way the DLM $\left(\mathrm{Cr}_{1-x} \mathrm{Mn}_{x}\right)_{2} \mathrm{AlC}$ phase with $x=0.5$ was represented by a random configuration of $\mathrm{Mn}$ atoms with up $\mathrm{Mn} \uparrow$ and down $\mathrm{Mn} \downarrow$ spins in a $\left(\mathrm{Cr}_{0.50} \mathrm{Mn}_{0.25} \uparrow \mathrm{Mn}_{0.25} \downarrow\right)_{2} \mathrm{GaC}$ alloy, with $\mathrm{Cr}$ and $\mathrm{Mn}$ in a solid solution. It should be kept in mind that it is challenging to theoretically resolve the exact magnetic ground state for disordered systems, as they are dictated by a delicate balance between magnetic interaction and chemical environment

\subsection{Linear optimization for prediction of phase stability}

This thesis evolves around phase stability of ground state structures, and an essential part is to identify the set of most competing phases relative to the material of interest. To determine the ground state of a system one needs to find, as a function of composition,

- any linear combination of phases that gives the material composition of interest. 
This set of ground-state structures forms a convex hull. For binary systems it's a rather straightforward task to construct, and visualize, a convex hull ${ }^{14}$ from calculated binary formation energies. That is illustrated in Figure 13 for three binary systems.

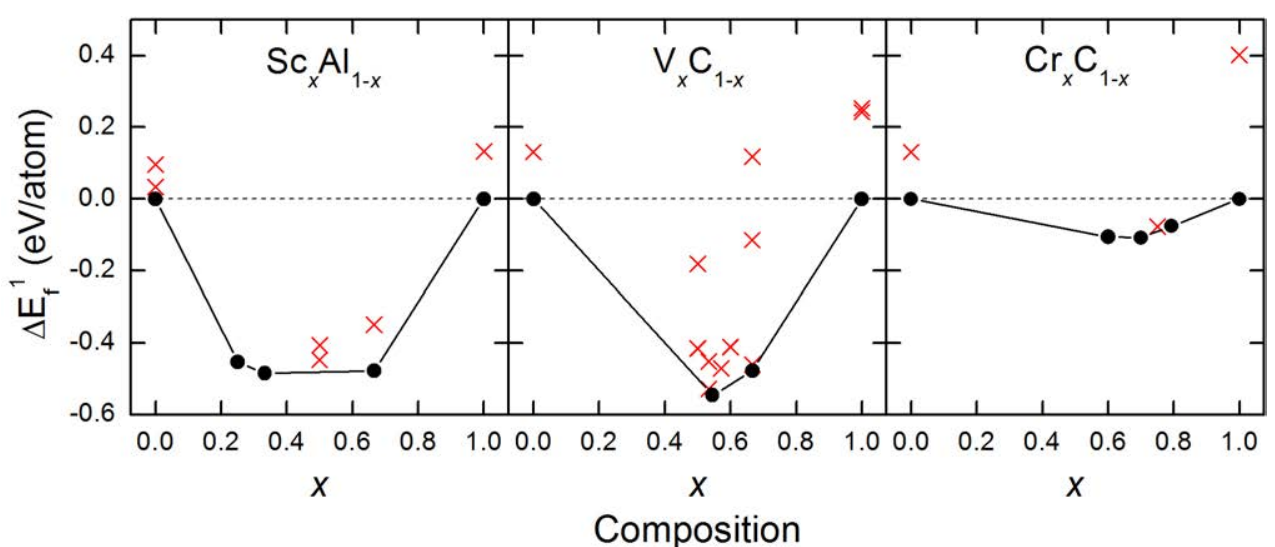

Figure 13. Calculated formation energies $\Delta E_{f}^{1}$ for $\mathrm{Sc}-\mathrm{Al}, \mathrm{V}-\mathrm{C}$, and $\mathrm{Cr}-\mathrm{C}$ binaries with ground state structures indicated by circles $(\bullet)$ lying on the convex hull (solid black line). Phases with positive formation energy $(x)$ are all above the convex hull line.

For ternary and especially higher order systems with a large number of phases it becomes a non-trivial task to identify the lowest energy combination of phases at a given composition. A solution for solving this is through linear optimization methods and one of the most wellknown and frequently used is the simplex method [118]. It is applied for e.g., maximizing the profit in distributional business. In short, the method maximizes or minimizes a function, i.e. finds an optimum, with respect to a set of variables and constraints.

A systematic scheme based on the simplex method was introduced in Paper I [57] and has since been used in most of the papers presented in this Thesis. For simplicity the notation presented below is for analyzing a general $M_{n+1} A X_{n}$ phase, consisting of three different elements $(M, A$, and $X)$, but the approach can be used for other ternary, quaternary or even higher order systems.

The most competitive combination of phases at a given elemental composition of $b^{M}, b^{A}$, and $b^{X}$, is identified using a linear optimization procedure of the form

$$
\min E_{c p}\left(b^{M}, b^{A}, b^{X}\right)=\sum_{i=1}^{n} x_{i} E_{i},
$$

\footnotetext{
${ }^{14}$ The Convex hull is the tie line between ground state structures. See Section 4 for further information.
} 
where $x_{i}$ and $E_{i}$ is the amount and energy of compound $i$, respectively, and $E_{c p}$ is the energy we want to minimize subject to the constraints

$$
x_{i} \geq 0, \quad \sum_{i=1}^{n} x_{i}^{M}=b^{M}, \quad \sum_{i=1}^{n} x_{i}^{A}=b^{A}, \quad \sum_{i=1}^{n} x_{i}^{X}=b^{X} .
$$

For $M_{n+1} A X_{n}$ phases the constraints are

$$
\begin{aligned}
& b^{M}=n+1 \\
& b^{A}=1 \\
& b^{X}=n .
\end{aligned}
$$

Using Eq. (8) it is thus possible to find the combination of phases which has the lowest total energy at the $\mathrm{M}_{n+1} \mathrm{AX}$ composition. The resulting formation enthalpy is thereafter calculated according to

$$
\Delta H_{c p}\left(M_{n+1} A X_{n}\right)=E\left(M_{n+1} A X_{n}\right)-\min E_{c p}\left(b^{M}, b^{A}, b^{X}\right)
$$

where $E\left(M_{n+1} A X_{n}\right)$ is the calculated total energy of the $\mathrm{M}_{n+1} \mathrm{AX}$ phase and $E_{c p}$ comes from solving Eq. (8). For a negative value of $\Delta H_{c p}$ the phase is stable, whereas a positive value indicates that the phase is not stable or at best metastable.

Illustrated in Figure 14 is a schematic flow chart summarizing the linear optimization procedure used to identify the set of most competitive phases at a given composition.

\begin{tabular}{|l|l|}
\hline 1. Data input & - Phases $i$ with energy $E_{i}$ \\
\hline $\begin{array}{l}\text { 2. Constraints } \\
\text { competitive phases }\end{array}$ & $\begin{array}{l}\text { - Compostion given by Eq. (10) } \\
\text { energy by solving the linear optimization problem } \\
\text { in Eq. (8) through use of the simplex metohd. }\end{array}$ \\
\hline 4. Calculate $\Delta H_{c p}$ (Eq. 11) & $\begin{array}{l}\text { - }<0 \text {, stable } \\
\text { end not stable }\end{array}$ \\
\hline
\end{tabular}

Figure 14. Schematic flow chart of how to calculate the formation enthalpy. 

"I'll make your visions sing

I'll open endless skies

And ride your broken wings

Welcome to my world"

Welcome to my world, Depeche Mode

\section{4}

\section{MAX PHASE STABILITY}

Bonds between constituent atoms of any molecule or solid can briefly be described as a way of redistributing valence electrons in order to make the resulting structure energetically favorable. To which extent depends not only on the internal energy $(E)$, but also on the environment (temperature $T$, pressure $p$, competing phases, etc.). This is taken into consideration in the free energy [119]

$$
G=E+p V-T S
$$

where $V$ is the volume and $S$ the entropy. At finite temperatures $(T>0 \mathrm{~K})$, the entropy $S$ contributes to the free energy. Entropy is a measure of disorder. Hence the term $-T S$ in the free energy favors disordered phases and their presence increases with $T$. At low temperatures, low energy excitations such as geometrical distortions determine the behavior of a system. In principle the free energy of a phase can be approximated with its ground state energy. This might be understood by the free energy having the shape of a "parabola" centered on the ground state energy and concentrations, as illustrated in Figure 15. As such, knowledge of the ground state energy is often a good approximation for evaluating the phase stability at low temperatures,. The set of tie lines that connects the structures of lowest energy for various composition, $(\bullet)$ in Figure 15, is called the convex hull and it represents the energy of the alloy at $\mathrm{T}=0 \mathrm{~K}$. Structures above the tie line are not stable with respect to the mixture of the two structures that defines the vertices of the tie line. This is exemplified in Figure 15 by the phase $\beta(\circ)$ being unfavorable or metastable ${ }^{15}$ with respect to a combination

15 A system, here phase $\beta$, in a local, but not a global, free energy minimum is dented as metastable. The existence of a free energy barrier between the metastable and globally stable state of the system allows the metastable state to exist. 
of phase $\alpha$ and $\gamma$. Although an approximation, calculations at $0 \mathrm{~K}$ is hence a good starting point for analysis of phase stability.

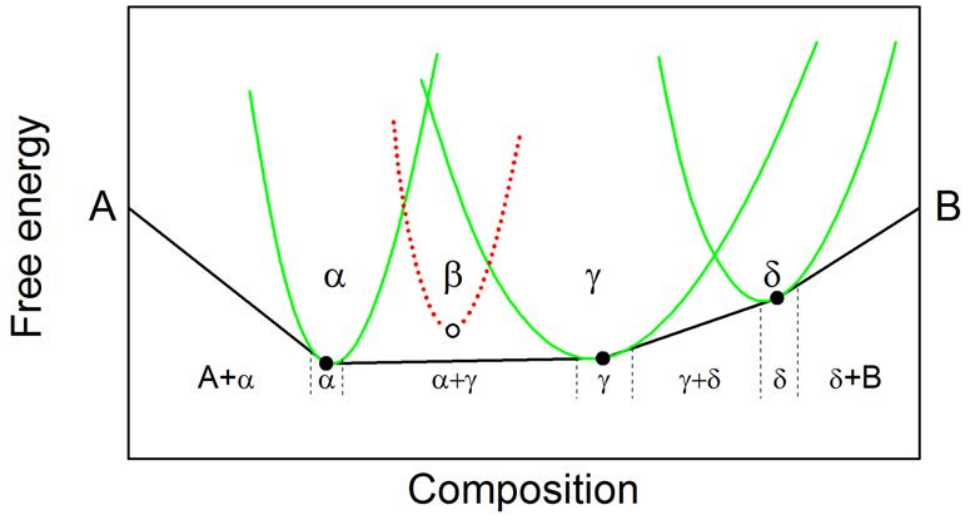

Figure 15. Schematic of stability in a two-component system where free energies of the binary phases have shapes like "parabolas" around their equilibrium ground state. At $\mathrm{T}=0 \mathrm{~K}$, the ground state energy $(\bullet$ and $\circ$ ) determine the stability of each phase. The minimization of the energy with respect to composition at $0 \mathrm{~K}$ is represented by the tie line between ground state structures (solid black line) and it is known as the convex hull.

When it comes to theoretical studies on hypothetical MAX phases, a reflection upon their possible existence is highly motivated. Is it stable or not from a theoretical point of view? Will it be possible to synthesize? What's the point of calculating every possible property of a material if it never will be realized? Still, hypothetical phases do fill a purpose for identification of materials to be attempted for synthesis, or as, included in systematic studies for increasing the understanding how electronic structure evolves or some materials property are affected upon change e.g. along a $M$-element series or similar.

Within this Chapter the concept of stability will be discussed and how to use electronic structure theory to investigate phase stability of solids, with focus on $M_{n+1} A X_{n}$ phases. Different ways of defining energy difference or relative energy will be discussed. Examples will be given to show what information, or lack thereof, one can gain from different approaches. The results presented within this thesis work are restricted to $0 \mathrm{~K}$ calculations, and it will be shown that this generalization is adequate for phase stability investigations of MAX phases. 


\subsection{Cohesive energy}

The cohesive energy $E_{c o h}$ of a solid is defined as the energy required for separating the crystal, or the condensed material, components into isolated free atoms in their ground state. This is illustrated in Figure 16.

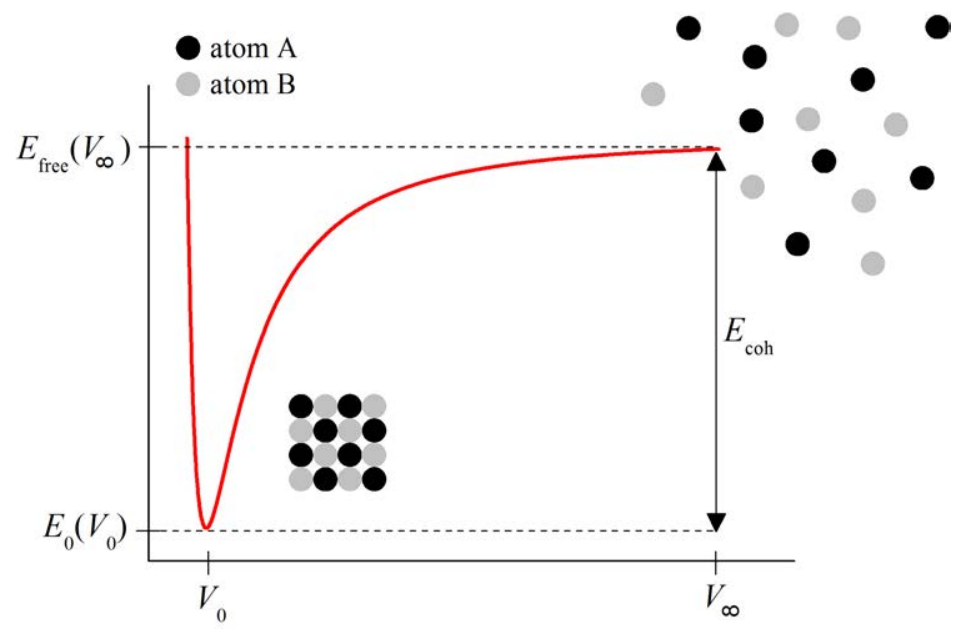

Figure 16. Schematic illustration of a typical energy-volume equation of state for atoms bonded in a solid crystal $\left(V_{0}\right)$ and separated infinitely in vacuum $\left(V_{\infty}\right)$. The cohesive energy $E_{c o h}$ is indicated and calculated according to Eq. (13).

Typical values of $E_{c o h}$ range from about $0.1 \mathrm{eV} /$ atom for inert gases to $9 \mathrm{eV} /$ atom for strongly bounded materials like tungsten, see Table 1 in Reference [120], and can be seen as a measure of the bond strength of the material. For a general two elemental compound $A_{x} B_{y}$ the cohesive energy is defined and calculated according to

$$
E_{\text {coh }}\left(A_{x} B_{y}\right)=x E_{\text {free }}(A)+y E_{\text {free }}(B)-E_{0}\left(A_{x} B_{y}\right)
$$

where $E_{0}\left(A_{x} B_{y}\right)$ is the total energy of the solid $A_{x} B_{y}$, and $E_{f r e e}(A$ or $B)$ the energy of an isolated free atom $(A$ or $B)$. Care must be taken when calculating $E_{\text {free }}$. An asymmetric "simulation box", size $a \times b \times c$ where $a \neq b \neq c$, of large enough size should be used to ensure the atom is considered as free and not interacting with any neighbor.. Spin polarization effects must also be included to make sure the correct spin state of the free atom is used.

In Figure 17, $E_{c o h}$ is shown for 24 existing and 91 hypothetical $M_{n+1} A X_{n}$ phases with $n=1$ 3. All 115 phases have positive cohesive energy and can thus be seen as stable with respect to separating the atoms infinitely apart from each other. However, the majority of the selected 
phases have not yet been synthesized, or at least not reported, although attempts have been made in the quest for, e.g., $\mathrm{Ti}_{2} \mathrm{SiC}^{16}[11,121]$.

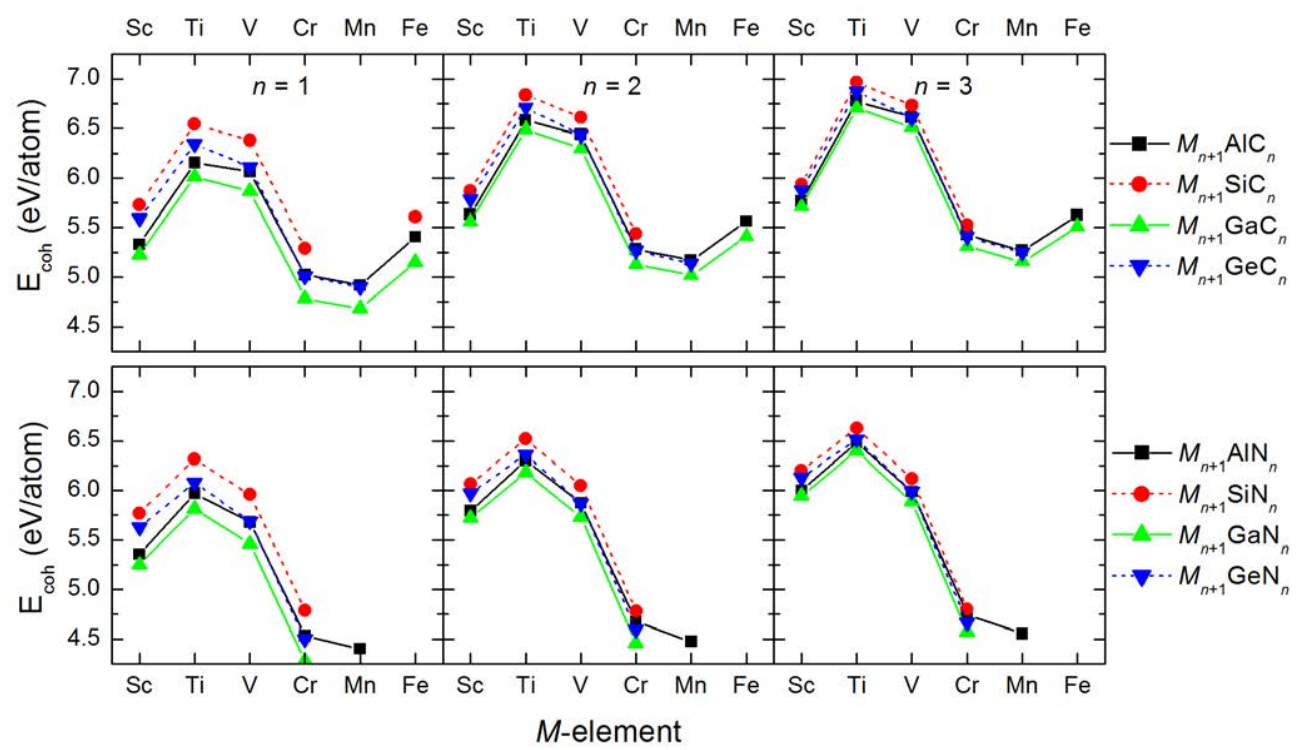

Figure 17. Calculated cohesive energy $E_{c o h}$ for known and hypothetical $M_{n+1} A X_{n}$ phases. Note that series with $A=\mathrm{Al}$ and Ge overlap.

The example above was shown to point out that cohesive energy by itself may not be of overriding importance for the stability, i.e. existence, of a phase. This will be further discussed below.

\subsection{Formation energy}

For a compound to be stable, it must not only be more stable than its constituent free atoms, but also stable with respect to its constituent atoms in their ground-state crystal structure. The concept of formation energy $\Delta E_{f}^{1}$ for $M_{n+1} A X_{n}$ phases is defined by

$$
\Delta E_{f}^{1}\left(M_{n+1} A X_{n}\right)=\frac{E_{0}\left(M_{n+1} A X_{n}\right)-(n+1) E_{0}(M)-E_{0}(A)-n E_{0}(X)}{2(n+1)},
$$

where $E_{0}(Z)$ expresses the total energy per formula unit of phase $Z$. $\Delta E_{f}^{1}$ determines if the considered phase is stable $(<0)$ or not $(>0) .{ }^{17}$ Shown in Figure 18 are calculated $\Delta E_{f}^{1}$ for 115 considered $M_{n+1} A X_{n}$ phases $(n=1-3)$. Note that stability is indicated for a positive value of

\footnotetext{
${ }^{16}$ Note that among the $39 M_{2} A X$ phases $\mathrm{Ti}_{2} \mathrm{SiC}$ was found with highest cohesive energy.

${ }^{17}$ Note that Eq. (13) and (14) are defined in different order hence the positive and mostly negative values in Figure 17 and Figure 18 , respectively.
} 
the cohesive energy $E_{c o h}$, and for a negative value of $\Delta E_{f}^{1}$, due to the choice of definition for the cohesive energy (Eq. (13)). Also note that the numbers have almost decreased by an order of magnitude as compared to $E_{c o h}$ in Figure 17 , due to subtraction between two large, almost equal, numbers. The $M_{n+1} A \mathrm{C}_{n}$ phases display a clear minimum, indicating maximum stability, at $M=\mathrm{Ti}$ (see corresponding maxima Figure 17). $M>\mathrm{Ti}$, there is an increase in $\Delta E_{f}^{1}$, i.e. a decreased stability. This result is in agreement with studies for $M \mathrm{C}, \mathrm{NaCl}$-struture, and is suggested to be due to band-filling of bonding $M d-\mathrm{C} p$ hybridized states [122, 123]. As more $d$-electrons are added, nonbonding and antibonding states are gradually populated causing a decreased stability. For N-based MAX phases this minimum is slightly shifted to the left $(M \leq \mathrm{Sc})$. Since $\mathrm{N}$ has one more valence electron as compared to $\mathrm{C}$, bands are filled earlier in the $M$-series. The kink observed around $M=\mathrm{Mn}$ is related to magnetism stabilizing the $M_{n+1} A X_{n}$ phases.

109 phases seem to be stable in terms of $\Delta E_{f}^{1}<0$, which is far from the 24 phases known experimentally. It becomes obvious that $\Delta E_{f}^{1}$ alone is an insufficient parameter in evaluating stability of $M_{n+1} A X_{n}$ phases.

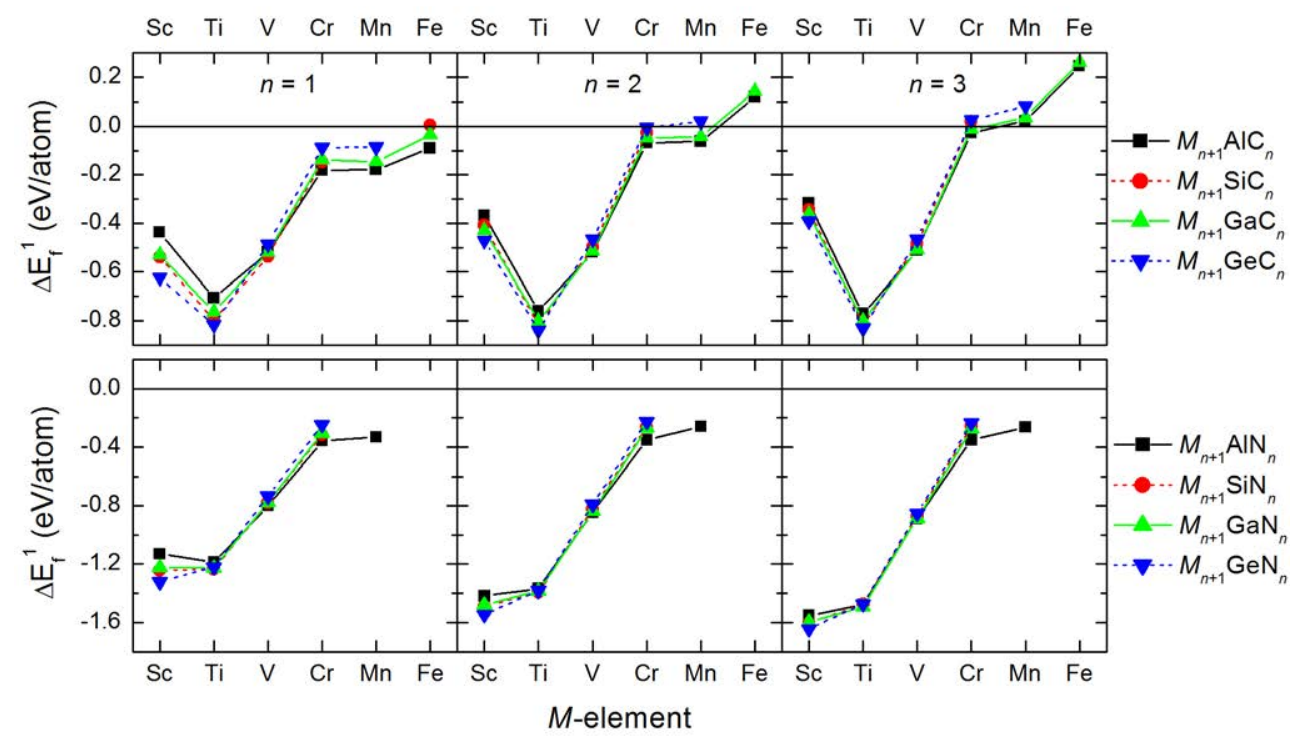

Figure 18. Formation energy $\Delta E_{f}^{1}$ for $M_{n+1} A X_{n}$ phases (with $n=1-3$ ) relative its constituent elements in their ground-state crystal structure.

For more reliable phase stability calculations, competing phases including constituent atoms in their ground-state crystal structure as well as binary and ternary phases need to be included. To emphasize that a phase is fully relaxed the calculated equilibrium total energy is denoted $E_{0}$. This notation can be related to the enthalpy $H=E_{0}-p V$, where $p$ is the pressure and $V$ 
the volume of the system. For fully relaxed phases $p=0$ and hence $H=E_{0}$. For $M_{n+1} A X_{n}$ the energy difference with respect to competing phases is then here defined as the formation enthalpy per atom as given by

$$
\Delta H\left(M_{n+1} A X_{n}\right)=\frac{E_{0}\left(M_{n+1} A X_{n}\right)-E_{0}(\text { competing phases })}{2(n+1)},
$$

where $E_{0}\left(M_{n+1} A X_{n}\right)$ is the total energy of $M_{n+1} A X_{n}$, and $E_{0}$ (competing phases) the total energy for a set of competing phases with of total stoichiometry equal to $M_{n+1} A X_{n}$.

In the literature there are studies where stability of MAX phases have been investigated, including binaries as well as ternaries, as competing phases. [13, 66, 124-126] In accordance with experiments Palmquist et al. [66] do find $\mathrm{Ti}_{4} \mathrm{SiC}_{3}$ as theoretically stable $(\Delta H=-29$ meV/atom). However, also $\mathrm{Ti}_{2} \mathrm{SiC}$ was predicted stable $(\Delta H=-8 \mathrm{meV} / \mathrm{atom})$ albeit its existence has not yet been reported [11]. Fang et al. [124] predicted the so far non-existing $\mathrm{Ti}_{2} \mathrm{SiC}$ to be stable ( $-50 \mathrm{meV} /$ atom) and the existing $\mathrm{Ti}_{3} \mathrm{SiC}_{2}$ to not be stable ( $+3 \mathrm{meV} /$ atom). One of the reasons for these discrepancies were the assumption of $x=0$ in $\mathrm{Ti}_{5} \mathrm{~S}_{3} \mathrm{C}_{x}$ in the latter study. In a later study the inclusion of $\mathrm{Ti}_{5} \mathrm{~S}_{3} \mathrm{C}_{x}$ with $x=1$ reveled $\mathrm{Ti}_{2} \mathrm{SiC}$ as not stable (+4 meV/atom), in accordance with phases like $M_{5} \mathrm{Si}_{3} \mathrm{C}_{x}(M=\mathrm{Ti}, \mathrm{V}, \mathrm{Nb})$, which are known to be stabilized upon incorporation of carbon [127, 128]. Other examples are evaluation of stability of $\mathrm{V}_{2} \mathrm{SiC}$ (-68 meV/atom), $\mathrm{V}_{3} \mathrm{SiC}_{2}$ (+2 $\mathrm{meV} /$ atom), and $\mathrm{Nb}_{3} \mathrm{SiC}_{2}$ (+20 meV/Atom).

The most ambitious study concerning stability calculations of $M_{n+1} A X_{n}$, excluding this work, is by Keast et al. [126] investigating five ternary systems $(M=\mathrm{Ti}$ and $\mathrm{Cr}, A=\mathrm{Al}$ and $\mathrm{Si}, X=$ $\mathrm{C}$ and $\mathrm{N}$ ). The overall result matches experimental observations very well, although the set of most competitive phases was not identified for some MAX phases. This is exemplified in Table 5 for $\mathrm{Ti}_{2} \mathrm{AlC}$ and $\mathrm{Ti}_{3} \mathrm{AlC}_{2}$, where the competing phases used in Ref [126] are compared to those identified using linear optimization (see Section 3.3). Even though $\mathrm{Ti}_{2} \mathrm{AlC}$ and $\mathrm{Ti}_{3} \mathrm{AlC}_{2}$ are stable with both sets of competing phases, the values of $\Delta H$ differ significantly

Table 5. Calculated $\Delta H$ from different ways of choosing competing phases based on data from Table 3 in Keast et al [126].

\begin{tabular}{lcc}
\hline \hline \multirow{2}{*}{ Choice of competing phases } & \multicolumn{2}{c}{$\Delta H$ (meV/atom) } \\
\cline { 2 - 3 } by-hand [126] & $\mathrm{Ti}_{2} \mathrm{AlC}$ & $\mathrm{Ti}_{3} \mathrm{AlC}_{2}$ \\
\hline \multirow{2}{*}{ use of linear optimization } & -91 & -22 \\
& $\mathrm{Ti}_{3} \mathrm{AlC}, \mathrm{TiC}, \mathrm{TiAl}$ & $\mathrm{Ti}_{2} \mathrm{AlC}, \mathrm{TiC}$ \\
\hline \hline
\end{tabular}

Table 5 illustrates the difficulties associated with identifying the set of most competitive phases by-hand. If investigating, e.g., a quaternary compound with 30 competing, the complexity increases. Therefore, use of linear optimization is an excellent tool for identification of the most competitive set of competing phases and hence avoid ad-hoc choices. 
Another important issue to take into consideration is what competing phases to include in the phase stability calculations. In Ref. [124] Fang et al. comments on the ambiguity of selecting competing phases in the ternary phase diagram. The few stability studies of MAX phases reported [13, 66, 124-126] make use of experimental ternary phase diagrams, with focus on tie lines and three-phase regions. However, to include all phases careful investigations of the phase diagrams are necessary to elucidate candidates. Low-temperature structures should be included, as these may be the ones of lowest energy, but also structures at higher temperature may be included. Binaries are often well-explored with known structures and compositions over a large temperature span. For ternary and higher-order compounds the larger "phase space" 18 often results in phase diagrams at a selected fixed temperature. Hypothetical phases should also be considered, based on known compounds in neighboring or similar systems to the one investigated. One example is the inverse perovskite ${ }^{19} M_{3} A X$, based on the mineral perovskite ${ }^{20} \mathrm{CaTiO}_{3}$, experimentally known in some MAX phase related systems (e.g. $\mathrm{Sc}_{3} \mathrm{AlN}$ [129, 130], $\mathrm{Sc}_{3} \mathrm{InC}$ [131], $\mathrm{Ti}_{3} \mathrm{AlC}$ [132], $\mathrm{Nb}_{3} \mathrm{GeC}$ [133]). In the Ti-Al-N system two versions of the $\mathrm{Ti}_{3} \mathrm{AlN}$ perovskite are reported - the cubic inverse perovskite [134] and a distorted perovskite of orthorhombic structure (filled $\mathrm{Re}_{3} \mathrm{~B}$-type) [48].

When one or several phases are not included in the identification of the set of most competitive competing phases the corresponding formation enthalpy represents a lower energy boundary. This might be pushed to higher values if competitive phases are included. As a consequence the values of $\Delta H$ can always become less negative or more positive.

The working process used throughout this work for phase stability calculations is illustrated in Figure 19. All issues discussed above are relevant in the second step of the figure.

\begin{tabular}{|l|l|}
\hline 1. Select material & \begin{tabular}{l} 
- Select what material system to study. \\
\hline 2. Competing phases to include
\end{tabular} \\
\hline similar/neighboring systems (hypothetical phase). \\
\hline 3. Calculate energy & \begin{tabular}{l} 
- Calculate total energy for each competing phase. \\
\hline 4. Identify most competitive phases
\end{tabular} \\
\hline $\begin{array}{l}- \text { Solve the linear optimization problem thru use of the } \\
\text { simplex method. }\end{array}$ \\
\hline 5. Calculate stability & $\begin{array}{l}-\Delta H_{c p}<0, \text { stable phase. } \\
-\Delta H_{c p}>0, \text { phase not stable. }\end{array}$ \\
\hline
\end{tabular}

Figure 19. Schematic work process used for phase stability calculations.

\footnotetext{
${ }^{18}$ In this context "phase space" is related to temperature range and the compositional combinations.

${ }^{19}$ Space group $\operatorname{Pm} \overline{3} m$ (\#221).

${ }^{20}$ Named after a Russian mineralogist, Count Lev Aleksevich von Perovski, and was discovered and named by Gustav Rose in 1839 from samples found in the Ural Mountains.
} 


\subsection{Validation of theoretical approach}

Within this section the phase stability will be presented for experimentally known and hypothetical carbide- and nitride-based $M_{n+1} \mathrm{Al} X_{n}(n=1-3)$ with $M=\mathrm{Sc}, \mathrm{Ti}, \mathrm{V}, \mathrm{Cr}, \mathrm{Mn}, \mathrm{Fe}$, and Co. The choice of $A=\mathrm{Al}$ is motivated by the comparatively large number of known MAX phases with this element. The results were first presented in Paper III and later extended in Paper VI. Since then, a few new competing phases has been included, e.g. $\mathrm{Ti}_{5} \mathrm{Al}_{2} \mathrm{C}_{3}$, based on recent discoveries [69-71]. The results presented here do include these in the analysis. For each of the 11 ternary systems, including 36 MAX phases in total, careful investigations of phase diagrams and experimental works have been conducted in order to avoid ad hoc choices of competing phases, see e.g. Refs. [32, 135].

Table 6 lists competing phases included in the investigation.. For Cr-, Mn-, Fe-, and Co-based compounds different magnetic configurations were tested and the one with lowest energy, considered as the magnetic ground-state, was included in the analysis as a competing phase. For each of the 36 MAX phases, the simplex method was used to solve the linear optimization problem and consequently identify the set of most competitive competing phases, see Table 5. Corresponding formation enthalpy $\Delta H_{c p}$ is calculated using Eq. (15) and listed in Table 7.

The calculated formation enthalpies are also displayed in Figure 20, showing minimum values of $\Delta H_{c p}$, or maximum stability, around $M=\mathrm{V}$ for $\mathrm{C}$-based phases and at $M=\mathrm{Ti}$ for $\mathrm{N}$-based phases. The explanation for this behavior can be related to the number of valence electrons with $\mathrm{N}$ having one more valence electron compared to $\mathrm{C}$ and hence bands are filled earlier in the $M$-series. Similar trends were also found for the formation energies in Figure 18. Another observation is the slight shift of these minima's to the left as $n$ increase. 
Table 6. Competing phases included for $M-\mathrm{Al}-X$ systems. Notation within parenthesis is the crystal structure used for corresponding phase as given by the Pearson symbol ${ }^{21}$. For Cr-, Mn, Fe-, and Co-based compounds different magnetic configurations were tested.

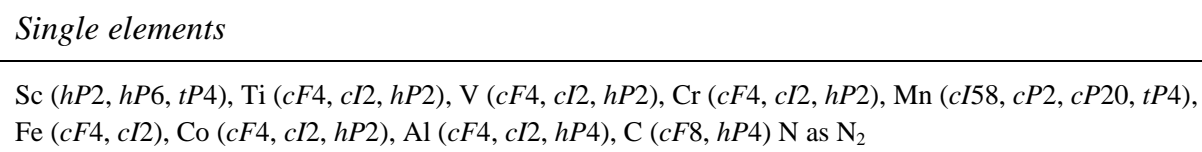

\section{Binary and ternary phases}

$\mathrm{Al}_{4} \mathrm{C}_{3}(h R 21), \mathrm{AlN}(c F 8, h P 4)$

$\mathrm{Sc}_{2} \mathrm{Al}(h P 6), \mathrm{ScAl}(c P 2, o C 8), \mathrm{ScAl}_{2}(c F 24), \mathrm{ScAl}_{3}(c P 4)$,

$\mathrm{Sc}_{2} \mathrm{C}(h P 3), \mathrm{Sc}_{4} \mathrm{C}_{3}(c I 28), \mathrm{ScC}(c F 8), \mathrm{ScC}_{0.875}(c F 8), \mathrm{Sc}_{3} \mathrm{C}_{4}(t P 70), \mathrm{Sc}_{2} \mathrm{AlC}(h P 8), \mathrm{Sc}_{3} \mathrm{AlC}_{2}(h P 12), \mathrm{Sc}_{4} \mathrm{AlC}_{3}$ $(h P 16), \mathrm{ScAl}_{3} \mathrm{C}_{3}(h P 14), \mathrm{Sc}_{3} \mathrm{AlC}(c P 5)$,

$\mathrm{ScN}(c F 8), \mathrm{ScN}_{0.875}(c F 8), \mathrm{Sc}_{2} \mathrm{AlN}(h P 8), \mathrm{Sc}_{3} \mathrm{AlN}_{2}(h P 12), \mathrm{Sc}_{4} \mathrm{AlN}_{3}(h P 16), \mathrm{Sc}_{3} \mathrm{AlN}(c P 5)$

$\mathrm{Ti}_{3} \mathrm{Al}(h P 8), \mathrm{TiAl}(t P 4), \mathrm{TiAl}_{2}(t I 24), \mathrm{TiAl}_{3}(t I 8)$,

$\mathrm{Ti}_{2} \mathrm{C}(c F 48), \mathrm{TiC}(c F 8, h P 4), \mathrm{TiC}_{0.875}(c F 8), \mathrm{TiC}_{0.75}(c F 8), \mathrm{Ti}_{2} \mathrm{AlC}(h P 8), \mathrm{Ti}_{3} \mathrm{AlC}_{2}(h P 12), \mathrm{Ti}_{4} \mathrm{AlC}_{3}(h P 16)$, $\mathrm{Ti}_{12} \mathrm{Al}_{3} \mathrm{C}_{8}(h P 46), \mathrm{Ti}_{5} \mathrm{AlC}_{4}(h P 20), \mathrm{Ti}_{6} \mathrm{AlC}_{5}(h P 24), \mathrm{Ti}_{5} \mathrm{Al}_{2} \mathrm{C}_{3}(h P 20, h P 30), \mathrm{Ti}_{7} \mathrm{Al}_{2} \mathrm{C}_{5}(h P 42), \mathrm{Ti}_{3} \mathrm{AlC}(c P 5$, oP20),

$\mathrm{Ti}_{2} \mathrm{~N}(t P 6), \mathrm{TiN}(c F 8), \mathrm{TiN}_{0.875}(c F 8), \mathrm{Ti}_{2} \mathrm{AlN}(h P 8), \mathrm{Ti}_{3} \mathrm{AlN}_{2}(h P 12), \mathrm{Ti}_{4} \mathrm{AlN}_{3}(h P 16), \mathrm{Ti}_{5} \mathrm{AlN}_{4}(h P 20)$, $\mathrm{Ti}_{6} \mathrm{AlN}_{5}(h P 24), \mathrm{Ti}_{3} \mathrm{AlN}(c P 5, o P 20)$

$\mathrm{V}_{3} \mathrm{Al}(c P 8), \mathrm{V}_{5} \mathrm{Al}_{8}(c I 52), \mathrm{VAl}_{3}(t I 8), \mathrm{V}_{3} \mathrm{Al}_{10}(c I 52), \mathrm{V}_{7} \mathrm{Al}_{45}(m C 104), \mathrm{VAl}_{10}(c F 176)$,

$\mathrm{V}_{2} \mathrm{C}(h P 3, o P 12), \mathrm{VC}_{0.5}(h P 4), \mathrm{VC}_{0.67}(h R 24), \mathrm{V}_{4} \mathrm{C}_{3}(h P 21), \mathrm{V}_{6} \mathrm{C}_{5}(h P 33), \mathrm{V}_{8} \mathrm{C}_{7}(c P 60), \mathrm{VC}(c F 8, h P 4), \mathrm{VC}_{0.875}$ $(c F 8), \mathrm{V}_{2} \mathrm{AlC}(h P 8), \mathrm{V}_{3} \mathrm{AlC}_{2}(h P 12), \mathrm{V}_{4} \mathrm{AlC}_{3}(h P 16), \mathrm{V}_{12} \mathrm{Al}_{3} \mathrm{C}_{8}(h P 46), \mathrm{V}_{5} \mathrm{Al}_{2} \mathrm{C}_{3}(h P 20, h P 30), \mathrm{V}_{7} \mathrm{Al}_{2} \mathrm{C}_{5}$ $(h P 42), \mathrm{V}_{3} \mathrm{AlC}(c P 5)$,

$\mathrm{V}_{2} \mathrm{~N}(h P 9), \mathrm{VN}(c F 8), \mathrm{VN}_{0.875}(c F 8), \mathrm{V}_{2} \mathrm{AlN}(h P 8), \mathrm{V}_{3} \mathrm{AlN}_{2}(h P 12), \mathrm{V}_{4} \mathrm{AlN}_{3}(h P 16), \mathrm{V}_{3} \mathrm{AlN}(c P 5)$

$\mathrm{Cr}_{2} \mathrm{Al}$ (tI6), $\mathrm{Cr}_{5} \mathrm{Al}_{8}$ (cI52), $\mathrm{Cr}_{4} \mathrm{Al}_{9}(h R 26), \mathrm{Cr}_{5} \mathrm{Al}_{21}$ ( $\left.h R 26\right), \mathrm{Cr}_{7} \mathrm{Al}_{43}(m C 104)$,

$\mathrm{Cr}_{23} \mathrm{C}_{6}(c F 116), \mathrm{Cr}_{3} \mathrm{C}(o P 16), \mathrm{Cr}_{7} \mathrm{C}_{3}(h P 20, o P 40), \mathrm{Cr}_{3} \mathrm{C}_{2}(o P 20), \mathrm{Cr}_{2} \mathrm{AlC}(h P 8), \mathrm{Cr}_{3} \mathrm{AlC}_{2}(h P 12), \mathrm{Cr}_{4} \mathrm{AlC}_{3}$ $(h P 16), \mathrm{Cr}_{3} \mathrm{AlC}(c P 5)$,

$\mathrm{Cr}_{2} \mathrm{~N}(h P 9), \mathrm{CrN}(c F 8, o P 8) \mathrm{CrN}_{0.875}(c F 8), \mathrm{Cr}_{2} \mathrm{AlN}(h P 8), \mathrm{Cr}_{3} \mathrm{AlN}_{2}(h P 12), \mathrm{Cr}_{4} \mathrm{AlN}_{3}(h P 16), \mathrm{Cr}_{3} \mathrm{AlN}(c P 5)$

$\mathrm{Mn}_{3} \mathrm{Al}(c P 20), \mathrm{Mn}_{7} \mathrm{Al}_{3}(c P 20), \mathrm{MnAl}(c P 2, t P 2, t P 4), \mathrm{Mn}_{4} \mathrm{Al}_{11}(a P 15), \mathrm{Mn}_{3} \mathrm{Al}_{10}(h P 26), \mathrm{MnAl}_{6}(o S 28)$, $\mathrm{Mn}_{23} \mathrm{C}_{6}(c F 116), \mathrm{Mn}_{3} \mathrm{C}(o P 16), \mathrm{Mn}_{5} \mathrm{C}_{2}(m S 28), \mathrm{Mn}_{7} \mathrm{C}_{3}(h P 20, o P 40), \mathrm{MnC}(h P 4), \mathrm{Mn}_{2} \mathrm{AlC}(h P 8), \mathrm{Mn}_{3} \mathrm{AlC}_{2}$ $(h P 12), \mathrm{Mn}_{4} \mathrm{AlC}_{3}(h P 16), \mathrm{Mn}_{3} \mathrm{AlC}(c P 5)$,

$\mathrm{Mn}_{4} \mathrm{~N}(c P 5), \mathrm{Mn}_{2} \mathrm{~N}(h P 3, h P 4), \mathrm{Mn}_{3} \mathrm{~N}_{2}(t I 10), \mathrm{MnN}(c F 8) \mathrm{MnN}_{0.875}(c F 8), \mathrm{Mn}_{2} \mathrm{AlN}(h P 8), \mathrm{Mn}_{3} \mathrm{AlN}_{2}(h P 12)$, $\mathrm{Mn}_{4} \mathrm{AlN}_{3}(h P 16), \mathrm{Mn}_{3} \mathrm{AlN}(c P 5)$

$\mathrm{Fe}_{3} \mathrm{Al}(c P 4, c F 16), \mathrm{FeAl}(c P 2), \mathrm{Fe}_{5} \mathrm{Al}_{8}(c I 52)$,

$\mathrm{Fe}_{3} \mathrm{C}(c P 5, o P 16, h P 8), \mathrm{Fe}_{5} \mathrm{C}_{2}(m S 28), \mathrm{Fe}_{2} \mathrm{C}(h P 6, o P 6), \mathrm{Fe}_{2} \mathrm{AlC}(h P 8), \mathrm{Fe}_{3} \mathrm{AlC}_{2}(h P 12), \mathrm{Fe}_{4} \mathrm{AlC}_{3}(h P 16)$,

$\mathrm{Fe}_{3} \mathrm{AlC}(c P 5)$

$\mathrm{Co}_{3} \mathrm{Al}(c P 4), \mathrm{CoAl}_{0.875}(c P 2), \mathrm{CoAl}(c P 2), \mathrm{Co}_{2} \mathrm{Al}_{5}(h P 28), \mathrm{CoAl}_{3}(c P 4), \mathrm{Co}_{2} \mathrm{Al}_{9}(m P 22), \mathrm{Co}_{2} \mathrm{AlC}(h P 8)$, $\mathrm{Co}_{3} \mathrm{AlC}_{2}(h P 12), \mathrm{Co}_{4} \mathrm{AlC}_{3}(h P 16), \mathrm{Co}_{3} \mathrm{AlC}(c P 5)$

\footnotetext{
${ }^{21}$ The Pearson symbol is used to describe the crystal structure and consists of two letters specifying one of the fourteen Bravais lattices followed by a number giving the number of atoms in the unit cell. Lower case letter specify the crystal class: $a$ (triclinic), $m$ (monoclinic, $o$ (orthorhombic), $t$ (tetragonal), $h$ (hexagonal or rhombohedral, $c$ (cubic). Upper case letters specify the lattice type: $P$ (primitive), $F$ (all face centered), $I$ (body centered), $R$ (rhombohedral), and $S, A, B, C$ (side face centered).
} 
Table 7. Identified set of most competing phases and corresponding formation enthalpy $\Delta H_{c p}$ for $M_{n+1} \mathrm{Al} X_{n}$ phases $(n=1-3)$. For clearness phases with $\Delta H_{c p}<0$, i.e. being stable, are marked as bold.

\begin{tabular}{|c|c|c|c|c|c|}
\hline \multirow[b]{2}{*}{$M$} & \multirow[b]{2}{*}{$n$} & \multicolumn{2}{|l|}{$\overline{\mathrm{M}_{n+1} \mathrm{AC}_{n}}$} & \multicolumn{2}{|l|}{$\overline{\mathrm{M}_{n+1} \mathrm{AN}_{n}}$} \\
\hline & & Most competing phases & $\begin{array}{c}\Delta H_{c p} \\
\text { (meV/atom) }\end{array}$ & Most competing phases & $\begin{array}{c}\Delta H_{c p} \\
\text { (meV/atom) }\end{array}$ \\
\hline \multirow{3}{*}{$\mathrm{Sc}$} & 1 & $\mathrm{Sc}_{3} \mathrm{AlC}, \mathrm{ScAl}_{3} \mathrm{C}_{3}$ & 117 & $\mathrm{ScN}, \mathrm{ScAl}_{2}, \mathrm{Sc}_{3} \mathrm{AlN}$ & 88 \\
\hline & 2 & $\mathrm{Sc}_{3} \mathrm{AlC}, \mathrm{Sc}_{3} \mathrm{C}_{4}, \mathrm{ScAl}_{3} \mathrm{C}_{3}$ & 155 & $\mathrm{ScN}, \mathrm{ScAl}_{2}, \mathrm{Sc}_{3} \mathrm{AlN}$ & 36 \\
\hline & 3 & $\mathrm{Sc}_{3} \mathrm{AlC}, \mathrm{Sc}_{3} \mathrm{C}_{4}, \mathrm{ScAl}_{3} \mathrm{C}_{3}$ & 191 & $\mathrm{ScN}, \mathrm{ScAl}_{2}, \mathrm{Sc}_{3} \mathrm{AlN}$ & 20 \\
\hline \multirow{3}{*}{$\mathrm{Ti}$} & 1 & $\mathrm{TiAl}, \mathrm{Ti}_{5} \mathrm{Al}_{2} \mathrm{C}_{3}(h P 30)$ & -18 & $\mathrm{Ti}_{3} \mathrm{AlN}_{2}, \mathrm{TiAl}_{2}, \mathrm{Ti}_{3} \mathrm{AlN}(o P 20)$ & -50 \\
\hline & 2 & $\mathrm{Ti}_{5} \mathrm{Al}_{2} \mathrm{C}_{3}(h P 30), \mathrm{Ti}_{7} \mathrm{Al}_{2} \mathrm{C}_{5}$ & -6 & $\mathrm{Ti}_{2} \mathrm{AlN}, \mathrm{Ti}_{4} \mathrm{AlN}_{3}$ & 13 \\
\hline & 3 & $\mathrm{Ti}_{3} \mathrm{AlC}_{2}, \mathrm{TiC}$ & 0 & $\mathrm{Ti}_{2} \mathrm{AlN}, \mathrm{Ti}_{6} \mathrm{AlN}_{5}$ & -15 \\
\hline \multirow{3}{*}{$\mathrm{V}$} & 1 & $\mathrm{~V}_{5} \mathrm{Al}_{2} \mathrm{C}_{3}(h P 30), \mathrm{V}_{3} \mathrm{Al}, \mathrm{VAl}_{3}$ & -50 & $\mathrm{~V}_{2} \mathrm{~N}, \mathrm{VAl}_{3}, \mathrm{AlN}$ & 15 \\
\hline & 2 & $\mathrm{~V}_{2} \mathrm{AlC}, \mathrm{V}_{6} \mathrm{C}_{5}, \mathrm{Al}_{4} \mathrm{C}_{3}$ & -5 & $\mathrm{~V}_{2} \mathrm{~N}, \mathrm{AlN}, \mathrm{VAl}_{3}$ & 154 \\
\hline & 3 & $\mathrm{~V}_{3} \mathrm{AlC}_{2}, \mathrm{~V}_{6} \mathrm{C}_{5}, \mathrm{Al}_{4} \mathrm{C}_{3}$ & $6^{\dagger}$ & $\mathrm{V}_{2} \mathrm{~N}, \mathrm{AlN}$ & 204 \\
\hline \multirow{3}{*}{$\mathrm{Cr}$} & 1 & $\mathrm{Cr}_{2} \mathrm{Al}, \mathrm{Cr}_{3} \mathrm{C}_{2}, \mathrm{Al}_{4} \mathrm{C}_{3}$ & -62 & $\mathrm{Cr}(c / 2)$, AlN & 353 \\
\hline & 2 & $\mathrm{Cr}_{2} \mathrm{AlC}, \mathrm{Cr}_{3} \mathrm{C}_{2}, \mathrm{C}(h P 4)$ & 81 & $\mathrm{Cr}(c / 2), \mathrm{Cr}_{2} \mathrm{~N}, \mathrm{AlN}$ & 324 \\
\hline & 3 & $\mathrm{Cr}_{2} \mathrm{AlC}, \mathrm{Cr}_{3} \mathrm{C}_{2}, \mathrm{C}(h P 4)$ & 108 & $\mathrm{Cr}_{2} \mathrm{~N}, \mathrm{AlN}$ & 306 \\
\hline \multirow{3}{*}{$\mathrm{Mn}$} & 1 & $\mathrm{Mn}_{3} \mathrm{AlC}, \mathrm{MnAl}, \mathrm{C}(h P 4)$ & 6 & Mn (cI58), AlN & 380 \\
\hline & 2 & $\mathrm{Mn}_{3} \mathrm{AlC}, \mathrm{C}(h P 4)$ & 95 & $\mathrm{Mn}_{2} \mathrm{~N}, \mathrm{Mn}_{4} \mathrm{~N}, \mathrm{AlN}$ & 363 \\
\hline & 3 & $\mathrm{Mn}_{3} \mathrm{AlC}, \mathrm{C}(h P 4), \mathrm{Mn}_{23} \mathrm{C}_{6}$ & 155 & $\mathrm{Mn}_{2} \mathrm{~N}, \mathrm{AlN}$ & 311 \\
\hline \multirow{3}{*}{$\mathrm{Fe}$} & 1 & $\mathrm{Fe}_{3} \mathrm{AlC}, \mathrm{C}(h P 4), \mathrm{Fe}_{5} \mathrm{Al}_{8}$ & 78 & & \\
\hline & 2 & $\mathrm{Fe}_{3} \mathrm{AlC}, \mathrm{C}(h P 4)$ & 258 & & \\
\hline & 3 & $\mathrm{C}(h P 4), \mathrm{Fe}_{3} \mathrm{AlC}, \mathrm{Fe}(c I 2)$ & 349 & & \\
\hline \multirow{3}{*}{ Co } & 1 & $\mathrm{Co}(h P 2), \mathrm{C}(h P 4), \mathrm{CoAl}$ & 255 & & \\
\hline & 2 & $\mathrm{Co}(h P 2), \mathrm{C}(h P 4), \mathrm{CoAl}$ & 395 & & \\
\hline & 3 & Co $(h P 2), \mathrm{C}(h P 4), \mathrm{CoAl}$ & 490 & & \\
\hline
\end{tabular}

$\Delta H_{c p}=-12 \mathrm{meV} /$ atom with $11 \%$ ordered vacancies on the carbon sublattice in a $\mathrm{V}_{12} \mathrm{Al}_{3} \mathrm{C}_{8}$ structure ( $\left.h P 46\right)$ (more specific, $1 / 3$ of $\mathrm{C}$ atoms in Wyckoff position 2a are empty). Experimentally observed by Etzkorn et al. [72].

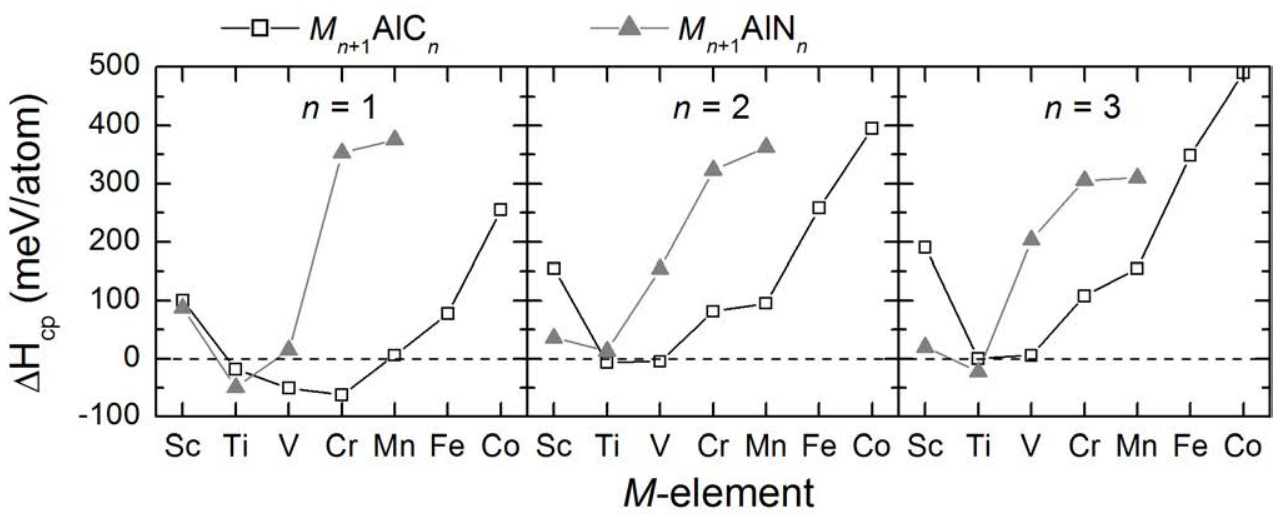

Figure 20. Calculated formation enthalpy $\Delta H_{c p}$ for $M_{n+1} \mathrm{Al} X_{n}$ phases $(n=1-3)$ relative to the identified set of most competing phases listed in Table 7. 
Table 8 shows experimentally known MAX phases in relation to those calculated with negative formation enthalpy $\left(\Delta H_{c p}<0\right)$. Hence, the theoretical results are consistent with existing as well as non-existing (hypothetical) $M_{n+1} \mathrm{Al} X_{n}$ phases. This study can be seen as a benchmark, demonstrating that the theoretical method used is a useful tool to be used as guidance in the search for new $M_{n+1} A X_{n}$ phases. The method may also be applicable to other complex ternary or higher-order materials systems. It should be stressed that even though this approach does not consider entropy or other temperature related effects, the excellent correspondence with experimental findings indicates that formation of $M_{n+1} A X_{n}$ phases are mainly governed by the total energy term in the Gibbs free energy $G$. A recent investigation of $\mathrm{Ti}_{n+1} \mathrm{AlC}_{n}$ stability at finite temperatures, also including effects from lattice vibrations (phonons), thermal expansion, and electronic excitation into $G$, shows that the total energy (at $0 \mathrm{~K}$ ) is the most important parameter, whereas other contributions almost cancel out in $\Delta G$ [136].

Table 8. Calculated $M_{n+1} \mathrm{Al} X_{n}$ phases with negative formation enthalpy $\left(\Delta H_{c p}<0\right)$ compared to experimentally known MAX phases for the here investigated ternary systems.

\begin{tabular}{ll}
\hline \hline Phases with $\Delta H_{c p}<0[137]$ & Phases known experimentally [11] \\
\hline $\mathrm{Ti}_{2} \mathrm{AlC}, \mathrm{Ti}_{3} \mathrm{AlC}_{2}, \mathrm{Ti}_{4} \mathrm{AlC}_{3}^{\dagger}$ & $\mathrm{Ti}_{2} \mathrm{AlC}, \mathrm{Ti}_{3} \mathrm{AlC}_{2}$ \\
$\mathrm{~V}_{2} \mathrm{AlC}, \mathrm{V}_{3} \mathrm{AlC}_{2}, \mathrm{~V}_{4} \mathrm{AlC}_{3}^{\dagger}$ & $\mathrm{V}_{2} \mathrm{AlC}, \mathrm{V}_{3} \mathrm{AlC}_{2}, \mathrm{~V}_{4} \mathrm{AlC}_{3}^{\ddagger}$ \\
$\mathrm{Cr}_{2} \mathrm{AlC}$ & $\mathrm{Cr}_{2} \mathrm{AlC}$ \\
$\mathrm{Ti}_{2} \mathrm{AlN}, \mathrm{Ti}_{4} \mathrm{AlN}_{3}$ & $\mathrm{Ti}_{2} \mathrm{AlN}, \mathrm{Ti}_{4} \mathrm{AlN}_{3}$ \\
\hline \hline
\end{tabular}

$\dagger \Delta H_{c p}=0.0 \mathrm{meV} /$ atom to the level of accuracy of our work.

$\$ 11 \%$ (or $1 / 9^{\text {th }}$ ) ordered carbon vacancies stabilize $\mathrm{V}_{4} \mathrm{AlC}_{3}$ in a $\mathrm{V}_{12} \mathrm{Al}_{3} \mathrm{C}_{8}$ structure ( $h P 46$ ). Experimentally observed by Etzkorn et al. [72].

\subsection{Prediction of new MAX phases}

Within this section the predictive power of our theoretical approach for phase stability investigations will be demonstrated for two different material systems. The results are based on Paper IV and VIII.

\subsection{1 $\mathrm{Nb}_{2} \mathrm{GeC}$}

One of the first materials investigated were $\mathrm{Nb}_{n+1} \mathrm{GeC}_{n}$ phases $(n=1-3)$. This hypothetical material was selected based on two criteria; (i) at the time no $\mathrm{Nb}_{n+1} \mathrm{GeC}_{n}$ was known and (ii) the material was suggested to be superconducting. In Table 9 are the complete list of included competing phases with corresponding calculated energy and structural parameters. The set of most competitive phases at compositions corresponding to $n=1-3$ was identified through use of the linear optimization procedure. Only $\mathrm{Nb}_{2} \mathrm{GeC}$ was found to be stable (-18 meV/atom) with $\mathrm{NbGe}_{2}, \mathrm{Nb}_{6} \mathrm{C}_{5}$, and $\mathrm{Nb}_{5} \mathrm{Ge}_{3} \mathrm{C}$ as set of most competitive phase. $\mathrm{Nb}_{3} \mathrm{GeC}_{2}$ and $\mathrm{Nb}_{4} \mathrm{GeC}_{3}$ are not stable relative to a combination of $\mathrm{Nb}_{2} \mathrm{GeC}, \mathrm{Nb}_{6} \mathrm{C}_{5}$, and $\mathrm{C}$. 
Table 9. Competing phases included in the $\mathrm{Nb}-\mathrm{Ge}-\mathrm{C}$ system with calculated total energies $E_{0}$ and lattice parameters. Based on Supplemental material in Ref. [77].

\begin{tabular}{|c|c|c|c|c|c|c|c|}
\hline Phase & Prototype & $\begin{array}{l}\text { Pearson } \\
\text { symbol }\end{array}$ & $a(\AA)$ & $b(\AA)$ & $c(\AA)$ & $\begin{array}{c}E_{0} \\
\text { (eV/f.u.) }\end{array}$ & Note \\
\hline $\mathrm{Nb}$ & $\mathrm{W}$ & $c I 2$ & 3.322 & & & -10.092 & \\
\hline $\mathrm{Ge}$ & $\mathrm{C}$ & $c F 8$ & 2.881 & & & -4.622 & diamond structure \\
\hline $\mathrm{C}$ & $\mathrm{C}$ & $h P 4$ & 2.464 & & 7.250 & -9.225 & graphite structure \\
\hline $\mathrm{NbC}$ & $\mathrm{NaCl}$ & $c F 8$ & 4.508 & & & -20.249 & \\
\hline $\mathrm{NbC}_{0.875}$ & $\mathrm{NaCl}$ & $c F 8$ & 4.490 & & & -19.076 & 4b-site partially occupied by C \\
\hline $\mathrm{Nb}_{6} \mathrm{C}_{5}$ & $\mathrm{~V}_{6} \mathrm{C}_{5}$ & $m C 22$ & 5.523 & 9.541 & 5.510 & -112.773 & $\beta=109.6^{\circ}$ \\
\hline $\mathrm{Nb}_{2} \mathrm{C}$ & $\mathrm{Fe}_{2} \mathrm{~N}$ & $h P 9$ & 5.455 & & 4.979 & -30.799 & \\
\hline $\mathrm{Nb}_{2} \mathrm{C}$ & $\mathrm{MoO}_{2}$ & $o P 12$ & 11.017 & 3.111 & 5.000 & -30.831 & \\
\hline $\mathrm{NbC}_{0.5}$ & NiAs & $h P 12$ & 3.173 & & 4.961 & -30.815 & $2 a$-site partially occupied by C \\
\hline $\mathrm{NbGe}_{2}$ & $\mathrm{CrSi}_{2}$ & $h P 9$ & 5.015 & & 6.840 & -20.366 & \\
\hline $\mathrm{Nb}_{3} \mathrm{Ge}$ & $\mathrm{Cr}_{3} \mathrm{Si}$ & $c P 8$ & 5.183 & & & -36.000 & \\
\hline $\mathrm{Nb}_{5} \mathrm{Ge}_{4}$ & $\mathrm{Mn}_{5} \mathrm{Si}_{3}$ & $h P 18$ & 8.027 & & 5.436 & -72.657 & $2 b$-site fully occupied by Ge \\
\hline $\mathrm{Nb}_{5} \mathrm{Ge}_{3.5}$ & $\mathrm{Mn}_{5} \mathrm{Si}_{3}$ & $h P 68$ & 7.857 & & 5.429 & -70.565 & $2 b$-site partially occupied by $\mathrm{Ge}$ \\
\hline $\mathrm{Nb}_{5} \mathrm{Ge}_{3} \mathrm{C}_{x}$ & $\mathrm{Mn}_{5} \mathrm{Si}_{3}$ & $h P 16$ & 7.717 & & 5.351 & -67.680 & $x=0.0$ \\
\hline $\mathrm{Nb}_{5} \mathrm{Ge}_{3} \mathrm{C}_{x}$ & $\mathrm{Mn}_{5} \mathrm{Si}_{3}$ & $h P 34$ & 7.724 & & 5.352 & -73.507 & $x=0.5(2 b$-site partially occupied by C) \\
\hline $\mathrm{Nb}_{5} \mathrm{Ge}_{3} \mathrm{C}_{x}$ & $\mathrm{Mn}_{5} \mathrm{Si}_{3}$ & $h P 18$ & 7.664 & & 5.531 & -78.330 & $x=1.0(2 b$-site fully occupied by C) \\
\hline $\mathrm{Nb}_{5} \mathrm{Ge}_{3}$ & $\mathrm{~W}_{5} \mathrm{Si}_{3}$ & $t I 32$ & 14.399 & 14.530 & 5.202 & -68.078 & \\
\hline $\mathrm{Nb}_{3} \mathrm{GeC}$ & $\mathrm{CaTiO}_{3}$ & $c P 5$ & 4.300 & & & -44.537 & inverse perovskite \\
\hline $\mathrm{Nb}_{3} \mathrm{GeC}$ & $\operatorname{Re}_{3} \mathrm{~B}$ & $o P 20$ & 3.347 & 10.662 & 8.422 & -46.835 & distorted perovskite \\
\hline $\mathrm{Nb}_{2} \mathrm{GeC}$ & $\mathrm{Cr}_{2} \mathrm{AlC}$ & $h P 8$ & 3.265 & & 12.655 & -36.100 & 211 MAX phase \\
\hline $\mathrm{Nb}_{3} \mathrm{GeC}_{2}$ & $\mathrm{Ti}_{3} \mathrm{SiC}_{2}$ & $h P 12$ & 3.179 & & 18.556 & -56.274 & 312 MAX phase \\
\hline $\mathrm{Nb}_{4} \mathrm{GeC}_{3}$ & $\mathrm{Ti}_{4} \mathrm{AlN}_{3}$ & $h P 16$ & 3.196 & & 23.616 & -76.650 & 413 MAX phase \\
\hline
\end{tabular}

Table 10. Calculate formation enthalpy $\Delta H_{c p}$ for $\mathrm{Nb}_{n+1} \mathrm{GeC}_{n}$ phases using Eq. (11) and corresponding identified set of most competitive phases.

\begin{tabular}{ccl}
\hline \hline$n$ & $\Delta H_{c p}$ (meV/atom) & Most competing phases \\
\hline 1 & $\mathbf{- 1 8}$ & $\mathrm{NbGe}_{2}, \mathrm{Nb}_{6} \mathrm{C}_{5}, \mathrm{Nb}_{5} \mathrm{Ge}_{3} \mathrm{C}_{x}(x=1.0)$ \\
2 & +26 & $\mathrm{Nb}_{2} \mathrm{GeC}, \mathrm{Nb}_{6} \mathrm{C}_{5}, \mathrm{C}$ \\
3 & +14 & $\mathrm{Nb}_{2} \mathrm{GeC}, \mathrm{Nb}_{6} \mathrm{C}_{5}, \mathrm{C}$ \\
\hline
\end{tabular}

Based on the prediction that $\mathrm{Nb}_{2} \mathrm{GeC}$ is stable, experimental synthesize $\mathrm{Nb}_{2} \mathrm{GeC}$ thin films by dc magnetron sputtering were initiated. Experimental details and results from characterization are given in Ref. [77]. The former hypothetical $\mathrm{Nb}_{2} \mathrm{GeC}$ was predicted stable, was successfully synthesized, and a new MAX ${ }^{22}$ phase was born.

\footnotetext{
${ }^{22}$ Note that $\mathrm{Nb}_{2} \mathrm{GeC}$ was the first $M_{2} A X(n=1)$ to be made since the 1960 s (not considering alloyed combinations).
} 


\subsection{2 $\mathrm{Mn}_{2} \mathrm{GaC}$}

Confident by the results from theoretical validation of already existing phases (Paper III), the successful prediction of a new MAX phase in Paper IV $\left(\mathrm{Nb}_{2} \mathrm{GeC}\right)$, and the first magnetic MAX upon alloying $\mathrm{Cr}_{2} \mathrm{AlC}$ with $\mathrm{Mn}$ (Paper VII), $M_{n+1} \mathrm{GaC}_{n}$ phases $(M=\mathrm{Ti}, \mathrm{V}, \mathrm{Cr}, \mathrm{Mn}$, and $n=1-3$ ) were selected for phase stability investigation based on two criteria;

(i) $\mathrm{Ga}$ is directly below $\mathrm{Al}$ in the periodic table with several experimentally known MAX phases $\left(\mathrm{Ti}_{2} \mathrm{GaC}, \mathrm{Ti}_{3} \mathrm{GaC}_{2}, \mathrm{Ti}_{4} \mathrm{GaC}_{3}, \mathrm{~V}_{2} \mathrm{GaC}\right.$, and $\left.\mathrm{Cr}_{2} \mathrm{GaC}\right)$.

(ii) Can $\mathrm{Mn}_{n+1} \mathrm{GaC}_{n}$ be stable $\left(\mathrm{Mn}_{2} \mathrm{AlC}\right.$ close to stable in Paper III)?

Careful investigations of phase diagrams and experimental works have been conducted in order to avoid ad hoc choices of competing phases, see e.g. Refs. [32, 135] and Table 11 display included competing phases. For all $\mathrm{Cr}$ - and Mn-based compounds nonmagnetic (NM), ferromagnetic (FM), and different antiferromagnetic (AFM) states were tested and the configuration with lowest energy, representing the magnetic ground-state, was included in the study. More details of the magnetic states for MAX phases will be given in Chapter 5. Based on the calculated total energy the set of most competing phases was identified, see Table 12, by solving the linear optimization problem.

Table 11. Competing phases included for $M$-Ga-C systems. Notation within parenthesis is the crystal structure used for corresponding phase as given by the Pearson symbol. For Cr- and Mn-based compounds different magnetic configurations were tested.

Single elements

$\mathrm{Ti}(c F 4, c I 2, h P 2), \mathrm{V}(c F 4, c I 2, h P 2), \mathrm{Cr}(c F 4, c I 2, h P 2), \mathrm{Mn}(c I 58, c P 2, c P 20, t P 4), \mathrm{Ga}(o C 4, o C 8, m C 4), \mathrm{C}$ $(c F 8, h P 4)$

\section{Binary and ternary phases}

$\mathrm{Ti}_{0.9} \mathrm{Ga}_{0.1}(h P 2), \mathrm{Ti}_{0.875} \mathrm{Ga}_{0.125}(h P 2), \mathrm{Ti}_{3} \mathrm{Ga}(h P 8), \mathrm{Ti}_{2} \mathrm{Ga}(h P 6), \mathrm{Ti}_{5} \mathrm{Ga}_{3}(h P 16, t P 32, t / 32), \mathrm{Ti}_{5} \mathrm{Ga}_{4}(h P 18), \mathrm{TiGa}$ (tP4), $\mathrm{Ti}_{2} \mathrm{Ga}_{3}(t P 10), \mathrm{Ti}_{3} \mathrm{Ga}_{5}(o C 16, t P 32), \mathrm{TiGa}_{2}(t I 24), \mathrm{TiGa}_{3}(t I 8), \mathrm{Ti}_{2} \mathrm{C}(c F 48), \mathrm{TiC}(c F 8, h P 4), \mathrm{TiC}_{0.875}$ $(c F 8), \mathrm{TiC}_{0.75}(c F 8), \mathrm{Ti}_{2} \mathrm{GaC}(h P 8), \mathrm{Ti}_{3} \mathrm{GaC}_{2}(h P 12), \mathrm{Ti}_{4} \mathrm{GaC}_{3}(h P 16), \mathrm{Ti}_{3} \mathrm{GaC}(c P 5, o P 20)$

$\mathrm{V}_{3} \mathrm{Ga}(c P 8), \mathrm{V}_{6} \mathrm{Ga}_{5}(h P 22), \mathrm{V}_{6} \mathrm{Ga}_{7}(c I 52), \mathrm{V}_{2} \mathrm{Ga}_{5}(t P 14), \mathrm{V}_{8} \mathrm{Ga}_{41}(h R 147), \mathrm{V}_{2} \mathrm{C}(h P 3, o P 12), \mathrm{VC}_{0.5}(h P 4), \mathrm{VC}_{0.67}$ $(h R 24), \mathrm{V}_{4} \mathrm{C}_{3}(h P 21), \mathrm{V}_{6} \mathrm{C}_{5}(h P 33), \mathrm{V}_{8} \mathrm{C}_{7}(c P 60), \mathrm{VC}(c F 8, h P 4), \mathrm{VC}_{0.875}(c F 8), \mathrm{V}_{2} \mathrm{GaC}(h P 8), \mathrm{V}_{3} \mathrm{GaC}_{2}(h P 12)$, $\mathrm{V}_{4} \mathrm{GaC}_{3}(h P 16), \mathrm{V}_{3} \mathrm{AlC}(c P 5)$

$\mathrm{Cr}_{3} \mathrm{Ga}(c P 8), \mathrm{CrGa}(h R 78), \mathrm{Cr}_{3} \mathrm{Ga}_{4}(m S 42), \mathrm{CrGa}_{4}(c I 10), \mathrm{Cr}_{23} \mathrm{C}_{6}(c F 116), \mathrm{Cr}_{3} \mathrm{C}(o P 16), \mathrm{Cr}_{7} \mathrm{C}_{3}(h P 20, o P 40)$, $\mathrm{Cr}_{3} \mathrm{C}_{2}(o P 20), \mathrm{Cr}_{2} \mathrm{GaC}(h P 8), \mathrm{Cr}_{3} \mathrm{GaC}_{2}(h P 12), \mathrm{Cr}_{4} \mathrm{GaC}_{3}(h P 16), \mathrm{Cr}_{3} \mathrm{AlC}(c P 5, o P 20)$

$\mathrm{Mn}_{3} \mathrm{Ga}(h P 8, t I 8), \mathrm{MnGa}(h P 2, h R 32, h R 78, t P 4), \mathrm{Mn}_{5} \mathrm{Ga}_{8}(h R 78), \mathrm{Mn}_{2} \mathrm{Ga}_{5}(t P 14), \mathrm{MnGa}_{4}(c I 10), \mathrm{MnGa}_{6}$ (oS28), $\mathrm{Mn}_{23} \mathrm{C}_{6}$ (cF116), $\mathrm{Mn}_{3} \mathrm{C}(o P 16), \mathrm{Mn}_{5} \mathrm{C}_{2}(m S 28), \mathrm{Mn}_{7} \mathrm{C}_{3}(h P 20, o P 40), \mathrm{MnC}(h P 4), \mathrm{Mn}_{2} \mathrm{GaC}(h P 8)$, $\mathrm{Mn}_{3} \mathrm{GaC}_{2}(h P 12), \mathrm{Mn}_{4} \mathrm{GaC}_{3}(h P 16), \mathrm{Mn}_{3} \mathrm{GaC}(c P 5, o P 20, t I 20)$ 
Table 12. Identified set of most competing phases for $M_{n+1} \mathrm{GaC}_{n}$ phases with $M=\mathrm{Ti}, \mathrm{V}, \mathrm{Cr}$, $\mathrm{Mn}$, and $n=1-3$.

\begin{tabular}{|c|c|c|c|}
\hline \multirow{2}{*}{$M$} & \multicolumn{3}{|c|}{ set of most competing phases } \\
\hline & $n=1$ & $n=2$ & $n=3$ \\
\hline $\mathrm{Ti}$ & $\mathrm{Ti}_{3} \mathrm{GaC}_{2}, \mathrm{TiGa}$ & $\mathrm{Ti}_{2} \mathrm{GaC}, \mathrm{Ti}_{4} \mathrm{GaC}_{3}$ & $\mathrm{Ti}_{3} \mathrm{GaC}_{2}, \mathrm{TiC}$ \\
\hline $\mathrm{V}$ & $\mathrm{V}_{3} \mathrm{GaC}_{2}, \mathrm{~V}_{6} \mathrm{Ga}_{5}, \mathrm{~V}_{2} \mathrm{Ga}_{5}$ & $\mathrm{~V}_{2} \mathrm{GaC}, \mathrm{V}_{6} \mathrm{C}_{5}, \mathrm{C}$ & $\mathrm{V}_{3} \mathrm{GaC}_{2}, \mathrm{~V}_{6} \mathrm{C}_{5}, \mathrm{C}$ \\
\hline $\mathrm{Cr}$ & $\mathrm{Cr}_{3} \mathrm{C}_{2}, \mathrm{CrGa}_{4}, \mathrm{Cr}_{7} \mathrm{C}_{3}$ & $\mathrm{Cr}_{2} \mathrm{GaC}, \mathrm{Cr}_{3} \mathrm{C}_{2}, \mathrm{C}$ & $\mathrm{Cr}_{2} \mathrm{GaC}, \mathrm{Cr}_{3} \mathrm{C}_{2}, \mathrm{C}$ \\
\hline $\mathrm{Mn}$ & $\mathrm{Mn}_{3} \mathrm{GaC}, \mathrm{C}, \mathrm{MnGa}_{4}$ & $\mathrm{Mn}_{2} \mathrm{GaC}, \mathrm{C}, \mathrm{Mn}_{23} \mathrm{C}_{6}$ & C, $\mathrm{Mn}_{2} \mathrm{GaC}, \mathrm{Mn}_{23} \mathrm{C}_{6}$ \\
\hline
\end{tabular}

Corresponding formation enthalpies $\Delta H_{c p}$ were calculated using Eq. (15) and are shown in Figure 21, with an overall appearance similar to the results for the $M_{n+1} \mathrm{AlC}_{n}$ phases presented in Figure 20. Prior to Paper VIII, five $M_{n+1} \mathrm{GaC}_{n}$ phases were experimentally known $\left(\mathrm{Ti}_{2} \mathrm{GaC}, \mathrm{Ti}_{3} \mathrm{GaC}_{2}, \mathrm{Ti}_{4} \mathrm{GaC}_{3}, \mathrm{~V}_{2} \mathrm{GaC}\right.$, and $\left.\mathrm{Cr}_{2} \mathrm{GaC}\right)$. These are all found to be stable with $\Delta H_{c p}$ $<0$, even though for the value for $\mathrm{Ti}_{4} \mathrm{GaC}_{3}(-0.4 \mathrm{meV} / \mathrm{atom})^{23}$ is very close to zero. Also $\mathrm{V}_{3} \mathrm{GaC}_{2}$ was found to be stable (-1 meV/atom).

Most interesting is the predicted stability of $\mathrm{Mn}_{2} \mathrm{GaC}$ ( $\left.-31 \mathrm{meV} / \mathrm{atom}\right)$. In comparison, this value clearly fits with those calculated for (other) experimentally known MAX phases, e.g. $\mathrm{Ti}_{2} \mathrm{GaC}$ (-37 meV/atom), $\mathrm{Cr}_{2} \mathrm{GaC}$ (-19 meV/atom), $\mathrm{Ti}_{2} \mathrm{AlC}$ (-18 meV/atom, $\mathrm{Cr}_{2} \mathrm{AlC}$ (-62 meV/atom, and $\mathrm{Nb}_{2} \mathrm{GeC}$ (-18 meV/atom). Motivated by this prediction, attempts for realizing the material were initiated, which eventually led to the first synthesized MAX phase with Mn as only $M$-element. ${ }^{24}$

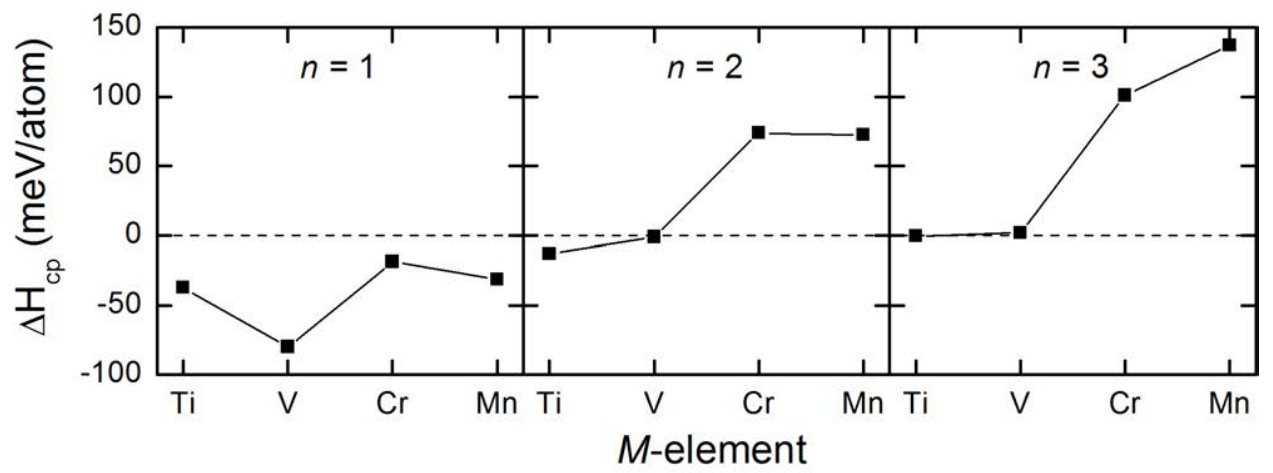

Figure 21. Calculated formation enthalpy $\Delta H_{c p}$ for $M_{n+1} \mathrm{GaC}_{n}$ phases with $M=\mathrm{Ti}, \mathrm{V}, \mathrm{Cr}, \mathrm{Mn}$, and $n=1-3$.

\footnotetext{
${ }^{23}$ Similar to $\mathrm{Ti}_{4} \mathrm{AlC}_{3}$ in Paper III.

${ }^{24} \mathrm{Mn}$ had previously been alloyed into known MAX phases, $(\mathrm{Cr}, \mathrm{Mn})_{2} \mathrm{AlC},(\mathrm{Cr}, \mathrm{Mn})_{2} \mathrm{GaC}$, and $(\mathrm{Cr}, \mathrm{Mn})_{2} \mathrm{GeC}$
} 


\subsection{Oxygen incorporation}

The element with atomic number eight is oxygen. It does not belong to the MAX phase family although it is of importance when forming protective oxide layers. For $\mathrm{Ti}_{2} \mathrm{AlC}$, a dense, passivating, stable, and well adherent $\mathrm{Al}_{2} \mathrm{O}_{3}$ layer is formed at elevated temperatures [50, 138140]. The high density of the oxide slows down diffusion of further oxygen to the MAX phase, preventing additional oxidation [141]. Oxygen can also be incorporated within the MAX phase structure. Significant amount of oxygen incorporation have been reported for $\mathrm{Ti}_{2} \mathrm{AlC}$, with oxygen stemming from either residual gas [54, 82] or from decomposed substrates reacting with substoichiometric $\mathrm{TiC}$ [142]. The latter behavior has also been observed for substoichiometric $\mathrm{TiN}$ deposited on $\mathrm{Al}_{2} \mathrm{O}_{3}$ (0001) substrates [143]. From a combination of first-principles calculation and energy electron-loss spectroscopy (EELS) it has been shown that oxygen is incorporated on the carbon site [57, 144]. $\mathrm{For} \mathrm{Cr}_{2} \mathrm{AlC}$, oxygen have been suggested to be interstitially incorporated in the Al-plane [55].

\subsubsection{Oxygen substituting for carbon in $\mathrm{Ti}_{2} \mathrm{AlC}$}

In order to investigate the stability of oxygen incorporated in $\mathrm{Ti}_{2} \mathrm{AlC}$, a comparison relative competing phases present in the quaternary system is needed. The choice of incorporating oxygen on the carbon site were based on compositional depth profile, obtained by Rutherford backscattering spectroscopy (RBS), where the oxygen concentration showed a strong inverse correlation with the carbon concentration ${ }^{25}$ [54]. This was later confirmed by measured and simulated EELS spectra. In Paper I, C and $\mathrm{O}$ ratios in $\operatorname{Ti}_{2} \mathrm{Al}\left(\mathrm{C}_{1-x} \mathrm{O}_{x}\right)$ was evaluated for $x=$ $0.00,0.25,0.50,0.75$, and 1.00 . To simulate a solid solution of $\mathrm{C}$ and $\mathrm{O}$, supercells were constructed through use of the SQS approach. Further details are given in Section 3.2.

Since Paper I was published additional competing phases 26 have been identified for the evaluation of phase stability of $\operatorname{Ti}_{2} \mathrm{Al}\left(\mathrm{C}_{1-x} \mathrm{O}_{x}\right)$. In total 43 different competing phases were included, and an additional five representing different oxygen contents $x$ in the MAX phase. Using the linear optimization approach, described in Section 3.3, the set of most competitive phases at each $\mathrm{x}$ were obtained, see Table 13. Note that two different sets of considered competing phases have been chosen for the phase stability evaluation; including (second column) or excluding $\mathrm{Ti}_{2} \mathrm{Al} X(X=\mathrm{C}$ and $\mathrm{O}$ ) (third column). Corresponding formation enthalpies $\Delta H_{c p}$ were calculated using Eq. (15) and are shown in Figure 22.

\footnotetext{
${ }^{25}$ An increase of oxygen showed a decrease of carbon (and the opposite).

${ }^{26}$ These are $\mathrm{Ti}_{5} \mathrm{Al}_{2} \mathrm{C}_{3}, \mathrm{Ti}_{7} \mathrm{Al}_{2} \mathrm{C}_{5}, \mathrm{TiO}_{0.5},\left(\mathrm{Ti}_{1-x} \mathrm{Al}_{x}\right)_{2} \mathrm{O}_{3}$ with $x=1 / 2,2 / 3,5 / 6,11 / 12, \mathrm{Ti}_{3} \mathrm{AlO}_{x}$ with $x=0.125,0.25$, $0.5, \mathrm{Ti}_{7} \mathrm{Al}_{2} \mathrm{O}_{15}, \mathrm{TiAl}_{2} \mathrm{O}_{5}$.
} 
Table 13. Identified set of most competing phases for $\operatorname{Ti}_{2} \mathrm{Al}\left(\mathrm{C}_{1-x} \mathrm{O}_{x}\right)$ with upper part presented in Paper I and bottom part includes additional competing phases included in Paper II.

\begin{tabular}{|c|c|c|}
\hline \multirow[b]{2}{*}{$x$} & \multicolumn{2}{|c|}{ Identified set of most competing phases (from Paper I) } \\
\hline & all cp & all cp but $\mathrm{Ti}_{2} \mathrm{Al} X(X=\mathrm{C}$ and $\mathrm{O})$ \\
\hline 0.00 & $\mathrm{Ti}_{2} \mathrm{AlC}$ & $\mathrm{TiAl}, \mathrm{Ti}_{3} \mathrm{AlC}_{2}$ \\
\hline 0.25 & $\mathrm{Ti}_{2} \mathrm{AlC}, \mathrm{Ti}_{2} \mathrm{AlO}$ & $\mathrm{TiAl}, \mathrm{Ti}_{3} \mathrm{AlC}_{2}, \mathrm{TiO}$ \\
\hline 0.50 & $\mathrm{Ti}_{2} \mathrm{AlC}, \mathrm{Ti}_{2} \mathrm{AlO}$ & $\mathrm{TiAl}, \mathrm{TiO}, \mathrm{Ti}_{3} \mathrm{AlC}_{2}$ \\
\hline 0.75 & $\mathrm{Ti}_{2} \mathrm{AlO}, \mathrm{Ti}_{2} \mathrm{AlC}$ & $\mathrm{TiAl}, \mathrm{TiO}, \mathrm{Ti}_{3} \mathrm{AlC}_{2}$ \\
\hline \multirow[t]{2}{*}{1.00} & $\mathrm{Ti}_{2} \mathrm{AlO}$ & TiO, TiAl \\
\hline & \multicolumn{2}{|c|}{ Identified set of most competing phases (from Paper II) } \\
\hline$x$ & all cp & all cp but $\mathrm{Ti}_{2} \mathrm{Al} X(X=\mathrm{C}$ and $\mathrm{O})$ \\
\hline 0.00 & $\mathrm{Ti}_{2} \mathrm{AlC}$ & $\mathrm{Ti}_{5} \mathrm{Al}_{2} \mathrm{C}_{3}, \mathrm{TiAl}$ \\
\hline 0.25 & $\mathrm{Ti}_{2} \mathrm{AlC}, \mathrm{TiO}_{0.5}, \mathrm{TiAl}_{2}, \mathrm{Al}_{2} \mathrm{O}_{3}$ & $\mathrm{TiO}_{0.5}, \mathrm{TiAl}_{2}, \mathrm{Ti}_{5} \mathrm{Al}_{2} \mathrm{C}_{3}$ \\
\hline 0.50 & $\mathrm{TiO}_{0.5}, \mathrm{Ti}_{2} \mathrm{AlC}, \mathrm{TiAl}_{2}, \mathrm{Al}_{2} \mathrm{O}_{3}$ & $\mathrm{TiO}_{0.5}, \mathrm{TiAl}_{2}, \mathrm{Ti}_{5} \mathrm{Al}_{2} \mathrm{C}_{3}, \mathrm{Al}_{2} \mathrm{O}_{3}$ \\
\hline 0.75 & $\mathrm{TiO}_{0.5}, \mathrm{TiAl}_{2}, \mathrm{Ti}_{2} \mathrm{AlC}, \mathrm{Al}_{2} \mathrm{O}_{3}$ & $\mathrm{TiO}_{0.5}, \mathrm{TiAl}_{2}, \mathrm{Ti}_{5} \mathrm{Al}_{2} \mathrm{C}_{3}, \mathrm{Al}_{2} \mathrm{O}_{3}$ \\
\hline 1.00 & $\mathrm{TiO}_{0.5}, \mathrm{TiAl}_{2}, \mathrm{Al}_{2} \mathrm{O}_{3}$ & $\mathrm{TiO}_{0.5}, \mathrm{TiAl}_{2}, \mathrm{Al}_{2} \mathrm{O}_{3}$ \\
\hline
\end{tabular}

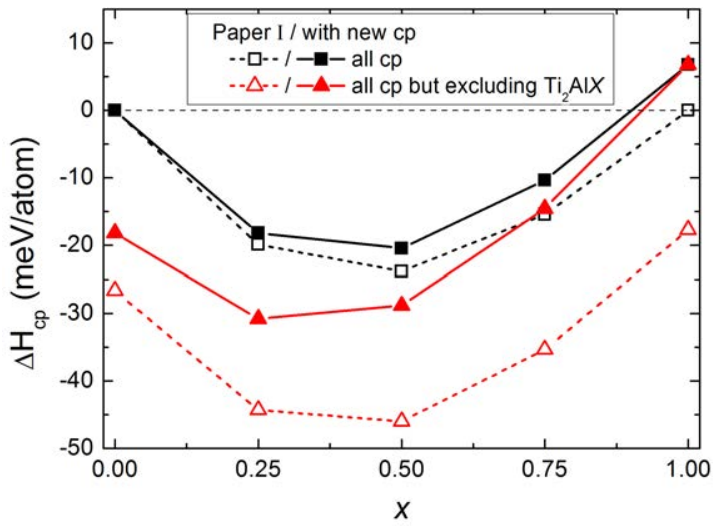

Figure 22. Formation enthalpy $\Delta H_{c p}$ for $\mathrm{Ti}_{2} \mathrm{Al}\left(\mathrm{C}_{1-x} \mathrm{O}_{x}\right)$ where open symbol represent data presented in Paper I and filled symbols including additional competing phases in Paper II. Square symbols represent all competing phases included in the evaluation whereas triangle symbols are for $\mathrm{Ti}_{2} \mathrm{Al} X(X=\mathrm{C}$ and $\mathrm{O})$ excluded.

\subsubsection{Oxygen incorporation in $M_{2} \mathrm{AlC}$ ( $\left.\mathrm{Ti}, \mathrm{V}, \mathrm{Cr}, \mathrm{Zr}, \mathrm{Hf}\right)$}

Oxygen incorporation in both $\mathrm{Ti}_{2} \mathrm{AlC}$ and $\mathrm{Cr}_{2} \mathrm{AlC}$ has been experimentally observed. In $\mathrm{Ti}_{2} \mathrm{AlC}$ oxygen substituting for carbon has been shown both by RBS as well as measured and simulated EELS spectra [54, 144]. For $\mathrm{Cr}_{2} \mathrm{AlC}$ there are indications of interstitial oxygen, likely in the Al-layer [55]. Paper II aim to explain why oxygen incorporation in $\mathrm{Ti}_{2} \mathrm{AlC}$ and $\mathrm{Cr}_{2} \mathrm{AlC}$ is different. In order to distinguish the different sites of oxygen incorporation the following notation is used; 
- $\mathrm{S}_{\mathrm{O}}^{\mathrm{C} \text { or Al }}$ Oxygen substituting carbon or aluminum.

- $\mathrm{I}_{0}^{\text {tri }}$ Interstitial oxygen in Al-layer at the center of a bitriangular pyramid with $M$ atoms at the vertex.

- $\mathrm{I}_{\mathrm{O}}^{\mathrm{pri}} \quad$ Interstitial oxygen in Al-layer incorporated by two $M$ triangles of the lower and upper basal plane.

- $\mathrm{I}_{\mathrm{O}}^{\mathrm{oct}}$ Interstitial oxygen, in between the Al- and $M$-layer, in an octahedral surrounded by three $\mathrm{M}$ atoms and three $\mathrm{Al}$ atoms.

We have investigated the phase stability resulting from intrinsic defects, Al- and C-vacancies, and oxygen incorporation, substituting for carbon and on three interstitial sites, in $M_{2} \mathrm{AlC}$ for $M=\mathrm{Ti}, \mathrm{V}, \mathrm{Cr}, \mathrm{Zr}$, Hf. It is shown in Paper II that out of the three interstitial sites, an interstitial oxygen in the Al-layer, $\mathrm{I}_{\mathrm{O}}^{\text {tri }}$, is always lower in energy. Figure 23(a-e) shows the calculated formation enthalpy $\Delta H_{c p}$ for both $\mathrm{S}_{\mathrm{O}}^{\mathrm{C}}$ and $\mathrm{I}_{\mathrm{O}}^{\mathrm{tri}}$. For $M=\mathrm{Ti}, \mathrm{V}, \mathrm{Zr}, \mathrm{Hf}$, the calculations show that $\Delta H_{c p}\left[\mathrm{~S}_{\mathrm{O}}^{\mathrm{C}}\right]<\Delta H_{c p}\left[\mathrm{I}_{\mathrm{O}}^{\mathrm{tri}}\right]$, indicating that oxygen substituting for carbon is favorable. For $\mathrm{Cr}_{2} \mathrm{AlC}$ the results is the opposite, $\Delta H_{c p}\left[\mathrm{~S}_{\mathrm{O}}^{\mathrm{C}}\right]>\Delta H_{c p}\left[\mathrm{I}_{\mathrm{O}}^{\text {tri }}\right]$. This difference may be related to a non-filled $\mathrm{Ti} 3 d-\mathrm{Al} 2 p$ hybridization for $\mathrm{Ti}_{2} \mathrm{AlC}$ and non-bonding $\mathrm{Cr} 3 d$ states for $\mathrm{Cr}_{2} \mathrm{AlC}$.

In $M_{2} \mathrm{AlC}$ the $M 3 d-\mathrm{C} 2 p$ hybridization is complete, with 6 electrons/fu. As oxygen substitutes for carbon, two extra electrons per replaced carbon are present within the M2Clayer. Since O $2 p$ also hybridizes with $M 3 d$, there will be an excess of electrons which results in a charge redistribution of the $M 3 d$ electrons, as illustrated in Figure 23(f). For $\mathrm{Ti}_{2} \mathrm{AlC}$, these go into the incomplete $\mathrm{Ti} 3 d-\mathrm{Al} 2 p$ hybridization hence lowering the energy of the system (evident from partial density of states, shown in Paper II). Oxygen thus stabilizes $\mathrm{Ti}_{2} \mathrm{AlC}$. For $x=0.5$, i.e. $50 \%$ of carbon replaced with oxygen, the $\mathrm{Ti} 3 d-\mathrm{Al} 2 p$ hybridization is complete. Experimental efforts have reached a maximum value of $52 \%$ oxygen substituting for carbon [82]. However, for $\mathrm{V}_{2} \mathrm{AlC}$ and $\mathrm{Cr}_{2} \mathrm{AlC}$, which already have a complete $M 3 d-\mathrm{C}$ $2 p$ hybridization, occupation of non-bonding $M 3 d$ states occur upon oxygen incorporation, which instead costs energy.

For interstitial oxygen, $\mathrm{I}_{\mathrm{O}}^{\mathrm{tri}}$, there is a significant charge transfer from Al to $\mathrm{O}$, most pronounced for $\mathrm{Ti}_{2} \mathrm{AlC}$, and from $\mathrm{M}$ to $\mathrm{O}$, increasing from $\mathrm{Ti}_{2} \mathrm{AlC}$ to $\mathrm{Cr}_{2} \mathrm{AlC}$. There is also charge redistribution for $M$ close to oxygen in $\mathrm{V}_{2} \mathrm{AlC}$ and $\mathrm{Cr}_{2} \mathrm{AlC}$. The latter is more prominent and illustrated in Figure 23(g). This can be related to the available non-bonding $M$ $3 d$-electrons, one in $\mathrm{V}_{2} \mathrm{AlC}$ and three in $\mathrm{Cr}_{2} \mathrm{AlC}$. Even though it generally costs energy for interstitial incorporation of oxygen in the Al-layer, $\mathrm{V}_{2} \mathrm{AlC}$ and $\mathrm{Cr}_{2} \mathrm{AlC}$ can gain some energy by de-populating non-bonding $M 3 d$ states. This is therefore not possible in $\mathrm{Ti}_{2} \mathrm{AlC}$.

In order to test the hypothesis of $\mathrm{S}_{0}^{\mathrm{C}}$ being favored over $\mathrm{I}_{0}^{\text {tri }}$ in $\mathrm{Ti}_{2} \mathrm{AlC}$, we have chosen the hypothetical $\mathrm{Zr}_{2} \mathrm{AlC}$ and $\mathrm{Hf}_{2} \mathrm{AlC}$ for investigation, as $\mathrm{Ti}, \mathrm{Zr}$, and $\mathrm{Hf}$ all belong to Group IV, with similar valence electron configuration.. Figure 23(d-e) shows the calculated formation enthalpies of oxygen-free $\mathrm{Zr}_{2} \mathrm{AlC}$ and $\mathrm{Hf}_{2} \mathrm{AlC}$, which are not found stable. Consistent with the 
result for Ti2AlC, $\Delta H_{c p}\left[\mathrm{~S}_{\mathrm{O}}^{\mathrm{C}}\right]<\Delta H_{c p}\left[\mathrm{I}_{\mathrm{O}}^{\text {tri }}\right]$ for $M=\mathrm{Zr}$ and Hf. Electronic structure analysis of (partial) density of states for $\mathrm{Zr}_{2} \mathrm{AlC}$ and $\mathrm{Hf}_{2} \mathrm{AlC}$ show peak structure, peak heights, and relative peak position for oxygen free, $\mathrm{S}_{\mathrm{O}}^{\mathrm{C}}$, and $\mathrm{I}_{\mathrm{O}}^{\text {tri }}$ to be very similar to $\mathrm{Ti}_{2} \mathrm{AlC}$. Although $\Delta H_{c p}$ is positive for $\mathrm{Zr}_{2} \mathrm{AlC}$ and $\mathrm{Hf}_{2} \mathrm{AlC}$, alloying between $\mathrm{Ti}-\mathrm{Zr}$ and $\mathrm{Ti}-\mathrm{Hf}$ seems plausible. Especially if we make use of the stabilizing effect arising from oxygen incorporation in $\mathrm{Ti}_{2} \mathrm{AlC}$.

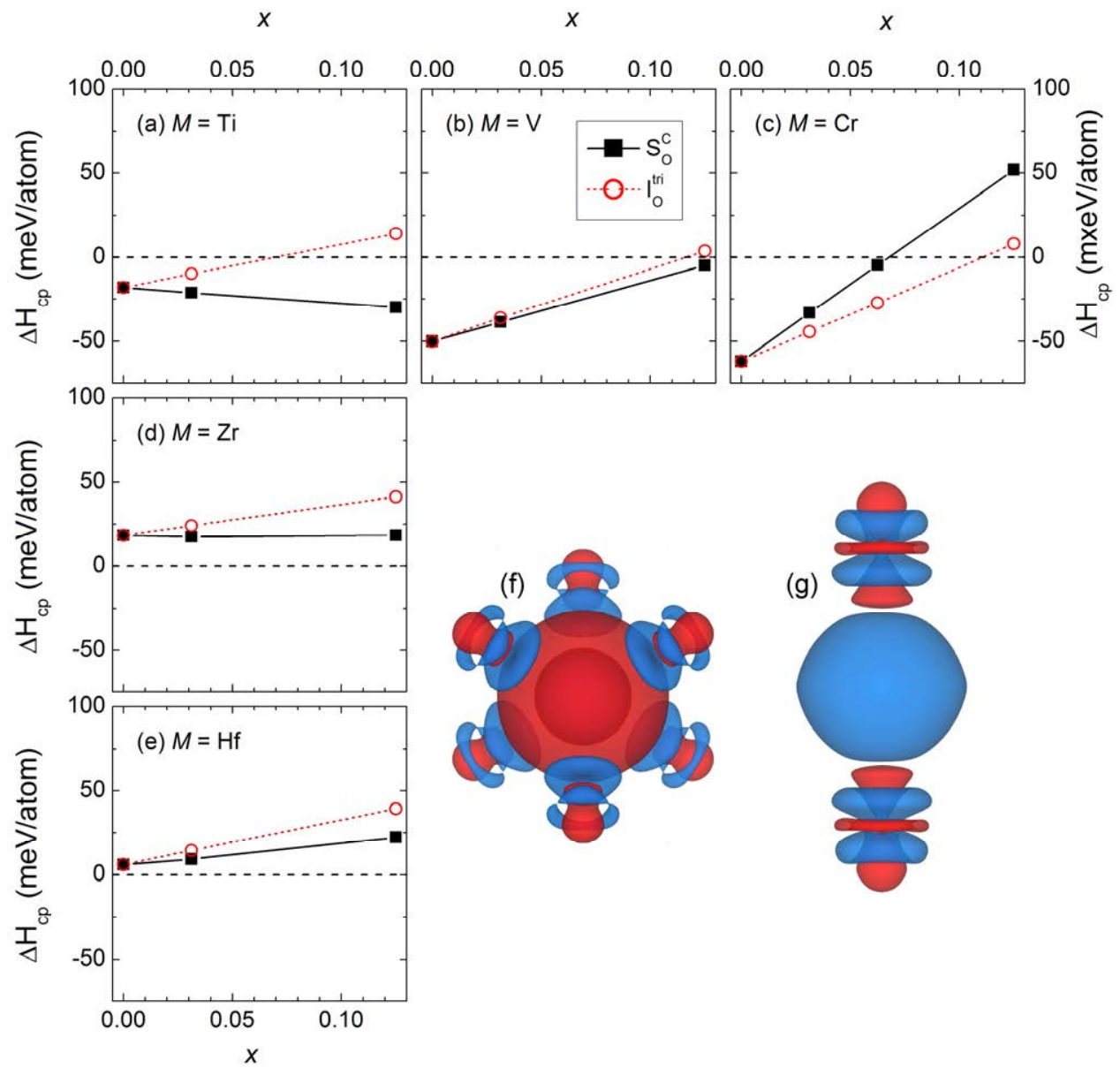

Figure 23. (a - e) Calculated formation enthalpy $\Delta H_{c p} M_{2} \mathrm{AlC}(M=\mathrm{Ti}, \mathrm{V}, \mathrm{Cr}, \mathrm{Zr}, \mathrm{Hf})$ as a function of oxygen concentration $x$ for $\mathrm{S}_{\mathrm{O}}^{\mathrm{C}}$ (black square, solid line) and $\mathrm{I}_{\mathrm{O}}^{\text {tri }}$ (open red circle, dashed line). Here the composition of $\mathrm{S}_{\mathrm{O}}^{\mathrm{C}}$ and $\mathrm{I}_{\mathrm{O}}^{\mathrm{tri}}$ is $M_{2} \mathrm{Al}\left(\mathrm{C}_{1-x} \mathrm{O}_{x}\right)$ and $M_{2} \mathrm{AlCO}_{x}$, respectively. Note that $M_{2} \mathrm{AlC}$ has not been included as a competing phase.. (f) Charge density difference of $\mathrm{S}_{\mathrm{O}}^{\mathrm{C}} \mathrm{Ti}_{2} \mathrm{AlC}$ as compared to oxygen-free $\mathrm{Ti}_{2} \mathrm{AlC}$ and $(\mathrm{g}) \mathrm{I}_{\mathrm{O}}^{\text {tri }} \mathrm{Cr}_{2} \mathrm{AlC}$ as compared to oxygenfree $\mathrm{Cr}_{2} \mathrm{AlC}$. The change in electron density is represented by isosurfaces at isosurface levels $0.025 \mathrm{e}^{-} / \AA^{3}$, where blue indicate gain of electrons and red loss of electrons as compared to the oxygen-free structure. Note that oxygen is in the center of (f) and (g). 
"They say it ain't complicated

Any fool can understand

Until the fuse is lit and

It blows up in your hand"

Rocket science, Lori McKenna

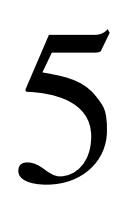

\section{Modeling MAGNETISM IN MAX PHASES}

Two milestones for understanding magnetic order were the discovery of the electron in $1890 \mathrm{~s}$ and the discovery of its intrinsic angular momentum, i.e., the spin, in the 1920s. Magnetism originates from a combination of Coulomb interaction between electrons and the Pauli exclusion principle. Commonly, the electrons of atoms are arranged in such a way that the magnetic moments, from orbital and/or intrinsic spin, cancel out. This is achieved either by combining electrons into filled subshells of zero net orbital motion, or by combining them in pairs of antiparallel spins, known as the Pauli exclusion principle, resulting in a non-magnetic (NM) material. However, when there are non-filled subshells and/or unpaired electrons in the material it may be energetically favorable for the electrons to align their spin in a specific way, i.e. there is magnetic order, and a magnetic moment arises. One example is iron, which have a spontaneous net magnetization in its body-centered cubic crystal structure due to parallel alignment of the unpaired electron spins. Such magnetic order is denoted ferromagnetism (FM). However, for iron in the face-centered cubic crystal structure the neighboring spins align antiparallel. This leads to a vanishing net magnetization and is called antiferromagnetism (AFM). Figure 24 shows schematic spin configurations for FM, AFM, and AFM like ordering. In a ferrimagnetic configuration the atoms on different sublattices are antiparallel but of unequal magnitude, and in spin-canted AFM there is slightly tilted antiparallel moments. Disordered direction of magnetic moments corresponds to paramagnetic (PM) configuration. 


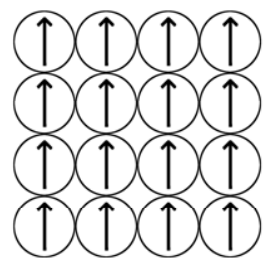

(a)

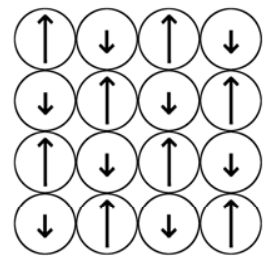

(c)

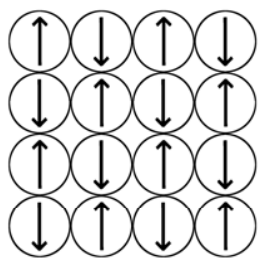

(b)

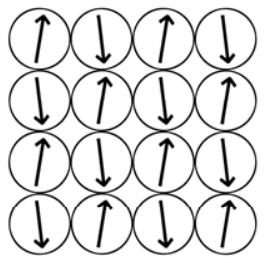

(d)

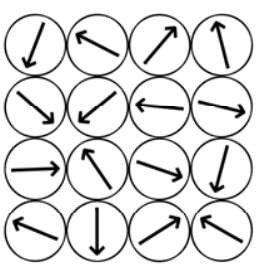

(e)

Figure 24. Schematic two dimensional descriptions of different types of spin alignments corresponding to (a) ferromagnetic, (b) antiferromagnetic, (c) ferrimagnetic, (d) spin-canted antiferromagnetic, and (e) disordered magnetic states.

The magnetic configuration of a material depends on the crystal structure and its constituent atoms $^{27}$, but also on temperature. At increased temperature, the magnetic spins cannot maintain their alignment, due to random thermal motion, resulting in a transition to disordered magnetic state of randomly aligned spins (PM), see (e) in Figure 24. For FM materials this transition occurs at the Curie temperature $T_{C}$ and for AFM configurations at the Néel temperature $T_{N}$.

Interest in layered magnetic materials was boosted by the observation of interlayer exchange in magnetic multilayers [2], followed by the discovery of giant magnetoresistance (GMR) [3, 4]. The MAX phase structure is by itself laminated but has not previously been shown to be magnetic. The first theoretically suggested magnetic MAX phases was Fe-based [13] but experimental evidence of their existence is still lacking. Likely explanations for this ambiguity are discussed in Paper III. Theoretical studies on MAX phases including magnetism are to date not many [13, 14, 27, 61, 62, 100-106, 145-148]. In the last two years the first magnetic MAX phases displaying a ferromagnetic response were experimentally synthesized; $\mathrm{Cr}_{2} A \mathrm{C}$ ( $A=\mathrm{Al}, \mathrm{Ga}, \mathrm{Ge}$ ) alloyed with $\mathrm{Mn}$ [61-63], $\mathrm{Cr}_{2} \mathrm{AlC}$ [149], and $\mathrm{Mn}_{2} \mathrm{GaC}$ (Paper IX) .

To illustrate the effect of magnetism on predicted stability for $M_{n+1} A X_{n}$ phases, the energy difference $\Delta E$ between the magnetic configuration of lowest energy and the non-magnetic (NM) can be compared. Further information of considered magnetic configurations is presented in Section 5.1. In Figure $25 \Delta E$ for four series of carbide and nitride $M_{n+1} A X_{n}$ is shown. For $M=\mathrm{Sc}$, Ti, V, Co, $\Delta E$ is zero since these MAX phases are all NM. However, for

\footnotetext{
${ }^{27}$ It's really the electron configuration that matters.
} 
$M=\mathrm{Cr}$ magnetic configurations below the NM state are found. For $M=\mathrm{Mn}$, the difference is around $100 \mathrm{meV} /$ atom in favor of the magnetic states. By adding more $d$-electrons $(M=\mathrm{Fe})$ the energy difference becomes smaller and for $M=\mathrm{Co}$ it is zero. For C-based phases, there is close to overlap in $\Delta E$ for all values of $n(1-3)$ over the $M$-series. Note the difference between Al-based carbides and nitrides, where the latter show a larger $\Delta E$ for a given $M$ element. However, this difference does not given any insight into phase stability.

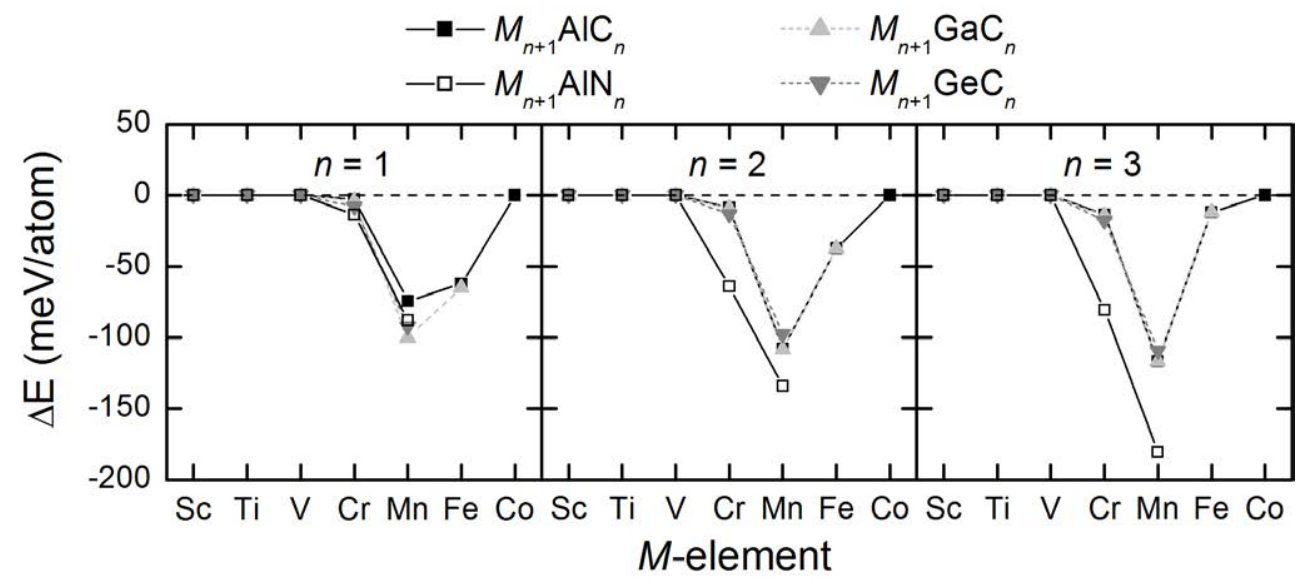

Figure 25. Energy difference between the magnetic configuration with lowest energy and the non-magnetic for $M_{n+1} A X_{n}$ phases. Note overlap for $M_{n+1} A C_{n}$ phases.

Identification of the magnetic ground state of the MAX phase is of importance for calculation of phase stability. Figure 26 shows the formation enthalpy $\Delta H_{c p}$ of $M_{2} \mathrm{AlC}$ and $M_{2} \mathrm{GaC}$, obtained from the NM as well as the lowest energy magnetic configurations. The largest differences in $\Delta H_{c p}$ are for $M=\mathrm{Mn}$, with $63 \mathrm{meV} /$ atom for $\mathrm{Mn}_{2} \mathrm{AlC}$ and $100 \mathrm{meV} /$ atom for $\mathrm{Mn}_{2} \mathrm{GaC}$. For the latter, instability would be concluded from $\Delta H_{c p}=+69 \mathrm{meV} /$ atom for the $\mathrm{NM}$ state, while assessment of magnetism results in a negative value of $\Delta H_{c p}(-31$ meV/atom), and therefore predicted stability. This value is in the same range as calculated for other experimentally known phases like $\mathrm{Ti}_{2} \mathrm{AlC}, \mathrm{Ti}_{2} \mathrm{GaC}$ and $\mathrm{V}_{2} \mathrm{GaC}$, and magnetism can thus not be excluded for correct predictions. 


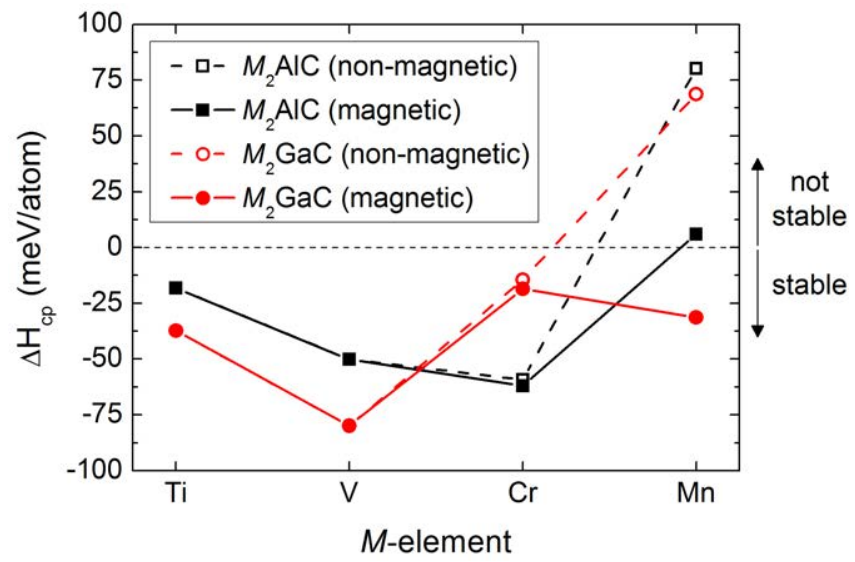

Figure 26. Calculated formation enthalpy $\Delta H_{c p}$ for non-magnetic (open symbols) and magnetic (filled symbols) $M_{2} \mathrm{AC}$ phases where $M=\mathrm{Ti}, \mathrm{V}, \mathrm{Cr}, \mathrm{Mn}$, and $A=\mathrm{Al}$ ( $\square$ and $\square$ ), $\mathrm{Ga}$ $(\bullet$ and $\circ)$

\subsection{Spin configurations of $M_{2} A X$ phases}

Figure 25 and Figure 26 showed the importance of including magnetism in any theoretical evaluation, however, no information was given about the magnetic states considered and what spin configuration represented the low energy state. Previous studies aiming for identification of the magnetic ground state of MAX phases include at most NM, FM, and one AFM state, where the definition of the AFM state is usually excluded [13, 101, 103-106, 146, 150, 151]. This section covers theoretical treatment of magnetic spin configuration for $M_{2} A X$ phases, starting with collinear description (spins are (anti)parallel), followed by a few examples of possible noncollinear configurations, all exemplified by the recently theoretically predicted and experimentally verified $\mathrm{Mn}_{2} \mathrm{GaC}$.

\subsubsection{Collinear configurations}

For an AFM state the set of possible collinear spin configurations are many, although, in practice, limited to configurations that maximize the number of anti-parallel moments over a few nearest neighbor shells. However, due to the symmetry of the $M_{2} A X$ phases there are several configurations which can fulfill this criterion. Illustrated in Figure 27 is the FM configuration (a), and five different collinear AFM configuration, (b) to (f). 

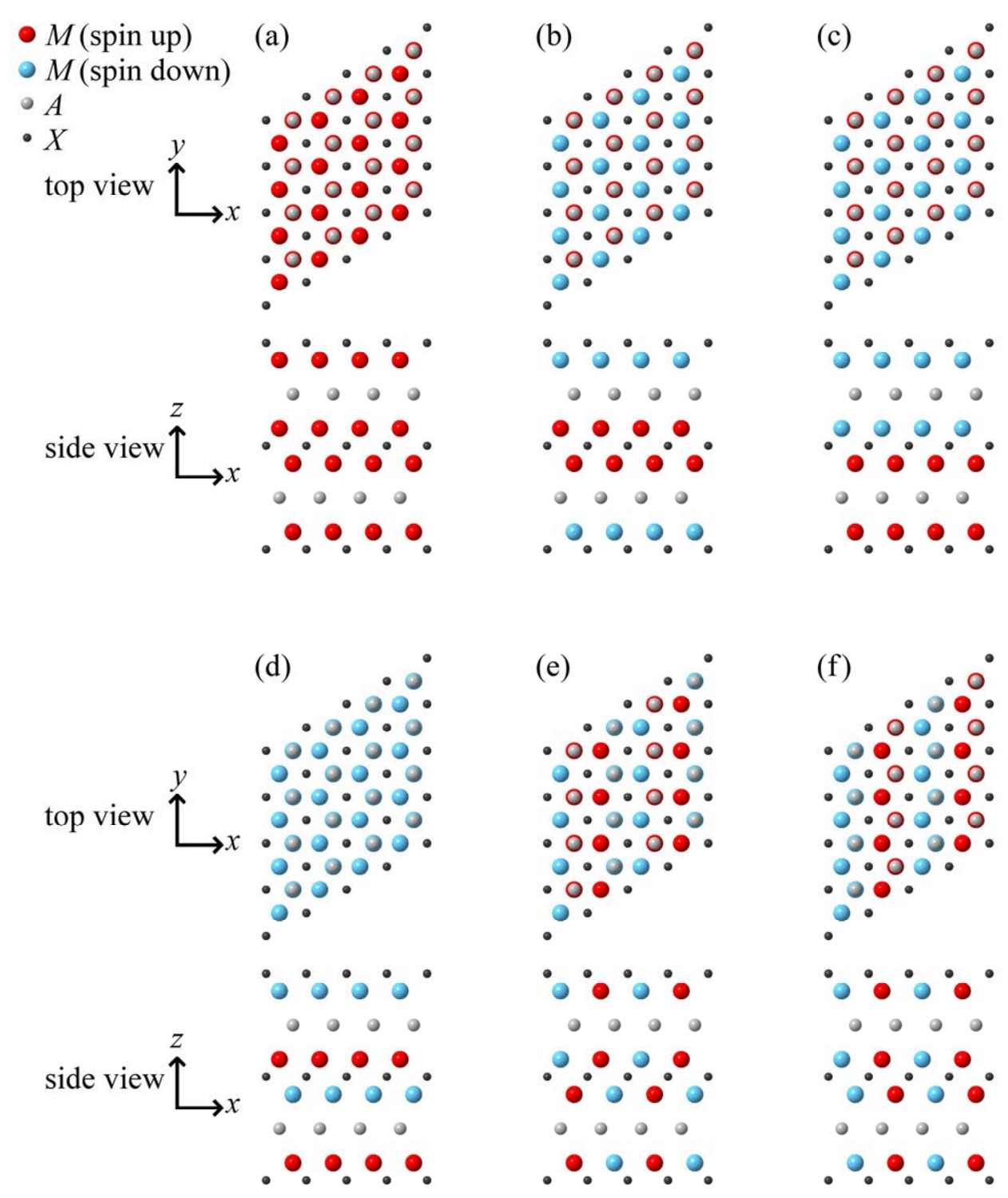

Figure 27. Schematic illustration of six ordered collinear magnetic structures for $M_{2} A X$ where (a) is FM, (b) $\operatorname{AFM}[0001]_{2}^{A}$, (c) $\operatorname{AFM}[0001]_{2}^{X}$, (d) $\mathrm{AFM}[0001]_{1}$, (e) in-AFM1, and (f) inAFM2. To clearly distinct the different AFM configurations, the $M_{2} A X$ phase is here represented by a supercell of $4 \times 4 \times 1$ unit cells (128 atoms in total). 
The notation for these were introduced in Paper V and the corresponding interpretation for (b) to (f) are

- $\operatorname{AFM}[0001]_{2}^{A}$, double layered AFM ordering with spins changing sign upon crossing an $A$ atom along [0001] direction.

- $\operatorname{AFM}[0001]_{2}^{X}$, double layered AFM ordering with spins changing sign upon crossing an $X$ atom along [0001] direction.

- $\operatorname{AFM}[0001]_{1}$, single layered AFM ordering with spins changing sign for every [0001]-layer of $\mathrm{M}$ atoms.

- in-AFM1 in-plane AFM.

- in-AFM2 in-plane AFM.

These can be differentiated from one another using spin correlation functions $\Phi_{\alpha}$ to describe the applied spins in different coordination shells $\alpha$ of the $M$ atoms. The spin correlation functions, defined as the average relative orientations of the magnetic moments in the $\alpha$ :th coordination shell of the $M$ atoms, is given by

$$
\Phi_{\alpha}=\frac{1}{N} \sum_{i, j \in \alpha} \mathbf{e}_{i} \cdot \mathbf{e}_{j},
$$

where $N$ is the number of terms in the sum, and $\mathbf{e}_{i}$ and $\mathbf{e}_{j}$ are unit vectors in the direction of the local magnetic moment on site $i$ and $j$. In our collinear case the spins are parallel and/or antiparallel to each other with unit vectors $\mathbf{e}_{i}$ and $\mathbf{e}_{j}$ of either +1 for spin up or -1 for spin down. Three characteristic, but not limited to, values of $\Phi_{\alpha}$ are described as follows;

- $\Phi_{\alpha}=1$, all atoms in shell $\alpha$ have the same spin direction as the center atom $\left(\mathbf{e}_{i}=\mathbf{e}_{j}\right)$.

- $\Phi_{\alpha}=-1$, antiparallel configuration with opposite spin direction of all neighboring spins in shell $\alpha$.

- $\Phi_{\alpha}=0$, there are in average equal amount of parallel and anti-parallel spin pairs in coordination shell $\alpha$ which is the case for an ideally random distribution of spins.

To distinct the six collinear magnetic configurations in Figure 27 the first four coordination shells for the $M$ atoms are needed, illustrated by unit vectors in Figure 28. Corresponding values $\Phi_{\alpha}$ for each shell $\alpha$ is shown in Table 14. Note that for modeling AFM within an $M$ plane (in-AFM1 and in-AFM2) the original unit cell of $M_{2} A X(1 \times 1 \times 1$ with 8 atoms $)$ is insufficient and needs to be expanded to $2 \times 1 \times 1$ unit cells (16 atoms). 

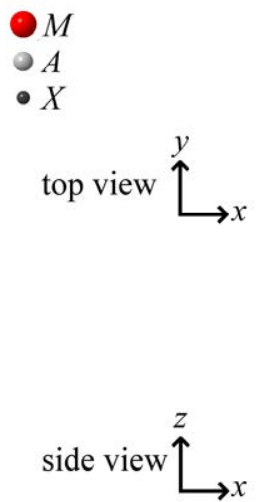
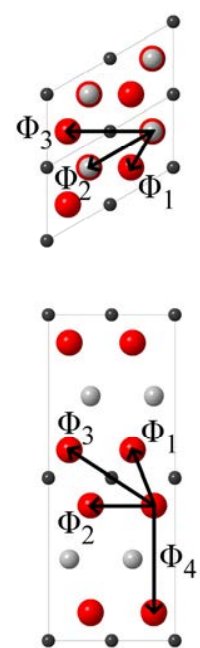

Figure 28. Schematic illustration of unit vectors representing the first four coordination shells of $M$ in $M_{2} A X$.

Table 14. Spin correlation function $\Phi_{\alpha}$ for the first four coordination shells of $M$ in $M_{2} A X$. The term $\mathrm{n}_{\alpha}$ is the number of atoms in shell $\alpha$, generally denoted by $N$ in Eq. (16). Also note the unit cell needed for modeling corresponding magnetic configuration.

\begin{tabular}{cccccc}
\hline \hline \multirow{2}{*}{$\begin{array}{c}\text { Magnetic } \\
\text { configuration }\end{array}$} & \multicolumn{4}{c}{ Spin correlation functions $\Phi_{\alpha}$} & Magnetic \\
\cline { 2 - 5 } & $\begin{array}{c}\Phi_{1} \\
\left(n_{\alpha}=3\right)\end{array}$ & $\begin{array}{c}\Phi_{2} \\
\left(n_{\alpha}=6\right)\end{array}$ & $\begin{array}{c}\Phi_{3} \\
\left(n_{\alpha}=3\right)\end{array}$ & $\begin{array}{c}\Phi_{4} \\
\left(n_{\alpha}=1\right)\end{array}$ & unit cell size \\
\hline $\mathrm{FM}$ & 1 & 1 & 1 & 1 & $1 \times 1 \times 1$ \\
$\mathrm{AFM}[0001]_{2}^{A}$ & 1 & 1 & 1 & -1 & $1 \times 1 \times 1$ \\
$\mathrm{AFM}[0001]_{2}^{X}$ & -1 & 1 & -1 & 1 & $1 \times 1 \times 1$ \\
$\mathrm{AFM}[0001]_{1}$ & -1 & 1 & -1 & -1 & $1 \times 1 \times 1$ \\
in-AFM1 & $-1 / 3$ & $-1 / 3$ & 1 & 1 & $2 \times 1 \times 1$ \\
in-AFM2 & $1 / 3$ & $-1 / 3$ & -1 & 1 & $2 \times 1 \times 1$ \\
\hline \hline
\end{tabular}

An extension of the double-layered AFM's, AFM[0001 $]_{2}^{A}$ and AFM[0001 $]_{2}^{X}$, would be to increase the number of consecutive $M$-layers with equal spin direction before changing sign. Quadruple-, sextuple-, and octuple-layered AFM configurations are illustrated in Figure 29, with a notation that follows the same principles as the double-layered AFM's (AFM $[0001]_{Z}^{A}$ and $\operatorname{AFM}[0001]_{Z}^{X}$ ) with $z=4,6,8$ depending on the number of consecutive $M$-layers with equal spin direction. The magnetic unit cell needed for modeling the extended multi-layered AFM ordered collinear magnetic structures for $M_{2} A X$ are $1 \times 1 \times 2$ unit cells $(z=4), 1 \times 1 \times$ 3 unit cells $(z=6)$, and $1 \times 1 \times 4$ unit cells $(z=8)$. For $z \rightarrow \infty$ the magnetic configuration becomes FM. 


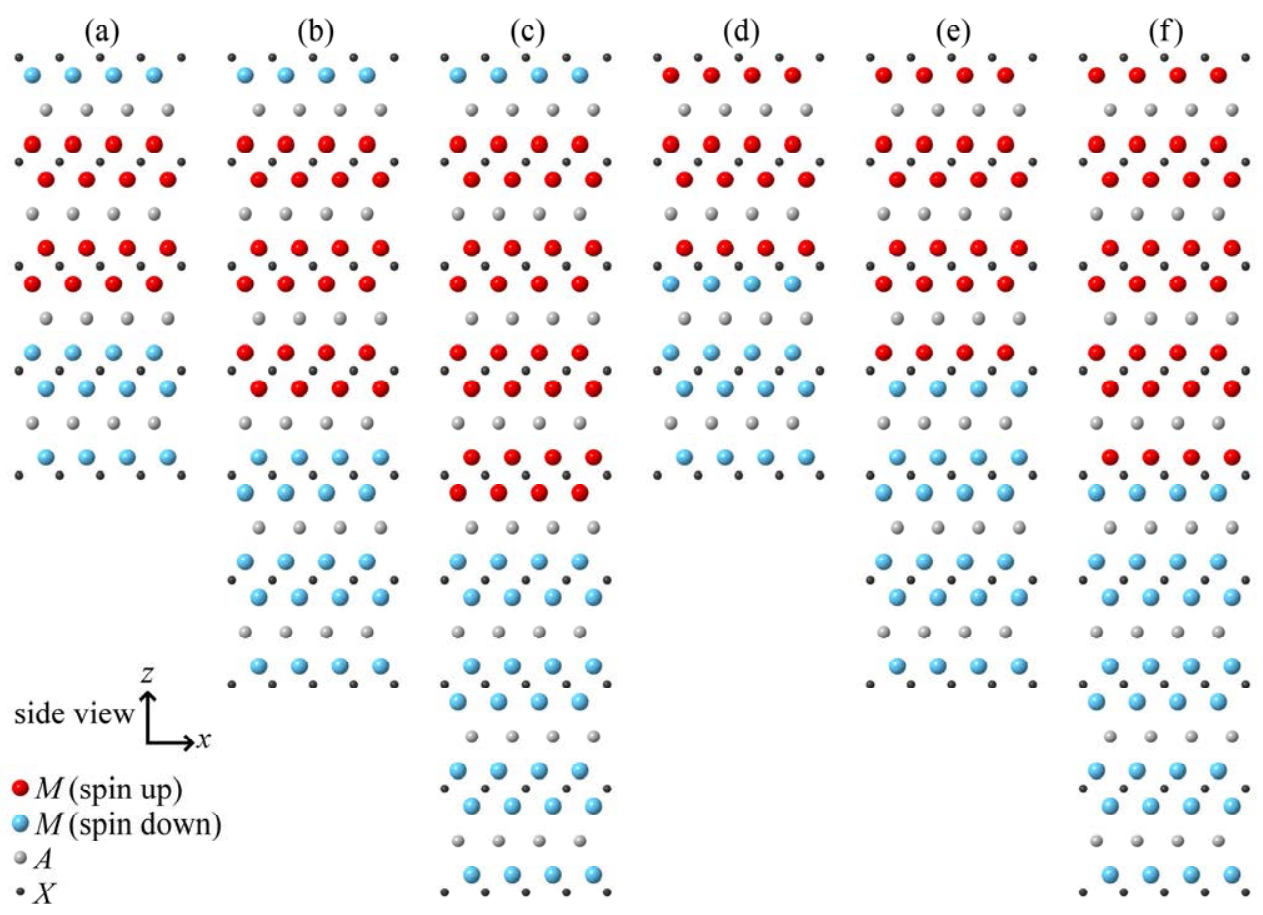

Figure 29. Schematic illustration of extended multi-layered AFM ordered collinear magnetic structures for $M_{2} A X$ where (a) is $\operatorname{AFM}[0001]_{4}^{A}$, (b) $\operatorname{AFM}[0001]_{6}^{A}$, (c) $\operatorname{AFM}[0001]_{8}^{A}$, (d) $\operatorname{AFM}[0001]_{4}^{X}$, (e) $\operatorname{AFM}[0001]_{6}^{X}$, and (f) $\operatorname{AFM}[0001]_{8}^{X}$.

$\mathrm{Mn}_{2} \mathrm{GaC}$ have been chosen to illustrate that the choice of considered spin configuration matters in terms of calculated total energy, structure, and magnetic properties. In Figure 30 the energy-volume curves are shown for 12 different collinear spin configuration including NM. From this a few observations can be made about the collinear magnetism of $\mathrm{Mn}_{2} \mathrm{GaC}$;

- $\quad$ each set of energies for specific volume is unique.

- $\quad \mathrm{NM} \mathrm{Mn}{ }_{2} \mathrm{GaC}$ is highest in energy, i.e. least stable state.

- in-plane AFM magnetic states, in-AFM1 and in-AFM2, are energetically unfavorable.

- The nine magnetic states found with lowest energy (FM, AFM[0001 $]_{Z}^{A}$ and $\operatorname{AFM}[0001]_{Z}^{X}$ ) all have equal spins within a Mn-layer.

- The five magnetic states of lowest energy are FM and $\operatorname{AFM}[0001]_{z}^{A}(z=2,4,6,8)$, all having equal spin within a Mn-C-Mn trilayer (or Mn double-layer). 


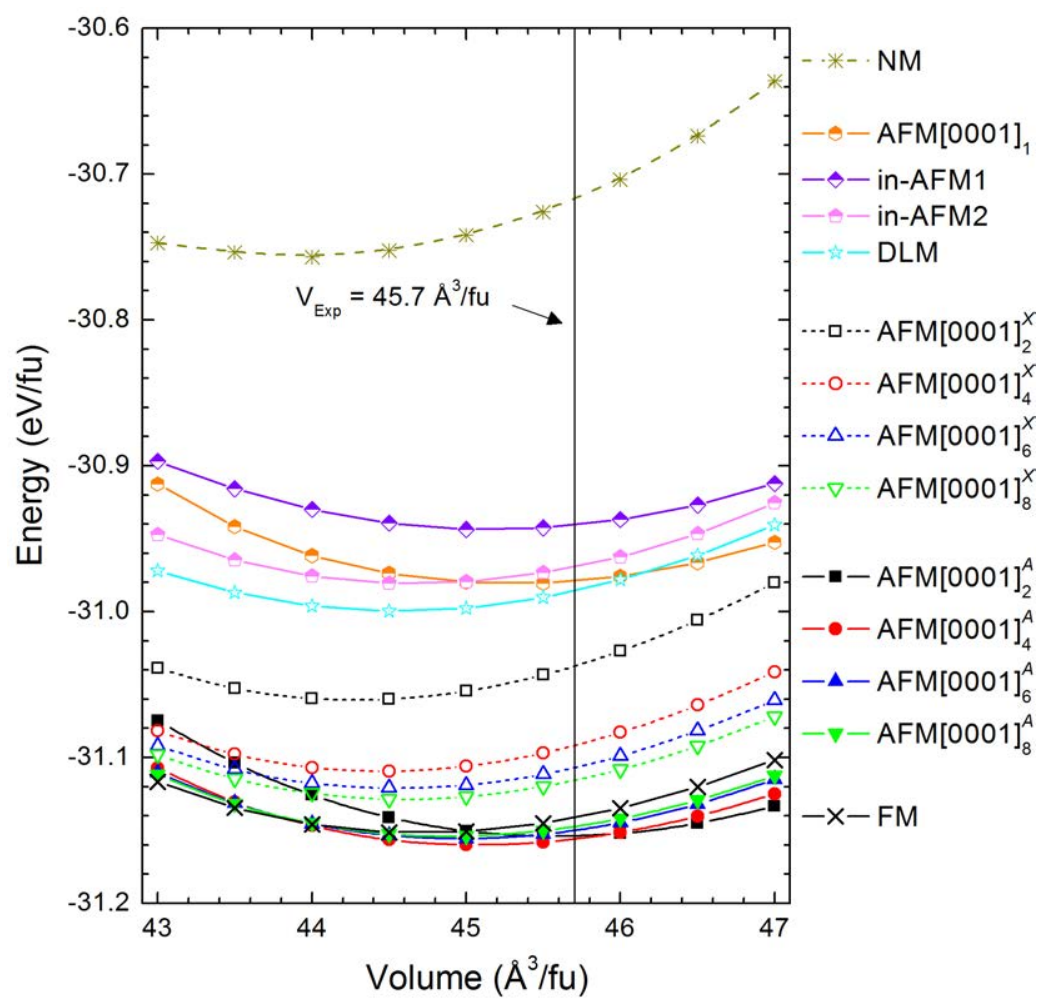

Figure 30. Calculated energy versus volume curves for $\mathrm{Mn}_{2} \mathrm{GaC}$, for the 12 different collinear magnetic states defined in Figure 27 and Figure 29, as well as the DLM, and NM states. The vertical dashed line indicates the experimental volume at room temperature.

Table 15 presents the calculated equilibrium structural parameters and local magnetic moments for $\mathrm{Mn}_{2} \mathrm{GaC}$. For most magnetic states, excluding AFM[0001] $]_{1}$ and NM, the inplane lattice parameter $a$ is comparable to the experimental value $(2.9 \AA)$. The major difference is instead found for $c$, going from 12.179 $\AA$ for AFM[0001] $]_{2}^{X}$ to $12.484 \AA$ for $\mathrm{AFM}[0001]_{2}^{X}$, significantly below the measured value of $12.55 \AA$. Also magnetic moments (absolute values) do show a dependence of spin configurations. 
Table 15. Calculated equilibrium volume $V_{0}$ with corresponding lattice parameters $a$ and $c$, and absolute magnetic moment per $\mathrm{Mn}$ for considered spin configurations of $\mathrm{Mn}_{2} \mathrm{GaC}$ using GGA. Experimental structural results are included for comparison.

\begin{tabular}{|c|c|c|c|c|}
\hline \multirow{2}{*}{$\begin{array}{l}\text { Magnetic } \\
\text { state }\end{array}$} & \multicolumn{3}{|c|}{ Structural parameters } & $\begin{array}{r}\text { Local moments for } \mathrm{Mn} \\
\text { atoms }\left(\mu_{B}\right)\end{array}$ \\
\hline & $V_{0}\left(\AA^{3} / \mathrm{fu}\right)$ & $a(\AA)$ & $c(\AA)$ & GGA \\
\hline NM & 43.90 & 2.892 & 12.211 & - \\
\hline FM & 44.72 & 2.899 & 12.290 & 1.95 \\
\hline $\mathrm{AFM}[0001]_{2}^{A}$ & 45.57 & 2.903 & 12.484 & 2.26 \\
\hline $\operatorname{AFM}[0001]_{2}^{X}$ & 44.29 & 2.898 & 12.179 & 1.59 \\
\hline $\mathrm{AFM}[0001]_{1}$ & 45.31 & 2.925 & 12.227 & 1.83 \\
\hline in-AFM1 & 45.15 & 2.916 & 12.265 & 1.95 \\
\hline in-AFM2 & 44.67 & 2.892 & 12.345 & 1.99 \\
\hline $\operatorname{AFM}[0001]_{4}^{A}$ & 45.07 & 2.898 & 12.392 & $1.99,2.17$ \\
\hline $\operatorname{AFM}[0001]_{6}^{A}$ & 44.96 & 2.900 & 12.344 & $1.92,2.01,2.17$ \\
\hline $\operatorname{AFM}[0001]_{8}^{A}$ & 44.89 & 2.902 & 12.314 & $1.94,1.97,2.00,2.16$ \\
\hline $\mathrm{AFM}[0001]_{4}^{X}$ & 44.46 & 2.900 & 12.207 & $1.52,1.95$ \\
\hline $\operatorname{AFM}[0001]_{6}^{X}$ & 44.55 & 2.899 & 12.243 & $1.54,1.91,1.97$ \\
\hline $\operatorname{AFM}[0001]_{8}^{X}$ & 44.60 & 2.899 & 12.258 & $1.54,1.94,1.96,1.97$ \\
\hline DLM & 44.67 & 2.887 & 12.375 & $0.57-2.27$ \\
\hline Expt. $^{*}$ & 45.70 & 2.9 & 12.55 & \\
\hline
\end{tabular}

${ }^{*}$ Reference [27].

\subsubsection{Noncollinear configurations}

The collinear description with (anti)parallel spins is often enough for describing magnetism in a material. However, some systems require an additional degree of freedom. Within a noncollinear configuration the relative directions of the spins can span over all spatial directions. One example is the complex cubic ground-state crystal structure of $\mathrm{Mn}$, known as $\alpha-\mathrm{Mn}$, which is paramagnetic at ambient conditions. At the Néel temperature of $95 \mathrm{~K}$, there is a transition to a complex noncollinear antiferromagnetic phases [152, 153].

Another example is $\mathrm{Cr}$ and $\mathrm{Mn}$ monolayers on a hexagonal lattice which are prototypical examples of frustrated spin systems in two dimensions [154, 155]. The best collinear description for a nearest neighbor AFM configuration in such lattice is the row-wise AFM illustrated in Figure 31(a). For MAX phases this corresponds to in-AFM1 and in-AFM2. For a hexagonal lattice the classical nearest neighbor Heisenberg model predicts a noncollinear ground state consisting of a three atom unit cell with magnetic moments aligned $\pm 120^{\circ}$, also known as the coplanar noncollinear Néel $\left(120^{\circ}\right)$ structure, see Figure 31(b). 
(a)

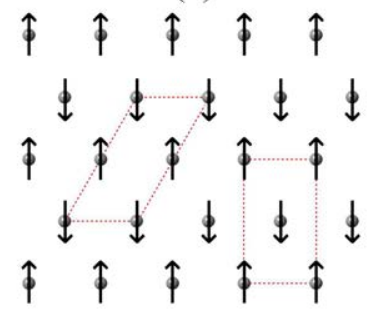

(b)

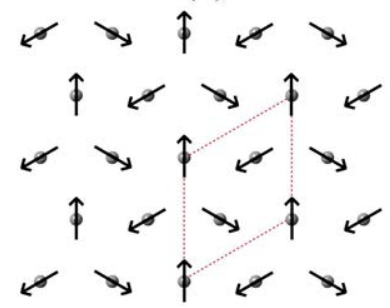

Figure 31. (a) The row-wise AFM structure and (b) the noncollinear Néel $\left(120^{\circ}\right)$ structure with corresponding two- and three-atom unit cell indicated. In (a) two different unit cells are illustrated; $2 \times 1 \times 1$ hexagonal which is the base for in-AFM1 and in-AFM2 and a rectangular base which would be represented by an orthorhombic unit cell for e.g. MAX phases

Introducing noncollinearity for MAX phases could thus lead to a large number of possible magnetic configurations. As a first step, in-plane AFM of $\mathrm{Mn}_{2} \mathrm{GaC}$ have been modelled using the Néel structure within each Mn-layer. To include the effect from interaction between Mn atoms in layer $i$ and $i+1$, different relative angles of the Néel structures between the individual layers have been considered. In Figure 32 the energy for five different layering of noncollinear Néel spin structure is shown for $\mathrm{Mn}_{2} \mathrm{GaC}$, and three distinct energy-volume curves are evident. Common for the low energy Néel structures 1111 and 1771 is the equivalent relative orientation of the three spins for three Mn atoms above and below the Galayer. For the high energy Néel structures 1717 and 1177 the configuration above and below a Ga layer is antiparallel. In comparison to the collinear AFM states (AFM[0001] $]_{1}$, in-AFM1, in-AFM2) the Néel states are less energetically favored.

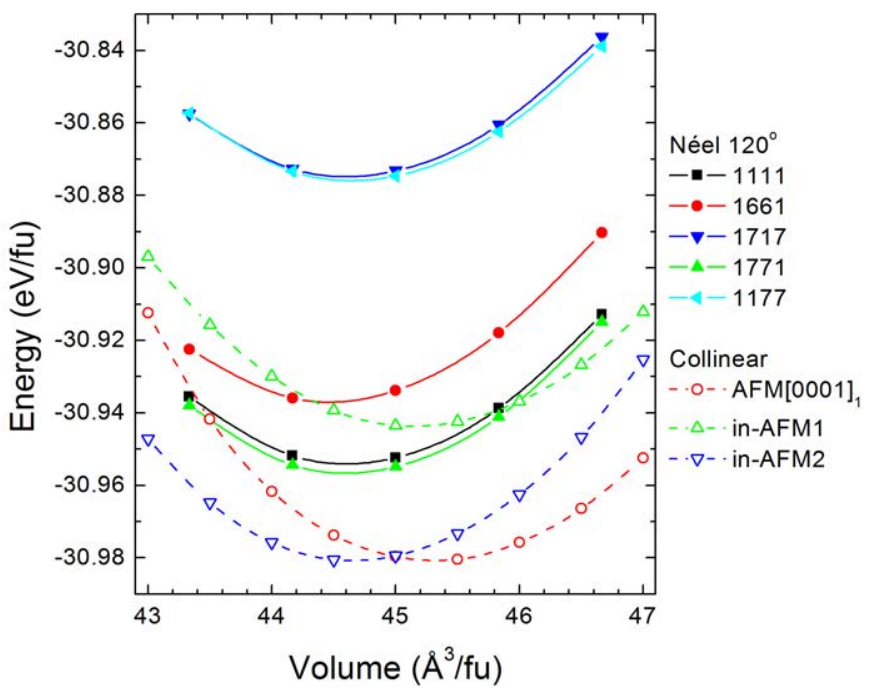

Figure 32. Calculated energy versus volume curves for five different layering of noncollinear Néel $120^{\circ}$ spin structure (solid lines) and three collinear AFM states (dashed lines). 
Another approach to model noncollinear configurations is to explore the change in energy, structure, and magnetic properties in between two collinear configurations. One such example is canted spins, illustrated in Figure 33, where the anti-parallel spins in (a), corresponding to the collinear $\mathrm{AFM}[0001]_{4}^{A}$, are canted by $\theta_{\mathrm{c}}$ degrees in $+\mathrm{z}$ direction (b) giving rise to a small net moment. Further canting of the spins eventually results in parallel spins (c), corresponding to FM.

(a)

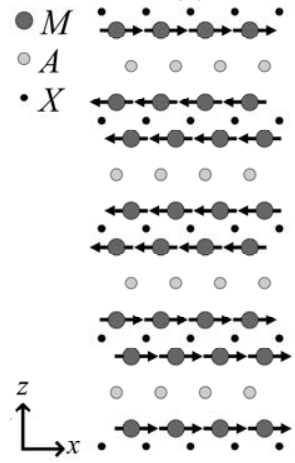

(b)
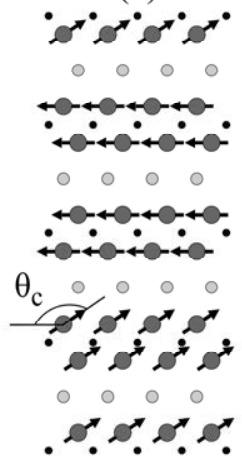

(c)

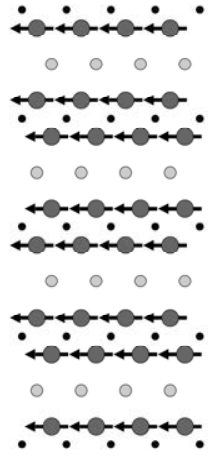

Figure 33. Schematic illustration of spins canted by an angle $\theta_{\mathrm{c}}$ where (a) is $\mathrm{AFM}[0001]_{4}^{A}$ $\left(\theta_{\mathrm{c}}=180^{\circ}\right),(\mathrm{b})$ an intermediate state $\left(\theta_{\mathrm{c}} \approx 155^{\circ}\right)$, and (c) FM $\left(\theta_{\mathrm{c}}=0^{\circ}\right)$. Note that the spins can as well be canted within the $M$-planes, i.e. rotated around the $z$-axis, but for illustrative reasons the rotation is around the $y$-axis. Such choice is only of importance when including spin-orbit coupling.

In Figure 34(a) the total energy as a function of canting angle $\theta_{c}$ is shown for a relaxed and two fixed lattices of $\mathrm{Mn}_{2} \mathrm{GaC}$. As $\theta_{\mathrm{c}}$ is increased, the magnetic state changes continuously from $\mathrm{FM}$ at $\theta_{\mathrm{c}}=0^{\circ}$ to $\operatorname{AFM}[0001]_{4}^{A}$ at $\theta_{\mathrm{c}}=180^{\circ}$, for both fixed and relaxed lattices. For angles close to $0^{\circ}$ and $180^{\circ}$ the corresponding fixed lattice represents the relaxed lattice well. In panel (b) of Figure 34 the local magnetic moment (absolute values) show a small but gradual increase as $\theta_{c}$ is increased. For half of the Mn atoms this is more pronounced, a structural-magnetic effect which will be further discussed below. Also shown is the net magnetization which gradually decreases as $\theta_{c}$ increases, from $1.83 \mu_{B}$ per $\mathrm{Mn}$ atom for the FM state to zero at $\theta_{\mathrm{c}}=180^{\circ}$. Close to $\theta_{\mathrm{c}}=180^{\circ}$ this decrease is most pronounced, although accompanied by only minor changes in energy; between $150^{\circ}$ and $180^{\circ}$, the energy changes with less than $1 \mathrm{meV} / \mathrm{fu}$.

For the relaxed lattice it is possible to see how the structural parameters are affected upon spin canting. In Figure 35(a) there is an almost unaffected basal plane lattice parameter $a$ for all $\theta_{c}$, as opposed to the lattice parameter $c$ which increases continuously from $12.29 \AA$ (FM) to $12.39 \AA$ (AFM). This increase can be related to the change in the Mn interlayer distance of $\mathrm{Mn}-\mathrm{Ga}-\mathrm{Mn}$, but only if the two Mn-layers have anti-parallel spin. For corresponding parallel spins the interlayer distance is almost unaffected by $\theta_{c}$. 


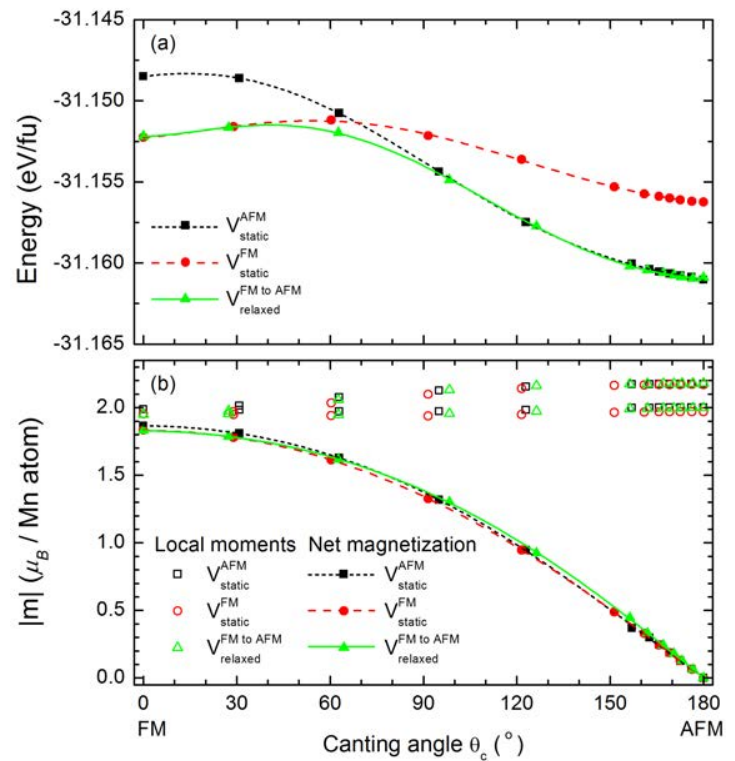

Figure 34. (a) Total energy and (b) magnetic moments for various canting angle $\theta_{c}$ of $\mathrm{Mn}_{2} \mathrm{GaC}$ assuming fixed FM structure (squares), fixed AFM[0001 ${ }_{4}^{A}$ structure (circles) and fully relaxed structure for each $\theta_{c}$ (triangles). In (b) both local magnetic moments (open symbols) and net magnetization (solid symbols) per Mn atom are shown.

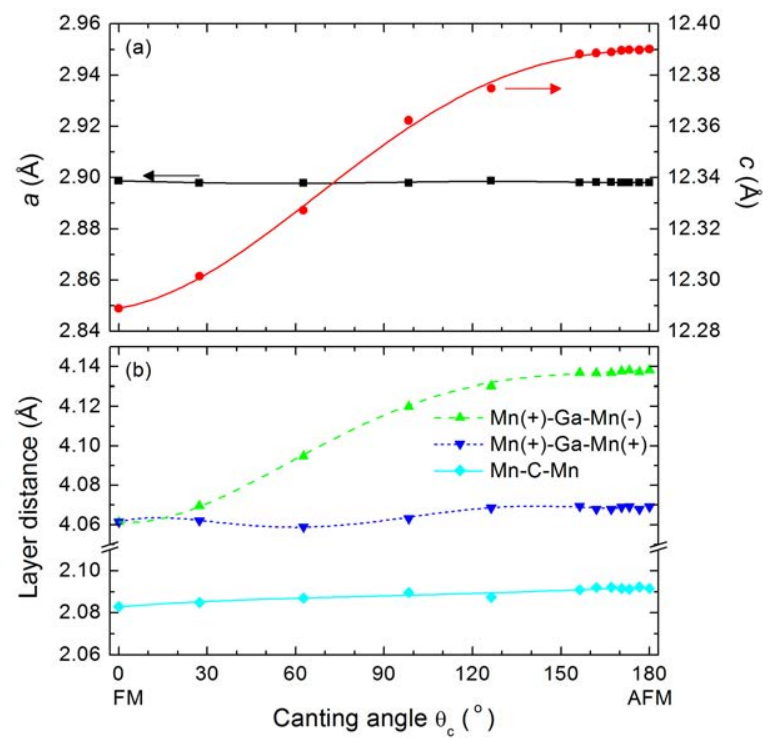

Figure 35. (a) Calculated lattice parameters $a(\bullet)$ and $c(\bullet)$, and (b) three different $\mathrm{Mn}$ interlayer distances vs canting angle $\theta_{c}$ for $\mathrm{Mn} 2 \mathrm{GaC}$. In (b) the three different $\mathrm{Mn}$ interlayer distances corresponds to Mn-C-Mn (»), Mn-Ga-Mn with parallel spins on both $\mathrm{Mn}$ of same spin direction $(\boldsymbol{\nabla})$, and Mn-Ga-Mn with anti-parallel spins of $\mathrm{Mn}(\Delta)$. 


\subsection{Magnetic ground state of $\mathrm{Cr}_{2} A \mathrm{C}(A=\mathrm{Al}, \mathrm{Ga}, \mathrm{Ge})$}

$\mathrm{Cr}_{2} \mathrm{AlC}$ is the prototypical structure for $M_{2} A X$ phases. Experimental work on magnetism of $\mathrm{Cr}_{2} A C$ has just recently been reported [149]. However, in the last decade several theoretical studies aimed at identifying the magnetic ground state including at most NM, FM, and one AFM state [13, 101, 103-106, 146, 150, 151]. For $\mathrm{Cr}_{2} \mathrm{AlC}$ a $\mathrm{NM}$ ground state has been predicted $[145,146]$ and only by using the DFT+U method were Ramzan et al. able to stabilize a magnetic state [101]. Note that the definition of the AFM configuration is usually not specified, but may be interpreted AFM[0001] $]_{1}$.

In Paper V and VI the magnetic ground state was investigated for $\mathrm{Cr}_{2} A \mathrm{C}(A=\mathrm{Al}, \mathrm{Ga}, \mathrm{Ge})$ by considering, at least, the six magnetic spin configurations illustrated in Figure 27. In Figure 36 the energies relative to the $\mathrm{NM}$ energy minimum, $E_{0}^{\mathrm{NM}}$, are presented, calculated from $\Delta E(V)=E(V)-E_{0}^{N M}\left(V_{0}\right)$. For $\mathrm{Cr}_{2} \mathrm{AlC}$ and $\mathrm{Cr}_{2} \mathrm{GaC}$ all magnetic states but in-AFM1 are close to degenerate with NM. For $\mathrm{Cr}_{2} \mathrm{GeC}$, the three AFM states AFM[0001] ${ }_{2}^{X}$, in-AFM1, and in-AFM2 are clearly separated from NM. Hence for all $\mathrm{Cr}_{2} A \mathrm{C}$, the in-AFM1 is the lowest energy configuration. This result does not change when treating the electron exchange correlation functional with a Hubbard $U(\mathrm{GGA}+U)$ method [107] to account for the electron correlations of $\mathrm{Cr} 3 d$-electrons as long as reasonable values of $\mathrm{U}$ are used. See Paper VI for further details.

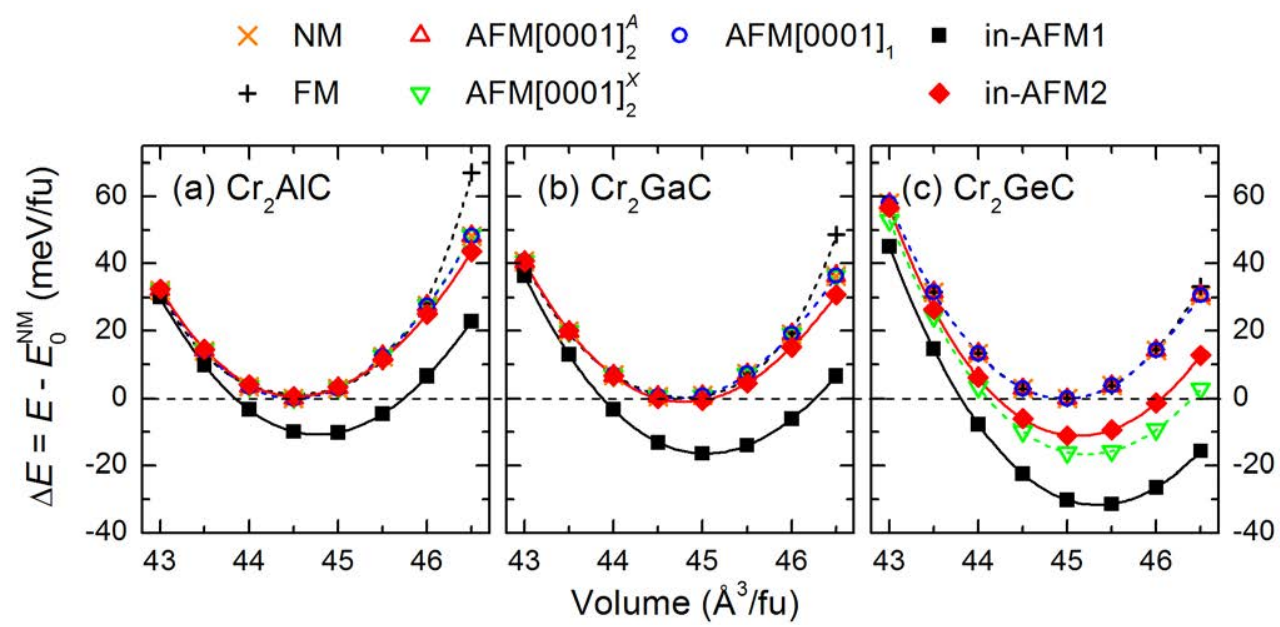

Figure 36. Calculated energy-volume curves for (a) $\mathrm{Cr}_{2} \mathrm{AlC}$, (b) $\mathrm{Cr}_{2} \mathrm{GaC}$, and (c) $\mathrm{Cr}_{2} \mathrm{GeC}$ considering NM, FM, and five AFM spin configurations.

Since energy and volume are dependent on choice of spin configurations, the structure will also be affected. In Table 16 and Table 17 the change of lattice parameter $a$ and $c$ relative the $\mathrm{NM}$ configuration are shown for $\mathrm{Cr}_{2} A C$ phases. Since the energy difference between the low energy state in-AFM1 and other states are rather small for $\mathrm{Cr}_{2} A \mathrm{C}$ as compared to $\mathrm{Mn}_{2} \mathrm{GaC}$ 
and the hypothetical $\mathrm{Mn}_{2} \mathrm{AlC}$, see e.g. Figure 25, the latter two has also been included. $\mathrm{Cr}$ based phases are moderately affected by choice of magnetic configuration with largest changes for in-AFM1. For $\mathrm{Mn}_{2} \mathrm{AlC}$ the effect of including spin correlation is most pronounced in-plane with $\Delta a \approx 1.5 \%$ whereas $\mathrm{Mn}_{2} \mathrm{GaC}$ have a spread of from 0 to $+1.2 \%$. The relative change in $c$ is more wide spread, $-1.0 \%$ to $+2.2 \%$ indicating that magnetic interactions out-of-plane, e.g. across the $X$-layer, play an important role in finding the magnetic ground-state.

Table 16. Relative change in lattice parameter $a$ (in \%) for different magnetic configurations relative NM for five $M_{2} A C$ phases. Values for NM are given in bottom row.

\begin{tabular}{cccccc}
\hline \multirow{2}{*}{$\begin{array}{c}\text { Magnetic } \\
\text { configuration }\end{array}$} & \multicolumn{5}{c}{$\Delta a$ relative $\mathrm{NM}(\%)$} \\
\cline { 2 - 6 } & $\mathrm{Cr}_{2} \mathrm{AlC}$ & $\mathrm{Cr}_{2} \mathrm{GaC}$ & $\mathrm{Cr}_{2} \mathrm{GeC}$ & $\mathrm{Mn}_{2} \mathrm{AlC}$ & $\mathrm{Mn}_{2} \mathrm{GaC}$ \\
\hline $\mathrm{FM}$ & 0.1 & 0.0 & 0.0 & 1.4 & 0.3 \\
$\mathrm{AFM}[0001]_{2}^{A}$ & 0.1 & 0.0 & 0.0 & 1.5 & 0.4 \\
$\mathrm{AFM}[0001]_{2}^{X}$ & 0.1 & 0.0 & 0.0 & 1.5 & 0.2 \\
$\mathrm{AFM}[0001]_{1}$ & 0.0 & 0.0 & 0.0 & 1.9 & 1.2 \\
$\mathrm{in}-\mathrm{AFM} 1$ & 0.2 & 0.4 & 0.5 & 1.5 & 0.8 \\
$\mathrm{in}-\mathrm{AFM} 2$ & 0.1 & 0.1 & 0.3 & 1.3 & 0.0 \\
$\mathrm{AFM}[0001]_{4}^{A}$ & 0.0 & 0.0 & 0.1 & 1.6 & 0.2 \\
$\mathrm{AFM}[0001]_{4}^{X}$ & 0.0 & 0.0 & 0.1 & 1.5 & 0.3 \\
\hline$a_{\mathrm{NM}}(\AA ̊)$ & 2.844 & 2.871 & 2.937 & 2.824 & 2.892 \\
\hline \hline
\end{tabular}

Table 17. Relative change in lattice parameter $c$ (in \%) for different magnetic configurations relative NM for five $M_{2} A C$ phases. Values for are NM given in bottom row.

\begin{tabular}{cccccc}
\hline \hline \multirow{2}{*}{$\begin{array}{c}\text { Magnetic } \\
\text { configuration }\end{array}$} & \multicolumn{5}{c}{$\Delta c$ relative $\mathrm{NM}(\%)$} \\
\cline { 2 - 6 } & $\mathrm{Cr}_{2} \mathrm{AlC}$ & $\mathrm{Cr}_{2} \mathrm{GaC}$ & $\mathrm{Cr}_{2} \mathrm{GeC}_{2}$ & $\mathrm{Mn}_{2} \mathrm{AlC}$ & $\mathrm{Mn}_{2} \mathrm{GaC}$ \\
\hline $\mathrm{FM}$ & -0.1 & 0.0 & -0.1 & -0.2 & 0.6 \\
$\mathrm{AFM}[0001]_{2}^{A}$ & -0.1 & 0.0 & 0.0 & 1.9 & 2.2 \\
$\mathrm{AFM}[0001]_{2}^{X}$ & -0.1 & 0.0 & 0.1 & -1.0 & -0.2 \\
$\mathrm{AFM}[0001]_{1}$ & 0.0 & 0.0 & 0.0 & -0.2 & 0.2 \\
$\mathrm{in}-\mathrm{AFM} 1$ & 0.2 & 0.1 & -0.1 & 0.1 & 0.4 \\
$\mathrm{in}-\mathrm{AFM} 2$ & -0.1 & 0.0 & -0.2 & 0.0 & 1.1 \\
$\mathrm{AFM}[0001]_{4}^{A}$ & 0.0 & 0.0 & 0.0 & 0.7 & 1.6 \\
$\mathrm{AFM}[0001]_{4}^{X}$ & 0.0 & 0.0 & 0.1 & -0.7 & 0.0 \\
\hline$c_{\mathrm{NM}}(\AA)$ & 12.707 & 12.531 & 12.036 & 12.466 & 12.211 \\
\hline \hline
\end{tabular}

Choice of magnetic configuration also affect the calculated materials properties, here exemplified by the bulk modulus $B_{0}$. In the $M_{2} \mathrm{AlC}$ series $(M=\mathrm{Ti}, \mathrm{V}, \mathrm{Cr})$ there has been an ongoing discussion concerning the deviation between first principles calculations and 
experimental results for $\mathrm{Cr}_{2} \mathrm{AlC}$, as opposed to the consistent results obtained for $\mathrm{Ti}_{2} \mathrm{AlC}$ and $\mathrm{V}_{2} \mathrm{AlC}$. This becomes particularly evident when comparing the theoretical and experimental trends for $B_{0}$ in Figure 37. Experiments show an increase in $B_{0}$ when going from Ti to $\mathrm{V}$ but a decrease from $\mathrm{V}$ to $\mathrm{Cr}[94,156]$. Theory on the other hand, shows a steady increase from Ti to $\mathrm{Cr}$ if the MAX phases are treated as NM [145, 157-159]. Several origins of this discrepancy have been investigated like temperature [75] and electron correlation effects using DFT+U $[100,101]$. Note that even though correlation effects may be potentially interesting for many materials, MAX phases have previously been well described by GGA with respect to both stability (Figure 8) and structural properties [77, 137, 160-162]. Without including any temperature effects or correlation effects through adjustable parameters, the bulk modulus was decreased by $10 \%$ for an in-AFM1 spin configuration as compared to NM. This is an improved agreement with experimental trends as illustrated in Figure 37. Similar comparison could not be made for $M_{2} A \mathrm{C}$ series with $A=\mathrm{Ga}$ and $\mathrm{Ge}$ due to lack of experimental data. However, $\mathrm{Cr}_{2} \mathrm{GaC}$ and $\mathrm{Cr}_{2} \mathrm{GeC}$ show similar decrease of $B_{0}$.

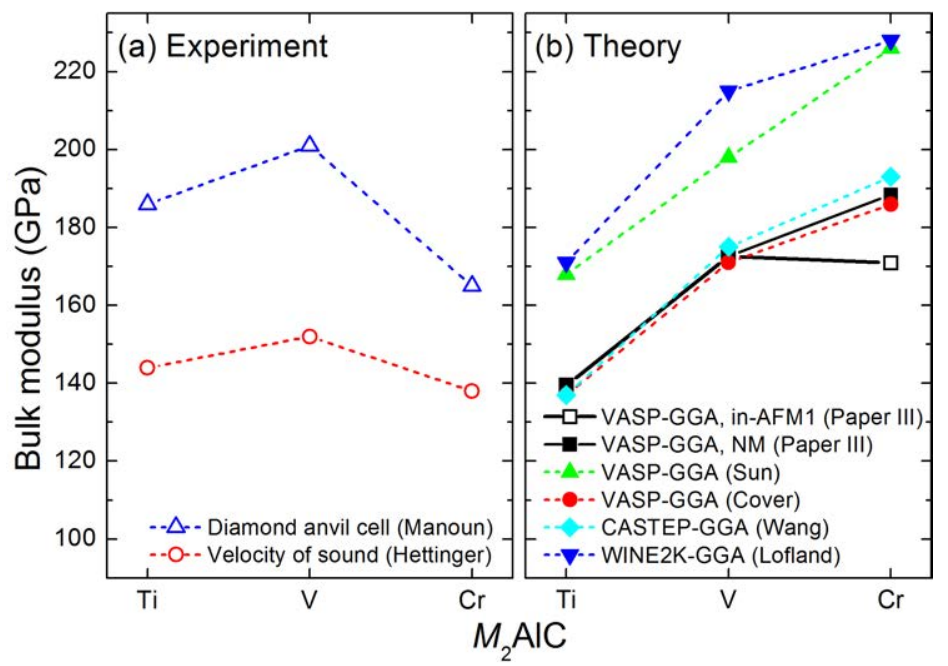

Figure 37. Bulk modulus $B_{0}$ for $M_{2} \mathrm{AlC}$ phases $(M=\mathrm{Ti}, \mathrm{V}, \mathrm{Cr})$, from (a) experimental data (open symbols, dashed lines) [94, 156], (b) our calculated data (square symbols, solid lines) [102] and previously published theoretical results (solid symbols with dashed lines) [145, 157-159].

\subsection{Effects from alloying $\mathrm{Cr}_{2} A \mathrm{C}$ with $\mathrm{Mn}$}

$\mathrm{Cr}_{2} \mathrm{AlC}$ is an experimentally known compound, synthesized already in the 1960 s by Jeitschko et al. [16]. It can be formed using various synthesis methods and under different conditions $[79,163,164]$, and have a theoretical formation enthalpy of $-62 \mathrm{meV} /$ atom which is one of the lowest numbers found (Paper II). One step to the right of $\mathrm{Cr}$ in the periodic table is $\mathrm{Mn}$. It has one additional electron, similar atomic radius as $\mathrm{Cr}$, and it is magnetic. A suggested approach 
of alloying $\mathrm{Cr}_{2} \mathrm{AlC}$ with $\mathrm{Mn}$ to obtain magnetic properties is therefore not that farfetched. Note also that the calculated formation enthalpy of $\mathrm{Mn}_{2} \mathrm{AlC}$ is $+6 \mathrm{meV} /$ atom which is not far from being stable.

In Paper VII the effects on phase stability upon alloying $\mathrm{Cr}_{2} \mathrm{AlC}$ with $\mathrm{Mn}$ was investigated for various spin configurations, amount of $\mathrm{Mn}$, and degree of $\mathrm{Cr}$ and $\mathrm{Mn}$ intermixing. Later the theoretically predicted stable $(\mathrm{Cr}, \mathrm{Mn})_{2} \mathrm{AlC}$ was successfully synthesized [61] followed by alloying $\mathrm{Mn}$ into $\mathrm{Cr}_{2} \mathrm{GeC}$ [62] and $\mathrm{Cr}_{2} \mathrm{GaC}$ [63]. This results in an accessible parameter space with various $\mathrm{Cr} / \mathrm{Mn}$ ratios and $A$-elements, potentially allowing for tunable magnetic properties, such as. transition temperatures and magnetic states..

\subsubsection{Stability $(A=\mathrm{Al})$}

Alloying $\mathrm{Cr}_{2} \mathrm{AlC}$ with $\mathrm{Mn}$ have been investigated for disordered as well as ordered configurations, selected examples are illustrated in Figure 38. Disordered configurations are those expected from experiments, and are achieved by simulating a solid solution of $\mathrm{Cr}$ and Mn on the $M$ sublattice by the SQS method. For ordered configurations, up to 8 consecutive Mn-layers were modelled and the most energetically favorable were those with trilayer blocks of $\mathrm{Mn}-\mathrm{C}-\mathrm{Mn}$, independent on the concentration of $\mathrm{Mn}$. In addition to the chemical configurations studied, different spin configurations were applied; FM, $\mathrm{AFM}[0001]_{2}^{\mathrm{A}},{ }^{28} \mathrm{AFM}[0001]_{1}$, in-AFM1, and DLM.

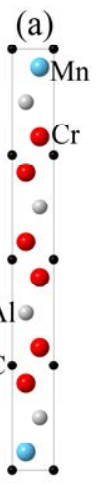

(f)

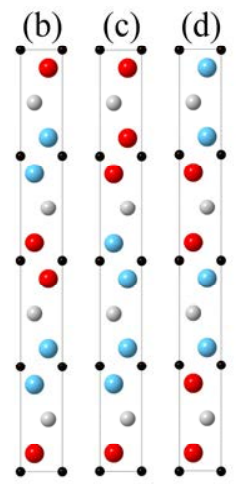

(g)

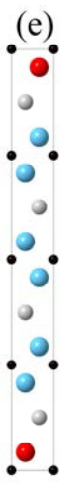

(h)

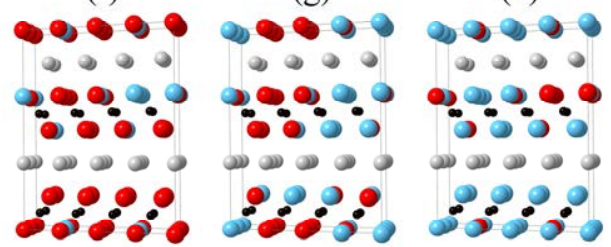

Figure 38. Schematic illustration of ordered (a - e) and disordered ( $\mathrm{f}-\mathrm{h})\left(\mathrm{Cr}_{1-x} \mathrm{Mn}_{x}\right)_{2} \mathrm{AlC}$ for $x$ $=0.25(\mathrm{a}, \mathrm{f}), 0.50(\mathrm{~b}-\mathrm{d}, \mathrm{g})$, and $0.75(\mathrm{e}, \mathrm{h})$.

\footnotetext{
${ }^{28}$ For $\left(\mathrm{Cr}_{1-x} \mathrm{Mn}_{x}\right)_{2} \mathrm{AlC}$ this notation is only focusing on the Mn atoms.
} 
In Table 18 the identified set of most competing phases, including and excluding $\mathrm{Cr}_{2} \mathrm{AlC}$, are given for $\left(\mathrm{Cr}_{1-x} \mathrm{Mn}_{x}\right)_{2} \mathrm{AlC}$. Due to the stability of $\mathrm{Cr}_{2} \mathrm{AlC}$, the set of most competing phases which includes $\mathrm{Cr}_{2} \mathrm{AlC}$ will be lower in energy, and therefore also used in the upcoming results.

Table 18. Identified set of most competing phases (cp) for $\left(\mathrm{Cr}_{1-x} \mathrm{Mn}_{x}\right)_{2} \mathrm{AlC}$ including and excluding $\mathrm{Cr}_{2} \mathrm{AlC}$ as cp.

\begin{tabular}{cll}
\hline \hline & \multicolumn{2}{c}{ Identified set of most competing phases } \\
\cline { 2 - 3 }$x$ & all cp & all cp, excluding MAX phases \\
\hline 0.00 & $\mathrm{Cr}_{2} \mathrm{AlC}$ & $\mathrm{Cr}_{2} \mathrm{Al}, \mathrm{C}_{3} \mathrm{C}_{2}, \mathrm{Al}_{4} \mathrm{C}_{3}$ \\
0.25 & $\mathrm{Cr}_{2} \mathrm{AlC}, \mathrm{MnAl}, \mathrm{C}, \mathrm{Mn}_{3} \mathrm{AlC}$ & $\mathrm{Cr}_{3} \mathrm{C}_{2}, \mathrm{MnAl}, \mathrm{Mn}_{4} \mathrm{Al}_{11}$ \\
0.50 & $\mathrm{Cr}_{2} \mathrm{AlC}, \mathrm{MnAl}, \mathrm{C}, \mathrm{Mn}_{3} \mathrm{AlC}$ & $\mathrm{MnAl}, \mathrm{C}, \mathrm{Cr}_{3} \mathrm{C}_{2}$ \\
0.75 & $\mathrm{Cr}_{2} \mathrm{AlC}, \mathrm{MnAl}, \mathrm{C}, \mathrm{Mn}_{3} \mathrm{AlC}$ & $\mathrm{MnAl}, \mathrm{C}, \mathrm{Mn}_{3} \mathrm{AlC}, \mathrm{C}_{3} \mathrm{C}_{2}$ \\
1.00 & $\mathrm{MnAl}, \mathrm{C}, \mathrm{Mn}_{3} \mathrm{AlC}$ & $\mathrm{MnAl}, \mathrm{C}, \mathrm{Mn}_{3} \mathrm{AlC}$ \\
\hline \hline
\end{tabular}

In Figure 39 the formation enthalpy $\Delta H_{c p}$ for ordered and disordered configurations of $\left(\mathrm{Cr}_{1-}\right.$ $\left.{ }_{x} \mathrm{Mn}_{x}\right)_{2} \mathrm{AlC}$ is shown. Ordered systems have negative values of $\Delta H_{c p}$ with a minimum of -10 $\mathrm{meV} /$ atom for a Mn-C-Mn configuration at $x=0.50$, corresponding to (b) in Figure 38. This ordered FM state is also found to be degenerate with $\operatorname{AFM}[0001]_{2}^{A}$. In comparison, ordered configurations (c) and (d) are higher in energy by $+7 \mathrm{meV} /$ atom and $+25 \mathrm{meV} / \mathrm{atom}$, respectively. In common for (b) and (c) are the Mn-C-Mn trilayer which seems energetically favorable as compared to other chemical configurations.

Disordered configurations, on the other hand, show positive values of $\Delta H_{c p}$, with a maximum of $+12 \mathrm{meV} /$ atom for the FM magnetic states at $x=0.50$. Note that FM is favorable as compared to AFM states. However, at elevated temperatures, the configurational entropy due to the solid solution of $\mathrm{Cr}$ and $\mathrm{Mn}$ will lower the displayed curve, e.g., at $600 \mathrm{~K} \Delta H_{c p}$ is estimated to $-6 \mathrm{meV} / \mathrm{atom}$. 


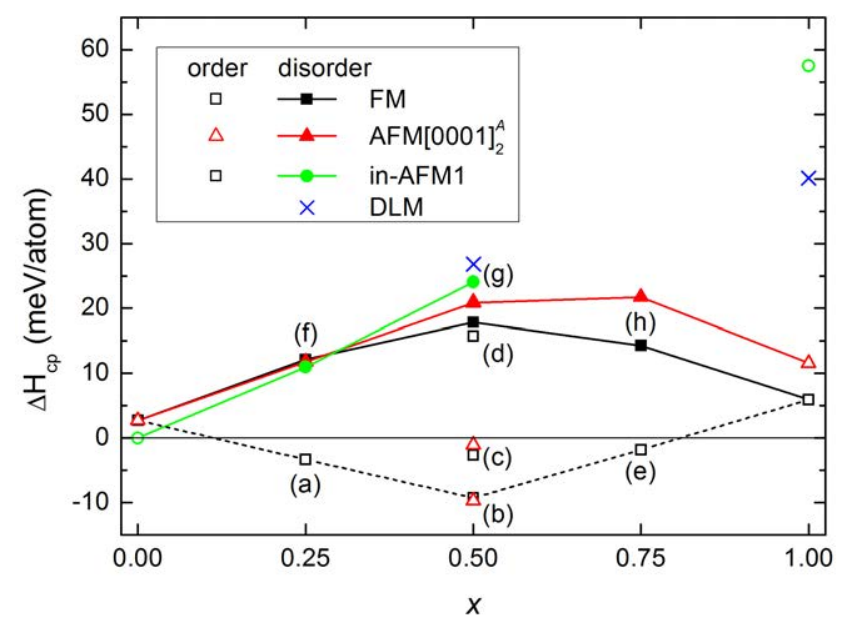

Figure 39. Calculated formation enthalpy $\Delta H_{c p}$ for configurationally ordered (open symbols) and disordered (filled symbols) FM and various AFM states of $\left(\mathrm{Cr}_{1-x} \mathrm{M}_{x}\right)_{2} \mathrm{AlC}$. Letters within parenthesis corresponds to schematics in Figure 38.

Magnetic moments for ordered (Figure 40) and disordered (Figure 41) configurations show that the major contribution to magnetism comes from Mn atoms (around $2 \mu_{\mathrm{B}}$ ). Cr moments instead show an evident dependence on surrounding atoms. Ordered systems, with layers of $\mathrm{Cr}$ (and $\mathrm{Mn}$ ), have $\mathrm{Cr}$ moments of about $1 / 8^{\text {th }}$ relative to those of $\mathrm{Mn}$. Note that for the low energy configurations, with blocks of $\mathrm{Mn}-\mathrm{C}-\mathrm{Mn}$ and $\mathrm{Cr}-\mathrm{C}-\mathrm{Cr}$ trilayers (a - $\mathrm{d}$ in Figure 40), $\mathrm{Cr}$ atoms adjacent to a Mn-layer always have the same orientation as the Mn moment. When there is a mixture of $\mathrm{Cr}$ and $\mathrm{Mn}$ within a M-layer, i.e. disordered solutions, an increase of the (average) $\mathrm{Cr}$ moments is clear, 0.5 to $0.7 \mu_{\mathrm{B}}$ depending on magnetic state and amount of $\mathrm{Mn}$ $(x)$. From this information the exchange coupling between $\mathrm{Cr}$ and $\mathrm{Mn}$ atoms seem to be dependent on the underlying chemical ordering. 

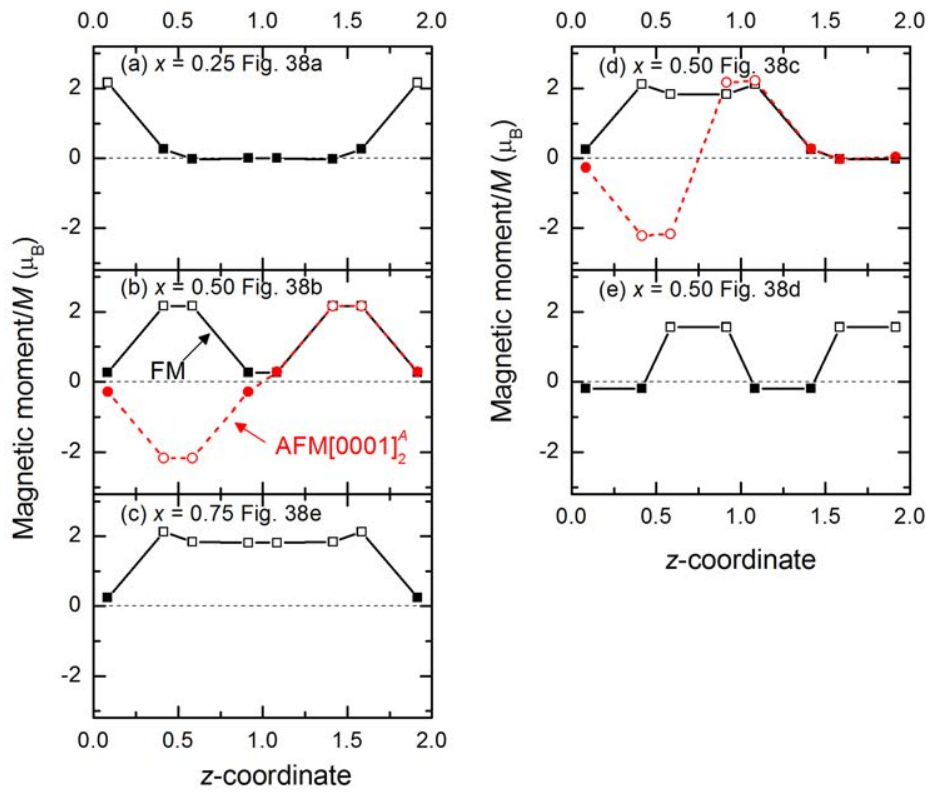

Figure 40. Local magnetic moments for $\mathrm{Cr}$ (filled symbols) and $\mathrm{Mn}$ (open symbols) of ( $\mathrm{Cr}_{1-}$ $\left.{ }_{x} \mathrm{Mn}_{x}\right)_{2} \mathrm{AlC}$ ordered configurations shown in Figure 38 for FM (squares) and AFM[0001] $]_{2}^{A}$ (circles) magnetic configurations. Note that $\mathrm{z}$-coordinates are given in fractions of a $1 \times 1 \times 1$ unit cell.
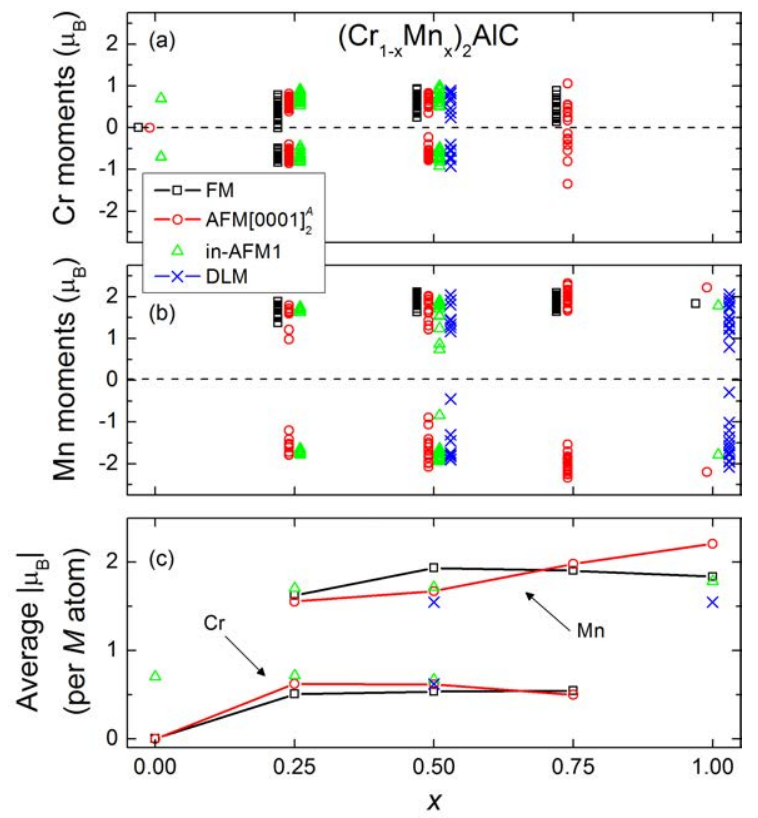

Figure 41. Local magnetic moments of (a) $\mathrm{Cr}$ and (b) $\mathrm{Mn}$ of $\left(\mathrm{Cr}_{1-x} \mathrm{Mn}_{x}\right)_{2} \mathrm{GaC}$ for $\mathrm{FM}(\square)$, $\operatorname{AFM}[0001]_{2}^{A}(\circ)$, in-AFM1 $(\Delta)$, and DLM $(\times)$ magnetic states. (c) Average of the absolute moments. 


\subsubsection{Intermixing - from order to disorder $(A=\mathrm{Al})$}

$\left(\mathrm{Cr}_{0.50} \mathrm{Mn}_{0.50}\right)_{2} \mathrm{AlC}$ in Figure 39 have degenerate ground states for ordered Mn-C-Mn configurations, while the FM state is energetically favorable for the solid solution. To evaluate the states between these configurations, Figure 42 show a detailed evaluation of the energies when going from chemical order to disorder, by gradually increasing the intermixing of $\mathrm{Cr}$ into the $\mathrm{Mn}-\mathrm{C}-\mathrm{Mn}$ trilayers, and conversely $\mathrm{Mn}$ into the $\mathrm{Cr}-\mathrm{C}-\mathrm{Cr}$ trilayers. Panel (a) displays a gradual increase of $\Delta H_{c p}$ with increasing disorder. Ppanel (b) show the energy for different AFM states relative to FM configuration. For complete order the FM and $\mathrm{AFM}[0001]_{2}^{A}$ are considered as degenerate states with an energy difference of just 0.4 meV/atom in favor of AFM. This can be compared to the result for disordered $\mathrm{Mn}$ and $\mathrm{Cr}$ moments (DLM state) at $+23 \mathrm{meV} /$ atom. This ground-state degeneracy is present up to a semi-degree of intermixing followed by a stabilization of the FM state at increased disorder. For complete disorder of $\mathrm{Cr}$ and $\mathrm{Mn}, \mathrm{FM}$ is most stable, 3 mwV/atom below AFM[0001 $]_{2}^{A}$ and other AFM states. Compared to DLM the difference is $10 \mathrm{meV} / \mathrm{atom}$.

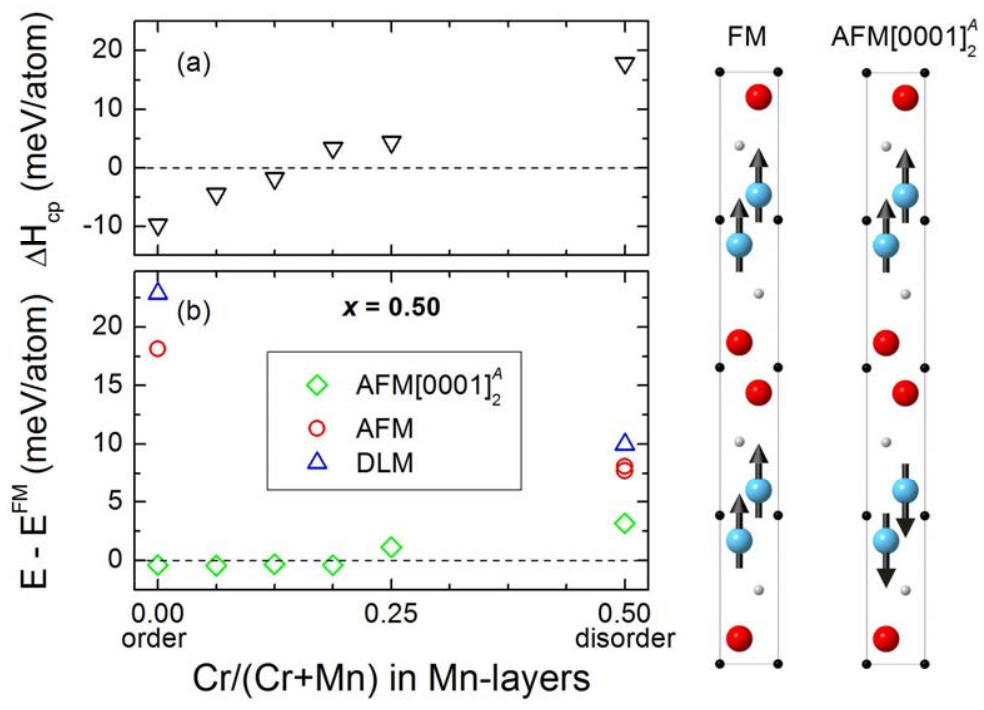

Figure 42. (a) Formation enthalpy of $\left(\mathrm{Cr}_{0.5} \mathrm{Mn}_{0.5}\right) 2 \mathrm{AlC}$ in its most stable magnetic state, and (b) the energy of AFM[0001 $]_{2}^{A}$, AFM, and DLM states relative to the FM state, as a function of the degree of $M$-site intermixing. The latter is defined as $\mathrm{Cr}$ concentration in Mn-C-Mn trilayers where 0 and 0.50 corresponds to configurations (b) and (g) in Figure 38.

\subsection{Magnetic ground state of $\mathrm{Mn}_{2} \mathrm{GaC}$}

From experiments it is known that $\mathrm{Mn}_{2} \mathrm{GaC}$ is magnetic, but the details of the magnetic ground state remains to be determined [27]. Figure 30 shows that spin configurations with 
spins aligned parallel within a Mn-C-Mn trilayer, FM and AFM $[0001]_{\alpha}^{A}$, are energetically favored, with $\alpha=4$ of lowest energy as compared to other collinear spin configurations. However, as there can be magnetic states which have been overlooked, a magnetic groundstate search is justified.

\subsubsection{Super-moment model}

In order to perform a complete magnetic ground-state search, large structures are needed to avoid limiting size effects. Also magnetic exchange interaction (MEI) parameters are required. However, we instead make use of the information in Figure 30 that spins aligned parallel within a Mn-C-Mn trilayer are energetically favored, i.e. FM and AFM[0001 $]_{z}^{A}(z=2$, $4,6,8)$. A coarse-grained model was proposed in Paper IX where each trilayer is seen as a super-moment. Hence, within a super-moment the magnetic interaction of $\mathrm{Mn}$ atoms within layers and across the C-layer is neglected. Only magnetic interactions between different trilayers are considered, and the model can thus be seen as an atomic chain. A schematic of this coarse-grained super-moment model is illustrated in Figure 43. The spin correlation functions $\Phi_{\alpha}$ shown in Table 19 are obtained through use of Eq. (16) for the first four supermoment coordination shells of each of the five magnetic structures.

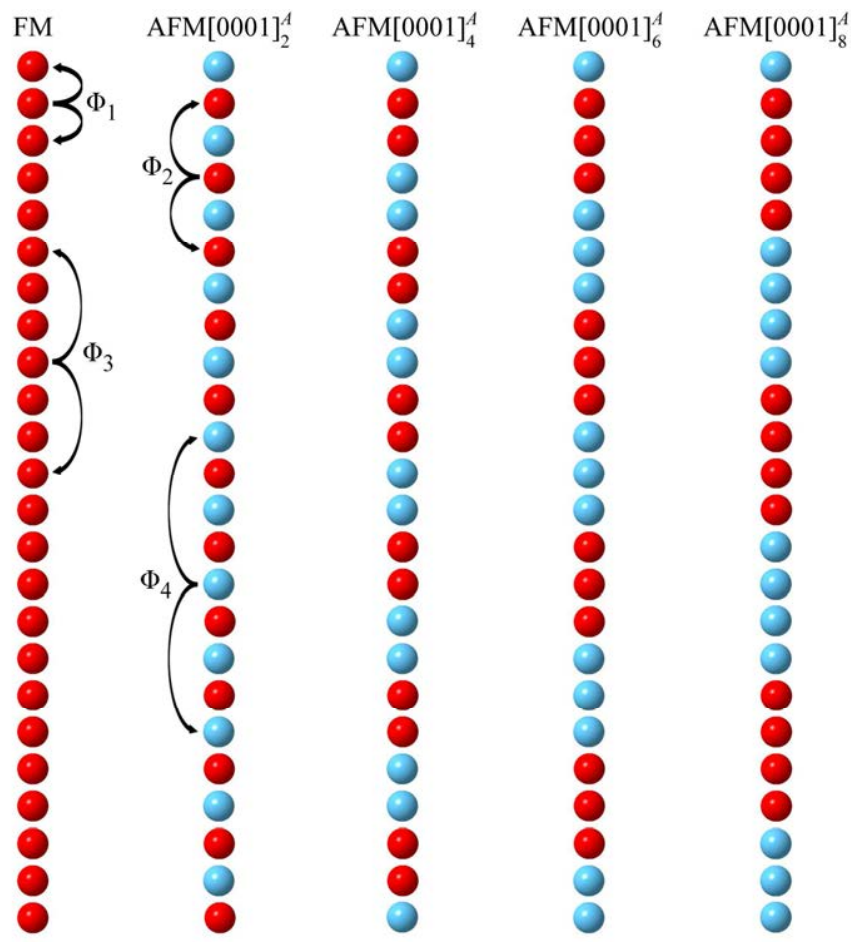

Figure 43. Super-moment model for the five low-energy collinear magnetic spin configurations of $\mathrm{Mn}_{2} \mathrm{GaC}$ in Figure 30. Here the magnetic chains are constructed by 30 super-moment beads. Note that the spin-correlation function $\Phi_{\alpha}$ for the four nearest neighbors are specified by arrows. 
Table 19. Spin correlation function $\Phi_{\alpha}$ for the four nearest neighbor super-moments $(\alpha=1,2$, 3,4 ) for the coarse-grained model illustrated in Figure 43.

\begin{tabular}{ccccc}
\hline \hline & \multicolumn{4}{c}{ Spin correlation function $\Phi_{\alpha}$} \\
\cline { 2 - 5 } Magnetic state & $\Phi_{1}$ & $\Phi_{2}$ & $\Phi_{3}$ & $\Phi_{4}$ \\
\hline $\mathrm{FM}$ & 1 & 1 & 1 & 1 \\
$\mathrm{AFM}[0001]_{2}^{A}$ & -1 & 1 & -1 & 1 \\
$\mathrm{AFM}[0001]_{4}^{A}$ & 0 & -1 & 0 & 1 \\
$\mathrm{AFM}[0001]_{6}^{A}$ & $1 / 3$ & $-1 / 3$ & -1 & $-1 / 3$ \\
$\mathrm{AFM}[0001]_{8}^{A}$ & $1 / 2$ & 0 & $-1 / 2$ & -1 \\
\hline \hline
\end{tabular}

For crystalline materials with magnetic configurational freedom the magnetization energy can be mapped onto a semi-classical model Hamiltonian like the Heisenberg model. This results in an effective Hamiltonian which describes magnetic interactions. Assuming fixed, or at least close to fixed, moments, i.e. variation of the spin direction under influence of temperature is slower than the adaption of the electronic system to the given set of directions, this model Hamiltonian reads as

$$
\mathcal{H}=-\sum_{i \neq j} J_{i j} \mathbf{e}_{i} \cdot \mathbf{e}_{j},
$$

where $J_{i j}$ 's being the MEI between pairs of magnetic atoms $(i, j)$ with unit vectors $\mathbf{e}_{i}$ and $\mathbf{e}_{j}$ along the local magnetic moment at site $i$ and $j$. This can be used in Heisenberg Monte Carlo (HMC) simulations to find the ground state magnetic configurations, or to obtain critical ordering temperatures. Here the focus will be on a ground state search. The volume dependent exchange interactions $J_{i j}$, or MEI, between super-moments (assumed as spin up (+1) or spin down (-1)) of the Heisenberg Hamiltonian were derived for the first four super-moment coordination shells. For this the magnetic Connolly-Williams structure inversion method was used, involving theenergies in Figure 30 and the spin correlation functions in Table 19 [165, 166]. In Figure 44 MEI for the nearest neighbor super-moments $J_{1}$ show a strong volume dependence favoring FM at small volumes and AFM at large volumes. 


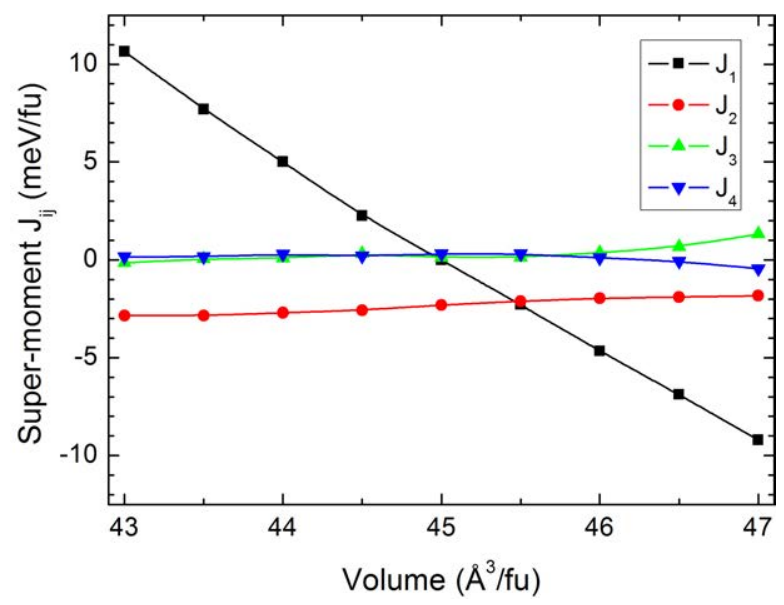

Figure 44. Super-moment magnetic exchange interaction parameters $J_{i j}$ for the first four coordination shells of the coarse-grained model illustrated Figure 43.

Based on the MEI's in Figure 44 and the model Hamiltonian in Eq.(17), a ground-state search was performed at different volumes, using the HMC approach. In order to avoid frustrated solutions, different super-moment chain lengths, between 8 and 36 beads, have been tested. Of interest here are only those chain lengths that display a minimum energy for a given set of MEI. In Figure 45 the magnetic properties concluded from these minima are shown. Panel (a) show a net magnetization of 1 up to volumes of $43.1 \AA^{3} / f u$, corresponding to a FM state. At $43.2 \AA^{3} /$ fu there is a sharp transition from a FM state to configurations with zero, or close to zero, net magnetization. Panel (b) display the angle of nearest neighbor spin vectors $\theta_{1}$ which is $\sim 0^{\circ}$ for FM. From the transition volume and above, $\theta_{1}$ increases continuously resulting in different noncollinear spin spiral solutions. The only exception is found at $45 \AA^{3} / \mathrm{fu}$ with an angle distribution between $2^{\circ}$ and $177^{\circ}$. A few selected identified states are illustrated in Figure 46. 


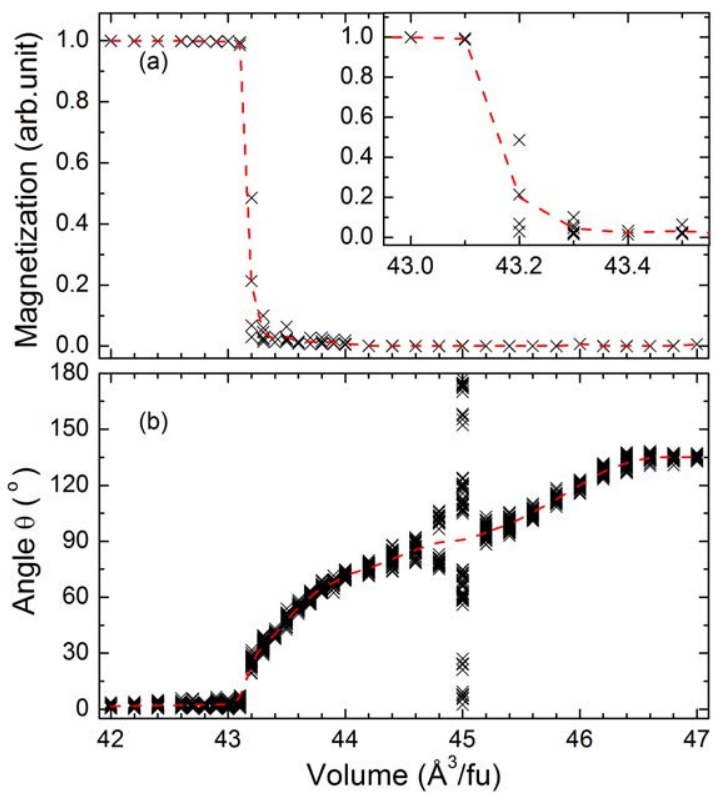

Figure 45. (a) Net magnetization of low energy configurations and (b) angle between nearest neighbor superatom spins as a function of volume for HMC simulations. Data for different chain lengths of minimum energy shown as $\times$ and corresponding average by red dashed lines. Inset in (a) show a close up of the transition from FM to AFM.

(a)

$\begin{array}{cc}\text { top } \\ \text { view } \\ \text { side } \\ \text { view } \\ & \vdots \\ & \vdots \\ & \vdots \\ & \bullet \\ & \bullet\end{array}$

(b)

(c)
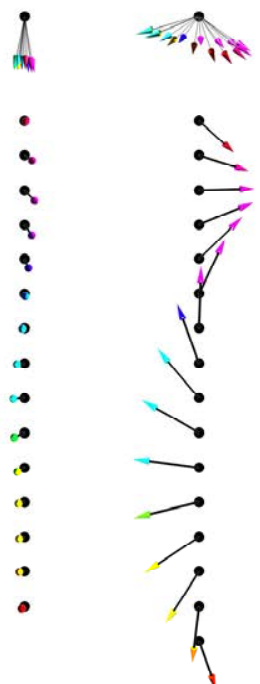

(d)
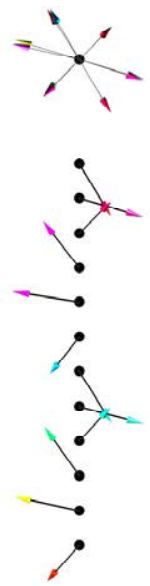

(e)
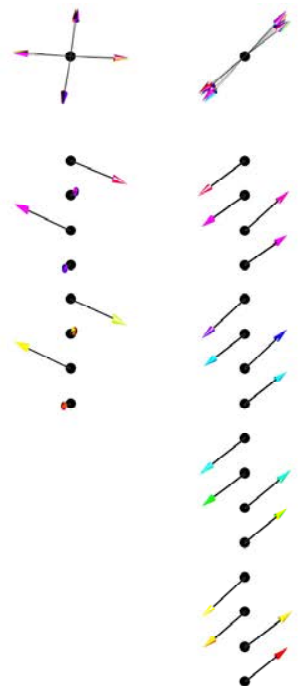

(g)
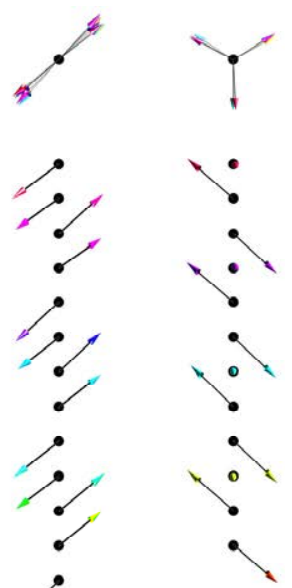

Figure 46. Examples of magnetic states at different volumes as obtained from HMC simulations. Chosen volumes are (a) 43.0, (b) 43.1, (c) 43.2, (d) 43.7, (e) and (f) 45.0, and (g) $46.0 \AA^{3} / \mathrm{fu}$. 


\subsubsection{Noncollinear configurations}

In an attempt to use these proposed spin spiral magnetic structure and obtain first-principles energies, the atoms are treated individually. The notation used for describing the spin spirals is $\operatorname{AFM}[0001]_{\alpha}^{A, \beta}$ where $\alpha$ is the number of consecutive $M$-layers with same spin vector and $\beta$ the rotation of the spin vector (in degrees) when passing the $A$-layer. For collinear AFM states $\beta=180^{\circ}$ whereas FM magnetic states have $\beta=0^{\circ}$. Seven different spin spirals have been evaluated, six of them proposed from the Monte Carlo simulations. Further information on structural and magnetic parameters for $\mathrm{AFM}[0001]_{\alpha}^{A, \beta}$ spin spiral states of $\mathrm{Mn}_{2} \mathrm{GaC}$, see Paper IX.

To compare the calculated spin spiral energies from VASP with the HMC energies. The latter can be calculated at different volumes using

$$
E^{\mathrm{HMC}}[V]=-n_{\alpha} \sum_{i=1}^{4} J_{i}[V] \cos \theta_{i}
$$

where $n_{\alpha}$ are equal to $2, J_{i}[\mathrm{~V}]$ the volume dependent MEI Figure 44, and $\theta_{i}$ the spin vector for coordination shell $i$ as obtained from the HMC simulation. In order to make VASP and HMC energies comparable we have to look at relative energies with the FM state as reference according to

$$
\Delta E^{\mathrm{HMC}}[V]=E_{\text {spin spiral }}^{\mathrm{HMC}}[V]-E_{\mathrm{FM}}^{\mathrm{HMC}}[V],
$$

and

$$
\Delta E^{\mathrm{VASP}}[V]=E_{\mathrm{spin} \text { spiral }}^{\mathrm{VASP}}[V]-E_{\mathrm{FM}}^{\mathrm{VASP}}[V]
$$

In Figure 47, the energy differences calculated by Eq.(19) and (20) demonstrate an overall resemblance between results from HMC and VASP. The transition from FM to AFM for here considered super-moment spin configurations, occurs at volume $43.3 \AA^{3} / \mathrm{fu}$ for the HMC and at $43.8 \AA 3$ /fu for VASP. In HMC the lowest energy solution varies with increasing volume

$$
\begin{aligned}
& \mathrm{FM} \rightarrow \operatorname{AFM}[0001]_{2}^{A, 45} \rightarrow=\operatorname{AFM}[0001]_{2}^{A, 60} \rightarrow \operatorname{AFM}[0001]_{2}^{A, 90}=\operatorname{AFM}[0001]_{2}^{A, 74,106} \\
& =\operatorname{AFM}[0001]_{2}^{A, 8,172} \rightarrow \operatorname{AFM}[0001]_{2}^{A, 120} .
\end{aligned}
$$

For VASP the low energy states with increasing volume are

$$
\mathrm{FM} \rightarrow \operatorname{AFM}[0001]_{4}^{A, 180} \approx \operatorname{AFM}[0001]_{2}^{A, 8,172} \rightarrow \operatorname{AFM}[0001]_{2}^{A, 120} \rightarrow \operatorname{AFM}[0001]_{2}^{A, 180}
$$


The largest discrepancy is found at intermediate volumes where the HMC simulations identify three spin configurations with similar or equal energy, which can be related to very similar spin vector $\theta_{i}$ averages. Within VASP these are separated as individual atoms and atomic layers can relax individually resulting in slightly different energies.

The major difference between the super-moment model used for creating $\Delta E^{\mathrm{HMC}}$ and the atomistic model for $\Delta E^{\mathrm{VASP}}$ can be related to the structure. For the atomistic model each spin configurations has a characteristic geometrical structure with given, e.g., interlayer distances and lattice parameters (compare FM and AFM $[0001]_{4}^{A}$ in Figure 35. In the super atom model the interlayer distances are equivalent for all spin configurations. In order to investigate this effect, different AFM spin configurations have been evaluated using the FM geometrical structure. In this way, the structural effects are minimized, and primary focus is instead on magnetic interactions, as is the case for the super-moment model. As a result, even better similarity between the results from $\Delta E^{\mathrm{HMC}}$ and $\Delta E^{\mathrm{VASP}}$ is found.

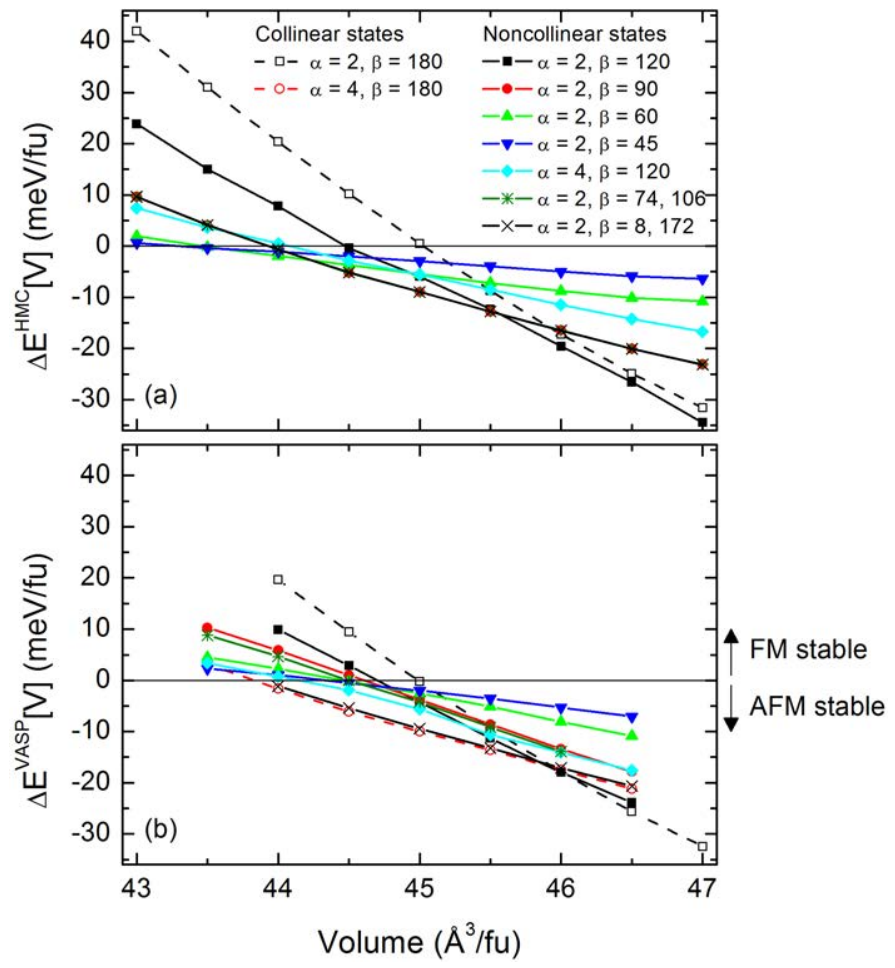

Figure 47. Energy difference of AFM vs FM spin configurations as function of volume for (a) HMC based energies, and (b) from first-principles with VASP. For $\Delta E>0$ the FM is lowest in energy and for $\Delta E<0$ the AFM spin configuration is favored. Note that in (a) three curves overlap with each other; $(\alpha=2, \beta=90),(\alpha=2, \beta=74,106)$, and $(\alpha=2, \beta=8,172)$, due to very similar averages of the spin vector $\theta_{i}$. 

"Naugels, Isaac Newton, Scientific EZ

Ben Franklin with the kite, getting over with the key Now rock shocking with the mic, of the many times times the time tables Rock well to dispel all of the old fables"

The sounds of science, Beastie Boys

\section{CONTRIBUTION TO THE FIELD}

Within this Thesis, examples of new nanolaminated MAX phase materials have been presented, investigated through use of first-principles calculations.

Phase stability calculations based on the here developed approach confirm previous experimental findings for a large set of ternary systems. This validation gives credential to the approach, and show that it is suitable for, but possibly not limited to, MAX phase predictions. Two new MAX phases, $\mathrm{Nb}_{2} \mathrm{GeC}$ and $\mathrm{Mn}_{2} \mathrm{GaC}$, have been predicted to be stable with subsequent successful synthesis. $\mathrm{Nb}_{2} \mathrm{GeC}$ is the first $\mathrm{M}_{2} \mathrm{AX}$ phase synthesized since the $1960 \mathrm{~s}$ whereas $\mathrm{Mn}_{2} \mathrm{GaC}$ is the first phase with $\mathrm{Mn}$ as sole $M$-element. Hence, phase stability calculations are shown to be a valuable tool for finding virtually stable materials before timeconsuming attempts are made in the laboratory. Moreover, the theory can also be used to understand trends in phase stability as a function of chemical composition, further aiding predictions of new, stable materials.

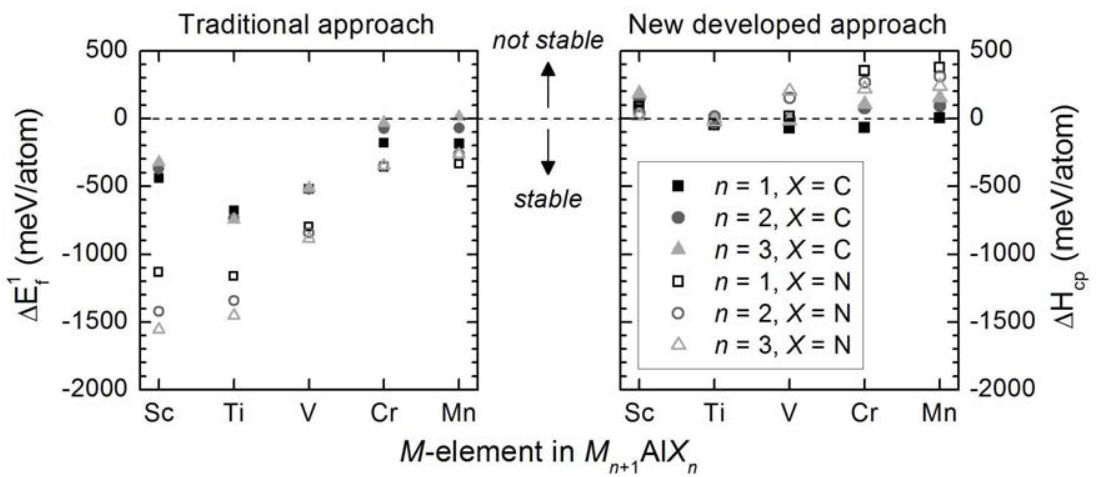

Figure 48. Comparison of traditional approach and the here developed approach for predicting stability of MAX phases. 
The theoretical phase stability approach has also been used to investigate MAX phase alloys. Incorporation of oxygen in synthesized MAX phases indicates different location of oxygen depending on choice of $M$-element. From both phase stability calculations and electronic structure analysis it has been suggested to be related to the number of $M d$-electrons. For $\mathrm{Ti}_{2} \mathrm{AlC}$, the calculations show that oxygen act as a stabilizer, which can explain the large amount (12.5 at\%) of oxygen found in synthesized samples.

In the last two years, experimental confirmation of magnetic MAX phases has been presented. Furthermore, it has been theoretically demonstrated that there are many possible magnetic spin configurations for the MAX phase structure. Diverging approaches and approximations have shown that the choice of spin configuration is of importance for phase stability predictions, identification of magnetic ground-state, and for evaluation of selected properties. The well-known $\mathrm{Cr}_{2} A \mathrm{C}(\mathrm{Al}=\mathrm{Al}, \mathrm{Ga}, \mathrm{Ge})$ phases have here been predicted to have an in-plane AFM as a low energy state, and the effect of electron-correlation approximation on this result is believed to be of minor importance, as compared to the choice of spin configuration. Alloying $\mathrm{Cr}_{2} A \mathrm{C}$ with $\mathrm{Mn}$ to obtain magnetic properties is also predicted to give both $\mathrm{FM}$ and AFM configurations, depending on both chemical composition and chemical order/disorder. Magnetic MAX phases in all these systems, $\mathrm{Cr}_{2} A \mathrm{C}(\mathrm{Al}=\mathrm{Al}, \mathrm{Ga}, \mathrm{Ge})$, have been experimentally synthesized, and a magnetic response verified. Advancing beyond alloying, the pure $\mathrm{Mn}_{2} \mathrm{GaC}$ has been predicted to have a large number of exotic low-energy magnetic states, with a spin-canted multilayered AFM suggested as the magnetic ground-state at low temperatures. The indicated complex magnetism remains to be experimentally verified. 
"From up and down, and still somehow

It's cloud illusions I recall I really don't know clouds at all" Both sides now, Joni Mitchell

\section{7}

\section{BIBLIOGRAPHY}

[1] W. Lowrie, Fundamentals of Geophysics (Cambridge University Press, New York, 2007).

[2] P. Grünberg, R. Schreiber, Y. Pang, M. B. Brodsky, and H. Sowers, Phys. Rev. Lett. 57, 2442 (1986).

[3] M. N. Baibich, J. M. Broto, A. Fert, F. N. Van Dau, F. Petroff, P. Etienne, G. Creuzet, A. Friederich, and J. Chazelas, Phys. Rev. Lett. 61, 2472 (1988).

[4] G. Binasch, P. Grünberg, F. Saurenbach, and W. Zinn, Phys. Rev. B 39, 4828 (1989).

[5] D. T. Pierce, J. Unguris, R. J. Celotta, and M. D. Stiles, J. Magn. Magn. Mater. 200, 290 (1999).

[6] A. Schreyer, J. F. Ankner, T. Zeidler, H. Zabel, M. Schäfer, J. A. Wolf, P. Grünberg, and C. F. Majkrzak, Phys. Rev. B 52, 16066 (1995).

[7] C. A. F. Vaz, J. A. C. Bland, and G. Lauhoff, Rep. Prog. Phys. 71, 056501 (2008).

[8] D. T. Pierce, A. D. Davies, J. A. Stroscio, D. A. Tulchinsky, J. Unguris, and R. J. Celotta, J. Magn. Magn. Mater. 222, 13 (2000).

[9] D. A. Tulchinsky, J. Unguris, and R. J. Celotta, J. Magn. Magn. Mater. 212, 91 (2000).

[10] M. W. Barsoum, Prog. Solid State Chem. 28, 201 (2000).

[11] P. Eklund, M. Beckers, U. Jansson, H. Högberg, and L. Hultman, Thin Solid Films 518, 1851 (2010).

[12] J. Rosen, M. Dahlqvist, S. I. Simak, D. R. McKenzie, and M. M. M. Bilek, Appl. Phys. Lett. 97, 073103 (2010).

[13] W. Luo and R. Ahuja, J. Phys. Cond. Matter 20, 064217 (2008).

[14] M. Dahlqvist, B. Alling, I. A. Abrikosov, and J. Rosen, Phys. Rev. B 84, 220403 (2011).

[15] H. Nowotny, Prog. Solid State Chem. 5, 27 (1971).

[16] W. Jeitschko, H. Nowotny, and F. Benesovsky, Monatshefte für Chemie 94, 672 (1963).

[17] W. Jeitschko, H. Nowotny, and F. Benesovsky, Monatsh. Chem. 94, 844 (1963). 
[18] W. Jeitschko, H. Nowotny, and F. Benesovsky, Monatshefte für Chemie 94, 1198 (1963).

[19] W. Jeitschko, H. Nowotny, and F. Benesovsky, Monatshefte für Chemie 94, 1201 (1963).

[20] W. Jeitschko, H. Nowotny, and F. Benesovsky, Monatsh. Chem. 95, 178 (1964).

[21] W. Jeitschko, H. Nowotny, and F. Benesovsky, Monatshefte für Chemie 95, 431 (1964).

[22] W. Jeitschko and H. Nowotny, Monatshefte für Chemie 98, 329 (1967).

[23] H. Wolfsgruber, H. Nowotny, and F. Benesovsky, Monatshefte für Chemie 98, 2403 (1967).

[24] M. W. Barsoum and T. El-Raghy, J. Am. Ceram. Soc. 79, 1953 (1996).

[25] M. W. Barsoum, L. Farber, I. Levin, A. Procopio, T. El-Raghy, and A. Berner, J. Am. Ceram. Soc. 82, 2545 (1999).

[26] S. Kuchida, T. Muranaka, K. Kawashima, K. Inoue, M. Yoshikawa, and J. Akimitsu, Physica C: Superconductivity (2013).

[27] A. S. Ingason, et al., Materials Research Letters 2, 89 (2014).

[28] M. I. Aroyo, A. Kirov, C. Capillas, J. M. Perez-Mato, and H. Wondratschek, Acta Crystallogr. Sect. A 62, 115 (2006).

[29] M. I. Aroyo, J. M. Perez-Mato, C. Capillas, E. Kroumova, S. Ivantchev, G. Madariaga, A. Kirov, and H. Wondratschek, Z. Kristall. 221, 15 (2006).

[30] M. I. Aroyo, J. M. Perez-Mato, C. Capillas, E. Kroumova, S. Ivantchev, G. Madariaga, A. Kirov, and H. Wondratschek, Zeitschrift für Kristallographie - Crystalline Materials 221, 15 (2006).

[31] M. I. Aroyo, J. M. Perez-Mato, D. Orobengoa, E. Tasci, G. de la Flor, and A. Kirov, Bulg. Chem. Commun. 43, 183 (2011).

[32] Springer Materials - The Landolt-Börnstein Database, Springer Materials, http://www.springermaterials.com, (2013)

[33] L. Farber, I. Levin, M. W. Barsoum, T. El-Raghy, and T. Tzenov, J. Appl. Phys. 86, 2540 (1999).

[34] Z. W. Wang, C. S. Zha, and M. W. Barsoum, Appl. Phys. Lett. 85, 3453 (2004).

[35] J. Y. Wang and Y. C. Zhou, Phys. Rev. B 69, 144108 (2004).

[36] T. Liao, J. Y. Wang, and Y. C. Zhou, Phys. Rev. B 73, 214109 (2006).

[37] T. Liao, J. Y. Wang, and Y. C. Zhou, J. Phys. Cond. Matter 18, 6183 (2006).

[38] B. Manoun, S. K. Saxena, T. El-Raghy, and M. W. Barsoum, Appl. Phys. Lett. 88, 201902 (2006).

[39] Z. J. Lin, M. J. Zhuo, Y. C. Zhou, M. S. Li, and J. Y. Wang, J. Mater. Res. 21, 2587 (2006).

[40] Z. J. Lin, M. J. Zhuo, Y. C. Zhou, M. S. Li, and J. Y. Wang, J. Mater. Res. 22, 816 (2007).

[41] J. Y. Wang, J. M. Wang, Y. C. Zhou, Z. J. Lin, and C. F. Hu, Scripta Mater. 58, 1043 (2008).

[42] C. J. Rawn, M. W. Barsoum, T. El-Raghy, A. Procipio, C. M. Hoffmann, and C. R. Hubbard, Mater. Res. Bull. 35, 1785 (2000).

[43] Z. Sun, R. Ahuja, and J. M. Schneider, Phys. Rev. B 68, 224112 (2003).

[44] J. Y. Wang and Y. C. Zhou, J. Phys. Cond. Matter 16, 2819 (2004). 
[45] F. L. Meng, Y. C. Zhou, and J. Y. Wang, Scripta Mater. 53, 1369 (2005).

[46] T. Cabioch, P. Eklund, V. Mauchamp, M. Jaouen, and M. W. Barsoum, J. Eur. Ceram. Soc. 33, 897 (2013).

[47] T. Cabioc'h, P. Eklund, V. Mauchamp, and M. Jaouen, J. Eur. Ceram. Soc. 32, 1803 (2012).

[48] M. A. Pietzka and J. C. Schuster, J. Am. Ceram. Soc. 79, 2321 (1996).

[49] R. Arróyave and M. Radovic, Phys. Rev. B 84, 134112 (2011).

[50] M. W. Barsoum, M. Ali, and T. El-Raghy, Metall. Mater. Trans. A 31, 1857 (2000).

[51] Y. L. Du, Z. M. Sun, H. Hashimoto, and M. W. Barsoum, Physics Letters A 374, 78 (2009).

[52] T. Scabarozi, A. Ganguly, J. D. Hettinger, S. E. Lofland, S. Amini, P. Finkel, T. ElRaghy, and M. W. Barsoum, J. Appl. Phys. 104, 073713 (2008).

[53] Y. L. Du, Z. M. Sun, H. Hashimoto, and M. W. Barsoum, Phys Lett A 374, 78 (2009).

[54] J. Rosen, P. O. Å. Persson, M. Ionescu, A. Kondyurin, D. R. McKenzie, and M. M. M. Bilek, Appl. Phys. Lett. 92, 064102 (2008).

[55] M. Baben, L. Shang, J. Emmerlich, and J. M. Schneider, Acta Mater. 60, 4810 (2012).

[56] N. I. Medvedeva, D. L. Novikov, A. L. Ivanovsky, M. V. Kuznetsov, and A. J. Freeman, Phys. Rev. B 58, 16042 (1998).

[57] M. Dahlqvist, B. Alling, I. A. Abrikosov, and J. Rosén, Phys. Rev. B 81, 02411 (2010).

[58] D. P. Sigumonrong, J. Zhang, Y. Zhou, D. Music, J. Emmerlich, J. Mayer, and J. M. Schneider, Scripta Mater. 64, 347 (2011).

[59] G. M. Song, Y. T. Pei, W. G. Sloof, S. B. Li, J. T. M. De Hosson, and S. van der Zwaag, Scripta Mater. 58, 13 (2008).

[60] H. J. Yang, Y. T. Pei, J. C. Rao, J. T. M. De Hosson, S. B. Li, and G. M. Song, Scripta Mater. 65, 135 (2011).

[61] A. Mockute, M. Dahlqvist, J. Emmerlich, L. Hultman, J. M. Schneider, P. O. Å. Persson, and J. Rosen, Phys. Rev. B 87, 094113 (2013).

[62] A. S. Ingason, et al., Phys. Rev. Lett. 110, 195502 (2013).

[63] S. Lin, P. Tong, B. S. Wang, Y. N. Huang, W. J. Lu, D. F. Shao, B. C. Zhao, W. H. Song, and Y. P. Sun, J. Appl. Phys. 113, 053502 (2013).

[64] Z. J. Lin, M. J. Zhuo, Y. C. Zhou, M. S. Li, and J. Y. Wang, J. Am. Ceram. Soc. 89, 3765 (2006).

[65] J. Zhang, B. Liu, J. Y. Wang, and Y. C. Zhou, J. Mater. Res. 24, 39 (2009).

[66] J. P. Palmquist, et al., Phys. Rev. B 70, 165401 (2004).

[67] H. Högberg, P. Eklund, J. Emmerlich, J. Birch, and L. Hultman, J. Mater. Res. 20, 779 (2005).

[68] N. J. Lane, M. Naguib, J. Lu, P. Eklund, L. Hultman, and M. W. Barsoum, J. Am. Ceram. Soc. 95, 3352 (2012).

[69] N. J. Lane, M. Naguib, J. Lu, L. Hultman, and M. W. Barsoum, J. Eur. Ceram. Soc. 32, 3485 (2012).

[70] X. H. Wang, H. Zhang, L. Zheng, Y. H. Ma, X. Lu, Y. Sun, and Y. C. Zhou, J. Am. Ceram. Soc. 95, 1508 (2012). 
[71] H. Zhang, X. Wang, Y. Ma, L. Sun, L. Zheng, and Y. Zhou, J Adv Ceram 1, 268 (2012).

[72] J. Etzkorn, M. Ade, and H. Hillebrecht, Inorg. Chem. 46, 7646 (2007).

[73] J. Etzkorn, M. Ade, and H. Hillebrecht, Inorg. Chem. 46, 1410 (2007).

[74] J. J. Nickl, K. K. Schweitzer, and P. Luxenberg, J. Less-Common Met. 26, 335 (1972).

[75] J. M. Schneider, D. P. Sigumonrong, D. Music, C. Walter, J. Emmerlich, R. Iskandar, and J. Mayer, Scripta Mater. 57, 1137 (2007).

[76] O. Wilhelmsson, et al., J. Cryst. Growth 291, 290 (2006).

[77] P. Eklund, M. Dahlqvist, O. Tengstrand, L. Hultman, J. Lu, N. Nedfors, U. Jansson, and J. Rosén, Phys. Rev. Lett. 109, 035502 (2012).

[78] O. Wilhelmsson, P. Eklund, H. Högberg, L. Hultman, and U. Jansson, Acta Mater. 56, 2563 (2008).

[79] C. Walter, D. P. Sigumonrong, T. El-Raghy, and J. M. Schneider, Thin Solid Films 515, 389 (2006).

[80] A. Anders and G. Y. Yushkov, J. Appl. Phys. 91, 4824 (2002).

[81] J. Rosen, L. Ryves, P. O. A. Persson, and M. M. M. Bilek, J. Appl. Phys. 101, 056101 (2007).

[82] A. Mockute, M. Dahlqvist, L. Hultman, P. O. Å. Persson, and J. Rosen, J. Mater. Sci. 48, 3686 (2013).

[83] L. H. Thomas, Math. Proc. Cambridge 23, 542 (1927).

[84] E. Fermi, Rend. Accad. Naz. Lincei 6, 602 (1927).

[85] P. Hohenberg and W. Kohn, Phys. Rev. 136, B864 (1964).

[86] W. Kohn and L. J. Sham, Phys. Rev. 140, A1133 (1965).

[87] R. M. Martin, Electronic Structure: Basic Theory and Practical Methods (Cambridge University Press, Cambridge, 2004).

[88] D. G. Anderson, J. ACM 12, 547 (1965).

[89] P. Bendt and A. Zunger, Phys. Rev. B 26, 3114 (1982).

[90] G. P. Srivastava, J. Phys. A: Math. Gen., 2737 (1984).

[91] A. D. Becke, Phys. Rev. A 38, 3098 (1988).

[92] J. P. Perdew and Y. Wang, Phys. Rev. B 45, 13244 (1992).

[93] J. P. Perdew, K. Burke, and M. Ernzerhof, Phys. Rev. Lett. 77, 3865 (1996).

[94] B. Manoun, R. P. Gulve, S. K. Saxena, S. Gupta, M. W. Barsoum, and C. S. Zha, Phys. Rev. B 73, 024110 (2006).

[95] J. Etzkorn, M. Ade, D. Kotzott, M. Kleczek, and H. Hillebrecht, J. Solid State Chem. 182, 995 (2009).

[96] B. Manoun, S. Kulkarni, N. Pathak, S. K. Saxena, S. Amini, and M. W. Barsoum, J. Alloys Compd. 505, 328 (2010).

[97] L. Wang, T. Maxisch, and G. Ceder, Phys. Rev. B 73, 195107 (2006).

[98] E. Finazzi, C. Di Valentin, G. Pacchioni, and A. Selloni, The Journal of Chemical Physics 129 (2008).

[99] B. Himmetoglu, A. Floris, S. de Gironcoli, and M. Cococcioni, International Journal of Quantum Chemistry 114, 14 (2014).

[100] Y. L. Du, Z. M. Sun, H. Hashimoto, and M. W. Barsoum, J. Appl. Phys. 109, 063707 (2011). 
[101] M. Ramzan, S. Lebègue, and R. Ahuja, Phys. Status Solidi Rapid Res. Lett. 5, 122 (2011).

[102] M. Dahlqvist, B. Alling, and J. Rosen, J. Appl. Phys. 113, 216103 (2013).

[103] M. Ramzan, S. Lebègue, and R. Ahuja, Solid State Commun. 152, 1147 (2012).

[104] N. Li, C. C. Dharmawardhana, K. L. Yao, and W. Y. Ching, Solid State Commun. 174, 43 (2013).

[105] N. Li, Y. Mo, and W.-Y. Ching, J. Appl. Phys. 114 (2013).

[106] M. Mattesini and M. Magnuson, J. Phys. Cond. Matter 25, 035601 (2013).

[107] S. L. Dudarev, G. A. Botton, S. Y. Savrasov, C. J. Humphreys, and A. P. Sutton, Phys. Rev. B 57, 1505 (1998).

[108] D. Vanderbilt, Phys. Rev. B 41, 7892 (1990).

[109] P. E. Blöchl, Phys. Rev. B 50, 17953 (1994).

[110] G. Kresse and D. Joubert, Phys. Rev. B 59, 1758 (1999).

[111] G. Kresse and J. Hafner, Phys. Rev. B 48, 13115 (1993).

[112] H. J. Monkhorst and J. D. Pack, Phys. Rev. B 13, 5188 (1976).

[113] A. Zunger, S. H. Wei, L. G. Ferreira, and J. E. Bernard, Phys. Rev. Lett. 65, 353 (1990).

[114] I. A. Abrikosov, S. I. Simak, B. Johansson, A. V. Ruban, and H. L. Skriver, Phys. Rev. B 56, 9319 (1997).

[115] A. V. Ruban and I. A. Abrikosov, Rep. Prog. Phys. 71, 046501 (2008).

[116] B. Alling, T. Marten, and I. A. Abrikosov, Phys. Rev. B 82, 184430 (2010).

[117] B. L. Gyorffy, A. J. Pindor, J. Staunton, G. M. Stocks, and H. Winter, J. Phys. F: Met. Phys. 15, 1337 (1985).

[118] J. Lundgren, M. Rönnqvist, and P. Värbrand, Linjär och ickelinjär optimering (Studentlitteratur, Lund, 2001).

[119] D. A. McQuarrie, Statistical Mechanics (Harper and Row, New York, 1976).

[120] C. Kittel, Introduction to Solid State Physics (Wiley, New York, 1996).

[121] J.-P. Palmquist, Carbide and MAX-Phase Engineering by Thin Film Synthesis (Acta Universitatis Upsaliensis, Uppsala, 2004).

[122] J. Häglund, A. Fernández Guillermet, G. Grimvall, and M. Körling, Phys. Rev. B 48, 11685 (1993).

[123] A. Fernández Guillermet and G. Grimvall, Phys. Rev. B 40, 10582 (1989).

[124] C. M. Fang, R. Ahuja, and O. Eriksson, J. Appl. Phys. 101, 013511 (2007).

[125] A. Grechnev, S. Li, R. Ahuja, O. Eriksson, U. Jansson, and O. Wilhelmsson, Appl. Phys. Lett. 85, 3071 (2004).

[126] V. J. Keast, S. Harris, and D. K. Smith, Phys. Rev. B 80, 214113 (2009).

[127] A. J. Thom, V. G. Young, and M. Akinc, J. Alloys Compd. 296, 59 (2000).

[128] J. J. Williams, Y. Y. Ye, M. J. Kramer, K. M. Ho, L. Hong, C. L. Fu, and S. K. Malik, Intermetallics 8, 937 (2000).

[129] C. Höglund, J. Birch, M. Beckers, B. Alling, Z. Czigány, A. Mücklich, and L. Hultman, European Journal of Inorganic Chemistry 2008, 1193 (2008).

[130] J. C. Schuster and J. Bauer, J. Less-Common Met. 109, 345 (1985).

[131] M. Kirchner, W. Schnelle, F. R. Wagner, and R. Niewa, Solid State Sciences 5, 1247 (2003).

[132] M. A. Pietzka and J. C. Schuster, Journal of Phase Equilibria 15, 392 (1994). 
[133] K. E. Spear and D. F. Palino, Mater. Res. Bull. 18, 549 (1983).

[134] J. C. Schuster and J. Bauer, J. Solid State Chem. 53, 260 (1984).

[135] T. B. Massalski, in Binary Alloy Phase Diagrams, ASM International, Metals Park, Ohio, 1986), Vol. 1 and 2.

[136] A. Thore, M. Dahlqvist, B. Alling, and J. Rosen, submitted (2014).

[137] M. Dahlqvist, B. Alling, and J. Rosén, Phys. Rev. B 81, 220102 (2010).

[138] J. Byeon, et al., Oxid. Met. 68, 97 (2007).

[139] M. Sundberg, G. Malmqvist, A. Magnusson, and T. El-Raghy, Ceram. Int. 30, 1899 (2004).

[140] X. H. Wang and Y. C. Zhou, J. Mater. Sci. Technol. 26, 385 (2010).

[141] X. H. Wang and Y. C. Zhou, Corros. Sci. 45, 891 (2003).

[142] P. O. Å. Persson, J. Rosen, D. R. McKenzie, M. M. M. Bilek, and C. Hoglund, J. Appl. Phys. 103, 066102 (2008).

[143] P. O. Å. Persson, C. Höglund, J. Birch, and L. Hultman, Thin Solid Films 519, 2421 (2011).

[144] P. O. Å. Persson, J. Rosen, D. R. McKenzie, and M. M. M. Bilek, Phys. Rev. B 80, 092102 (2009).

[145] Z. Sun, R. Ahuja, S. Li, and J. M. Schneider, Appl. Phys. Lett. 83, 899 (2003).

[146] J. M. Schneider, Z. Sun, R. Mertens, F. Uestel, and R. Ahuja, Solid State Commun. 130, 445 (2004).

[147] W. Sun, W. Luo, and R. Ahuja, J. Mater. Sci. 47, 7615 (2012).

[148] A. Petruhins, et al., Phys. Status Solidi Rapid Res. Lett. 7, 971 (2013).

[149] M. Jaouen, P. Chartier, T. Cabioc'h, V. Mauchamp, G. André, and M. Viret, J. Am. Ceram. Soc. 96, 3872 (2013).

[150] W. Zhou, L. J. Liu, and P. Wu, J. Appl. Phys. 106, 7 (2009).

[151] C. Li, Z. Wang, D. Ma, C. Wang, and B. Wang, Intermetallics 43, 71 (2013).

[152] D. Hobbs and J. Hafner, J. Phys. Cond. Matter 13, L681 (2001).

[153] D. Hobbs, J. Hafner, and D. Spizak, Phys. Rev. B 68, 014407 (2003).

[154] P. Kurz, G. Bihlmayer, and S. Blugel, J. Appl. Phys. 87, 6101 (2000).

[155] M. Wasniowska, S. Schröder, P. Ferriani, and S. Heinze, Phys. Rev. B 82, 012402 (2010).

[156] J. D. Hettinger, et al., Phys. Rev. B 72, 115120 (2005).

[157] M. F. Cover, O. Warschkow, M. M. M. Bilek, and D. R. McKenize, J. Phys. Cond. Matter 21, 305403 (2009).

[158] S. E. Lofland, J. D. Hettinger, K. Harrell, P. Finkel, S. Gupta, M. W. Barsoum, and G. Hug, Appl. Phys. Lett. 84, 508 (2004).

[159] J. Y. Wang and Y. C. Zhou, Phys. Rev. B 69, 214111 (2004).

[160] M. Magnuson, et al., Phys. Rev. B 72, 245101 (2005).

[161] D. Music, R. Ahuja, and J. M. Schneider, Appl. Phys. Lett. 86, 031911 (2005).

[162] Y. C. Zhou, Z. M. Sun, X. H. Wang, and S. Chen, J. Phys. Cond. Matter 13, 10001 (2001).

[163] J. J. Li, L. F. Hu, F. Z. Li, M. S. Li, and Y. C. Zhou, Surf. Coat. Tech. 204, 3838 (2010).

[164] T. Ouisse, E. Sarigiannidou, O. Chaix-Pluchery, H. Roussel, B. Doisneau, and D. Chaussende, J. Cryst. Growth 384, 88 (2013). 


\section{CHAPTER 7 - BIBLIOGRAPHY}

[165] J. W. D. Connolly and A. R. Williams, Phys. Rev. B 27, 5169 (1983).

[166] A. Lindmaa, R. Lizárraga, E. Holmström, I. A. Abrikosov, and B. Alling, Phys. Rev. B 88, 054414 (2013). 



\section{Included Papers}

The articles associated with this thesis have been removed for copyright reasons. For more details about these see:

http://urn.kb.se/resolve?urn=urn:nbn:se:liu:diva-104764 